\title{
Burden of care and health -related quality of life among caregivers of children with autism spectrum disorder
}

\author{
Rahul Khanna \\ West Virginia University
}

Follow this and additional works at: https://researchrepository.wvu.edu/etd

\section{Recommended Citation}

Khanna, Rahul, "Burden of care and health -related quality of life among caregivers of children with autism spectrum disorder" (2010). Graduate Theses, Dissertations, and Problem Reports. 4618.

https://researchrepository.wvu.edu/etd/4618

This Dissertation is protected by copyright and/or related rights. It has been brought to you by the The Research Repository @ WVU with permission from the rights-holder(s). You are free to use this Dissertation in any way that is permitted by the copyright and related rights legislation that applies to your use. For other uses you must obtain permission from the rights-holder(s) directly, unless additional rights are indicated by a Creative Commons license in the record and/ or on the work itself. This Dissertation has been accepted for inclusion in WVU Graduate Theses, Dissertations, and Problem Reports collection by an authorized administrator of The Research Repository @ WVU.

For more information, please contact researchrepository@mail.wvu.edu. 
Burden of Care and Health-Related Quality of Life among Caregivers of Children with Autism Spectrum Disorder

\author{
Rahul Khanna
}

Dissertation Submitted to the

School of Pharmacy

at West Virginia University

in partial fulfillment of the requirements

for the degree of

\author{
Doctor of Philosophy \\ In \\ Pharmaceutical Systems and Policy
}

S. Suresh Madhavan, MBA, Ph.D., Chair Michael J. Smith, Ph.D., R.Ph., Co-Chair

Cindy Tworek, Ph.D., M.P.H.

Julie Hicks Patrick, Ph.D.

Barbara Becker-Cottrill, Ed.D.

Department of Pharmaceutical Systems and Policy

\author{
Morgantown, West Virginia \\ 2010
}

Keywords: Autism, children, caregiver, burden, and health-related quality of life

Copyright 2010 Rahul Khanna 


\section{Abstract \\ Burden of Care and HealthRelated Quality of Life among Caregivers of Children with Autism Spectrum Disorder}

\section{Rahul Khanna}

Caring for a child with autism is a challenging experience for parents, who also have to assume the role of a caregiver. Several studies have documented the occurrence of negative outcomes among caregivers of children with autism. Autism has been shown to affect every aspect of caregivers' lives, whether it is their mental health, physical health, financial health, or social health. The purpose of this study was to gather in-depth information about the impact of autism on primary caregivers. Both qualitative and quantitative research methods were used for this purpose. As part of the project, three studies were conducted. Data for study one was collected using focus groups, while that for study two and three were collected using a cross-sectional survey of primary caregivers of children with autism. In the first study, focus group discussions were conducted to understand caregivers' experiences, needs, and concerns. Participants in focus groups described an adverse impact of autism on their emotional, physical, and social health. Participants reported an urgent need for respite care, support services, informational support from service providers, and insurance coverage of autism treatments. In the second study, psychometric properties of the Caregiver Strain Questionnaire (CGSQ) were tested for use among caregivers of children with autism. The results indicated acceptable factorial validity, convergent validity, discriminant validity, internal consistency reliability of the CGSQ in this population. Until a burden instrument specific to caregivers of children with autism is developed, researchers could use the CGSQ to capture the caregiving experiences in this population. The third study assessed the impact of caregiving on health-related quality of life (HRQOL) of primary caregivers of children with autism. After adjusting for age and gender, the HRQOL scores of caregivers were found to be lower than those of the general US population. Caregiving situational factors such as family functioning, social support, and coping mechanisms were found to have a significant effect on caregiver burden and HRQOL. These findings emphasize the use of multi-pronged intervention approach that incorporates components aimed at improving family functioning, increasing support services, and assisting caregivers in developing healthy coping skills. 


\section{DEDICATION}

This dissertation is dedicated to my mom, dad, Vikas, Mridula, and Saisha. 


\section{ACKNOWLEDGMENTS}

There are several individuals who helped me directly or indirectly in the completion of this dissertation, and I am truly grateful to all of them. I would like to acknowledge the role of my mentor and chair Dr. S. Suresh Madhavan in providing me with the financial, emotional, and intellectual support that made the completion of this project possible. His guidance and support over the past few years has been instrumental in shaping my career. Another individual without whom this project would not have been possible is Dr. Michael J. Smith. Mike was a co-chair for this project, and helped me in all aspects of the study. In is his role as a mentor and friend, Mike has made a lasting impression on my career. I am truly indebted to Dr. Madhavan and Mike for their support.

I would also like to acknowledge the role of Drs. Cindy Tworek and Julie H. Patrick in the completion of this project. Cindy has been an excellent faculty mentor to me. Her comments and suggestions markedly improved the quality of work that was undertaken as a part of this project. Julie played a key role in ensuring that the analytical framework of the project was sound. I am thankful for having both these wonderful individuals as a part of my committee. This project would not have been possible without the support of Dr. Barbara BeckerCottrill and her colleagues at the West Virginia Autism Training Center (Huntington, WV). Dr. Cottrill and her staff made things so much easier for me and helped me in every step of the way. I would like to especially acknowledge the role of Julie O'Malley in helping me with the logistics of the project. I would also like to thank Peggy Hovatter and Nada Prickett for their logistical support.

This project would have remained just a thought had it not been for the caregivers who participated in this study. I was truly humbled listening to the caregivers during my focus 
groups, and reading their comments in my survey phase. Despite the time pressure that they face in their daily lives, caregivers participated with enthusiasm in this study. I sincerely hope that this project serves the purpose of improving our knowledge of the challenges and experiences of caregivers of children with autism.

I would like to acknowledge the support provided by Dr. Ginger Scott, and my friends and colleagues in the department. Over the course of my graduate education, I have made some good friends who provided me with the emotional support that was needed especially since my family was far away. I am thankful to Khalid, Nazli, Anand, Reema, Anuja, and Pallavi for their friendship.

Finally, I would like to acknowledge my family - mom, dad, Vicky, and Mridula - for their support and encouragement all my life. I feel blessed to have wonderful and amazing parents (Prem and Suman Khanna), brother (Vikas Khanna), sister-in-law (Mridula McMullen Khanna), and niece (Saisha Khanna). 


\section{TABLE OF CONTENTS}

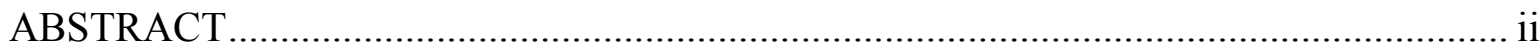

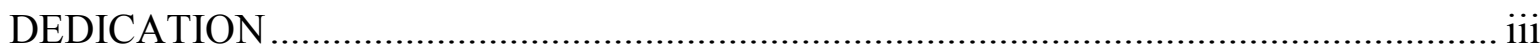

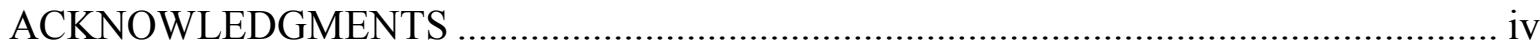

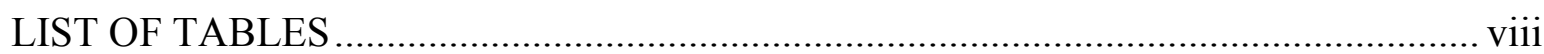

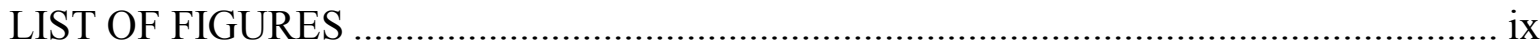

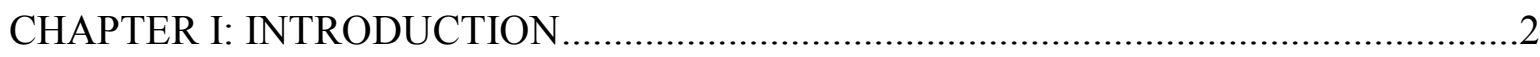

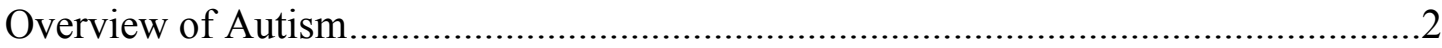

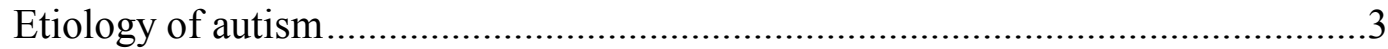

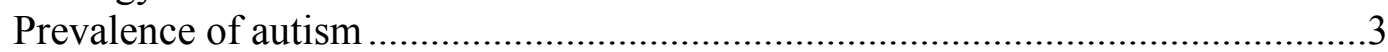

Healthcare utilization and costs associated with autism .......................................

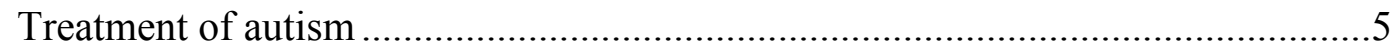

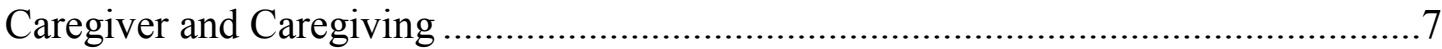

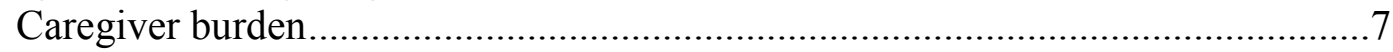

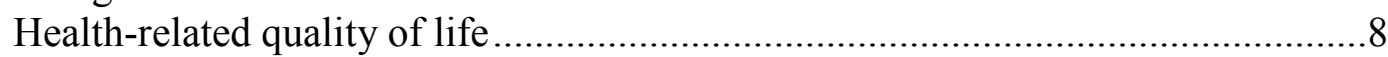

Caregiving Outcomes in Autism.......................................................................11

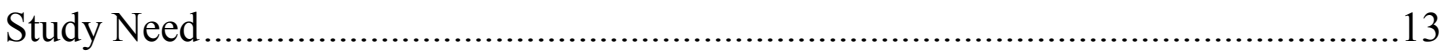

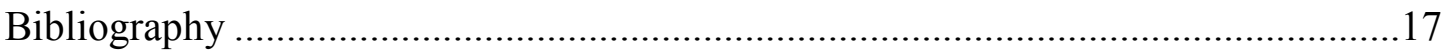

CHAPTER 2: A QUALITATIVE STUDY OF THE EXPERIENCES OF PRIMARY CAREGIVERS OF CHILDREN WITH AUTISM SPECTRUM DISORDER ...........23

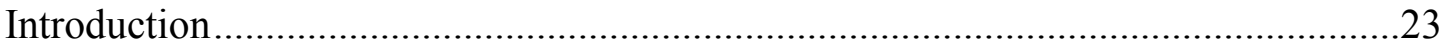

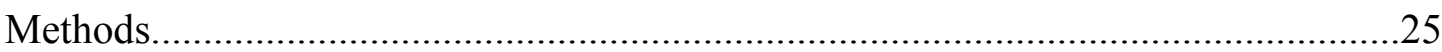

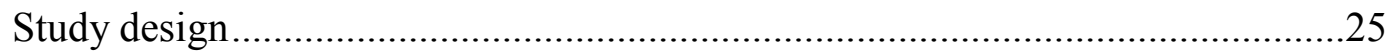

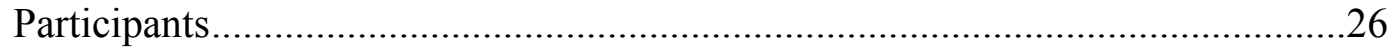

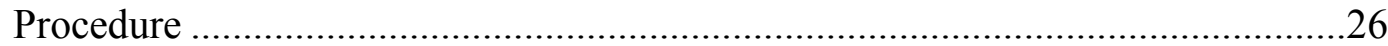

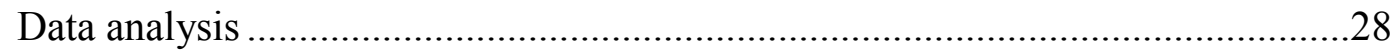

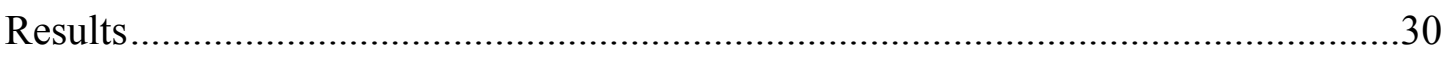

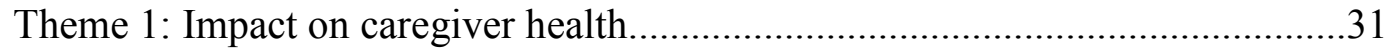

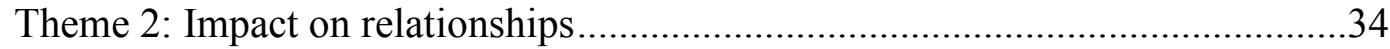

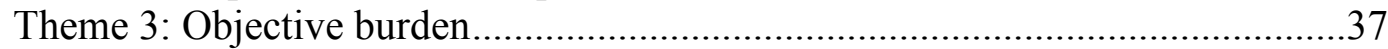




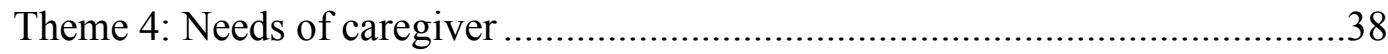

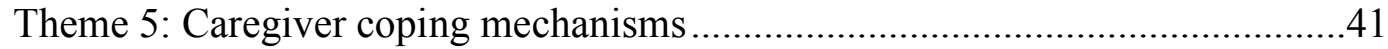

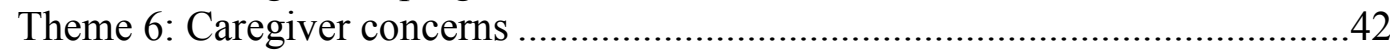

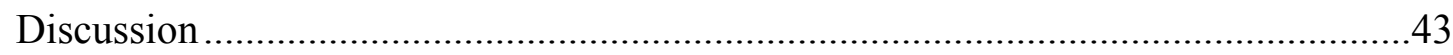

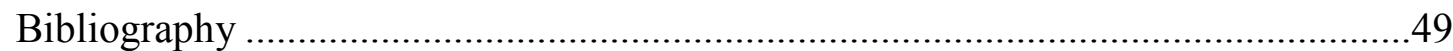

CHAPTER 3: PSYCHOMETRIC PROPERTIES OF THE CAREGIVER STRAIN QUESTIONNAIRE AMONG CAREGIVERS OF CHILDREN WITH AUTISM ....53

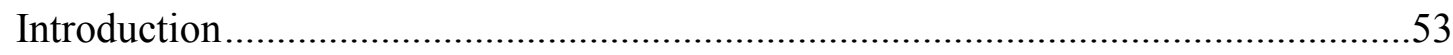

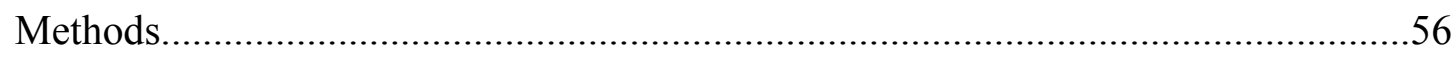

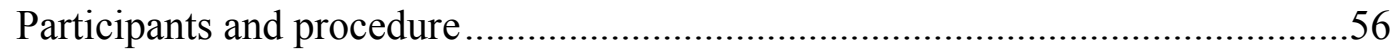

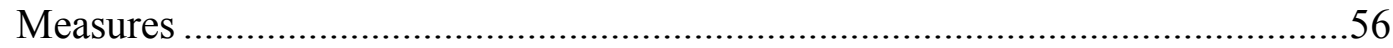

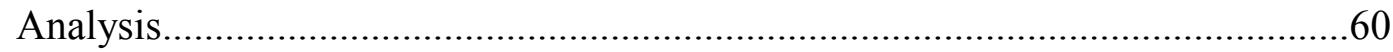

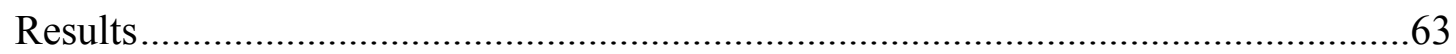

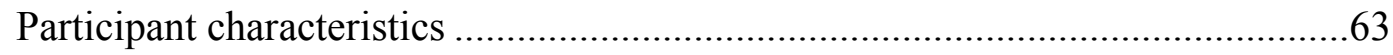

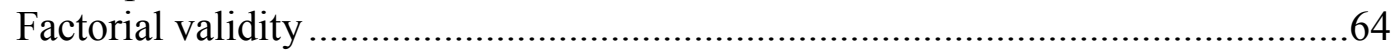

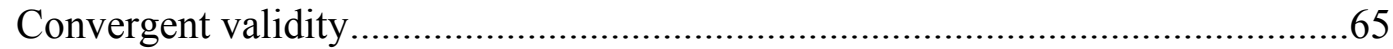

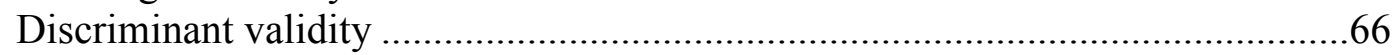

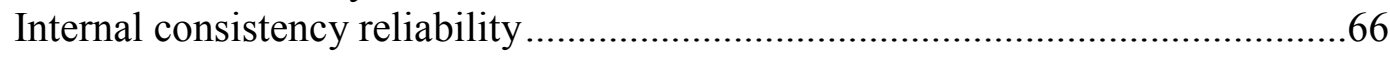

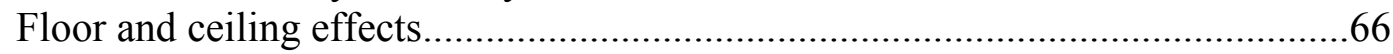

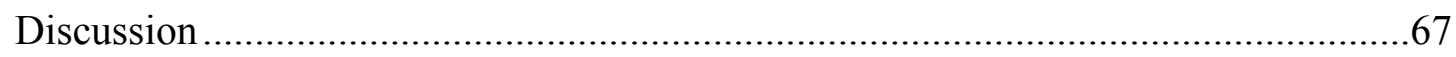

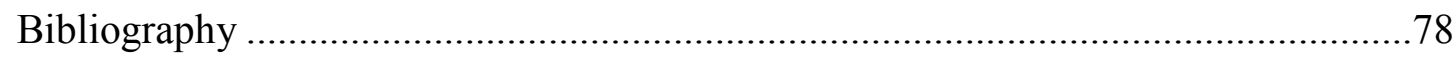

CHAPTER 4: ASSESSMENT OF HEALTH-RELATED QUALITY OF LIFE AMONG PRIMARY CAREGIVERS OF CHILDREN WITH AUTISM SPECTRUM

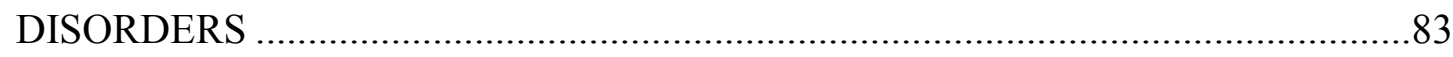

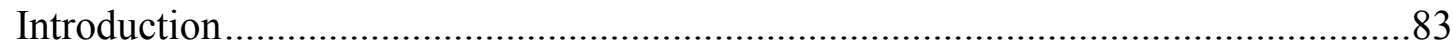

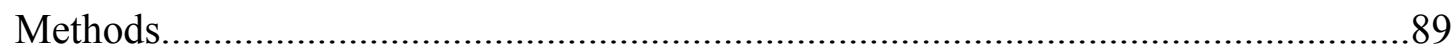

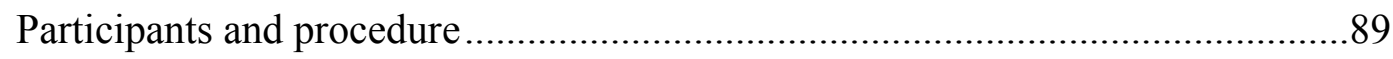

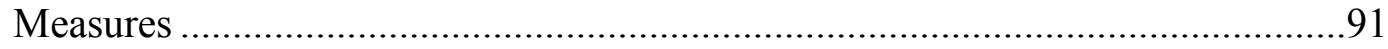

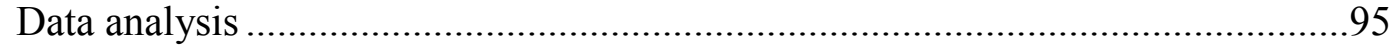

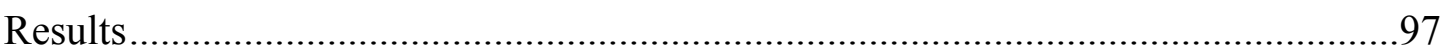

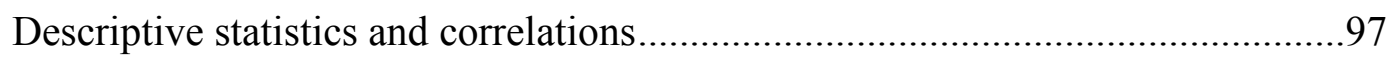

Comparison of caregiver HRQOL with US norms ........................................98

Hierarchical regression analysis of factors predicting caregiver HRQOL ............99

Structural equation model of theoretical models .............................................100 
Discussion .103

Bibliography 121

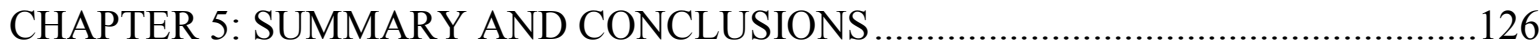

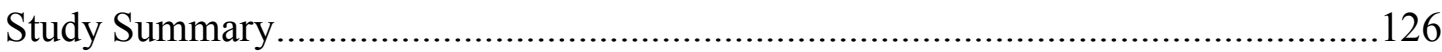

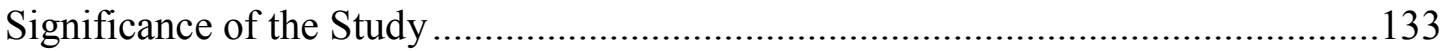

Study Limitations.............................................................................................135

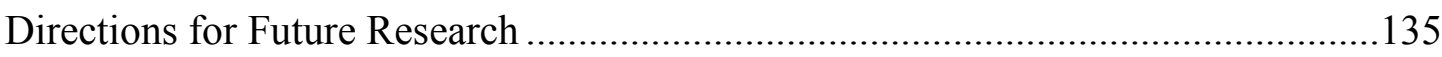

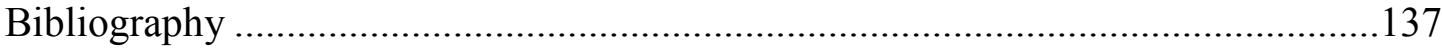

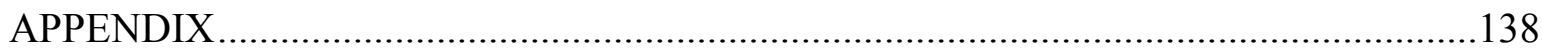

Appendix A. Script for Telephonic Invitation to Focus Groups..................................139

Appendix B. Follow-up Cover Letter for Focus Groups ............................................142

Appendix C. Information Sheet for Focus Groups …………...................................143

Appendix D. Socio-demographic Questionnaire for Focus Groups ............................144

Appendix E. Addresses of Counseling Facilities in Emotional Distress Experienced from Focus Group Discussion ............................................................146

Appendix F. Discussion Guide for Focus Groups ……….......................................147

Appendix G. Acknowledgment Statement for Focus Groups .....................................149

Appendix H. Questionnaire packet for Survey .......................................................150

Appendix H1. Survey Cover Letter from the West Virginia Autism Training

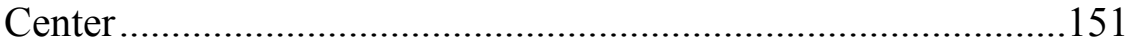

Appendix H2. Survey Cover Letter for First Mailing..........................................152

Appendix H3. Survey Covert Letter for Second Mailing .....................................153

Appendix H4. Survey Cover Letter for Third Mailing ......................................154

Appendix H5. Addresses of Counseling Facilities if Emotional Distress Experienced from Survey ………………………………............155

Appendix H6. Survey Questionnaire ..............................................................156

Appendix H7. Survey Acknowledgment Statement ............................................173

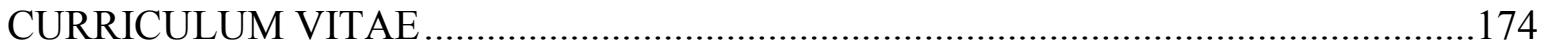




\section{LIST OF TABLES}

Table 2.1. Descriptive characteristics of focus group participants .................................48

Table 3.1. Socio-demographic characteristics of survey participants.............................73

Table 3.2. Summary statistics of the Caregiver Strain Questionnaire ...............................75

Table 3.3. The 18-item three-factor solution of the Caregiver Strain Questionnaire based on principal component analysis with promax rotation ...........................76

Table 3.4. Correlation of Caregiver Strain Questionnaire subscales with other caregiving situational constructs ........................................................... 77

Table 4.1. Descriptive statistics of study measures ..................................................117

Table 4.2. Correlation between theoretical variables.................................................. 118

Table 4.3. Hierarchical regression analyses to determine predictors of caregiver HRQOL

Table 4.4. Standardized regression estimates of total, direct, and indirect effects for the significant relationships observed between theoretical variables in the final model. 


\section{LIST OF FIGURES}

Figure 4.1. Conceptual model of factors influencing HRQOL among caregivers of children with autism (modified version of Chappell and Reid [2002] Caregiving Model)

Figure 4.2a. Comparison of mean HRQOL scores among caregivers of children with autism $(n=69)$ to general US population norms $(n=631-632)$, female 25-34 year

Figure 4.2b. Comparison of mean HRQOL scores among caregivers of children with autism $(n=149)$ to general US population norms $(n=839)$, female $35-44$ years

Figure 4.3. Final model of factors influencing HRQOL among caregivers of children with autism 
CHAPTER 1 


\section{CHAPTER 1: \\ INTRODUCTION}

\section{Overview of Autism}

Autism spectrum disorders (ASDs) are a set of neurodevelopmental disabilities that are characterized by deficiencies in three core domains: social interaction, communication/language skills, and behavior development (Newschaffer et al., 2007). This condition was first studied in the early 1940s by Dr. Leo Kanner, an Austrian-American child psychiatrist who described a new category of syndrome "inborn autistic disturbances of affective contact" based on his observation of 11 children who displayed severe behavioral and developmental problems that included obsessions, stereotypy, and echolalia (Kanner, 1943). During the same period, an Austrian pediatrician named Dr. Hans Asperger published a paper wherein he described a condition "autistic psychopathy" based on his observation of four children who had normal intelligence but displayed problems in social interaction (Asperger, 1944).

There are three conditions that fall under the gamut of ASDs: autistic disorder, Asperger syndrome, and pervasive developmental disorder not otherwise specified (PDD-NOS). Autistic disorder is also known as classical autism and is characterized by impairments in social interaction and communication, and restricted or repetitive behavior. In contrast to individuals with autistic disorder, those with Asperger syndrome have normal or near-normal intelligence and in most cases do not experience delays in language development. However, individuals with Asperger's syndrome do experience significant difficulty in social interaction. The level of intelligence, behavioral development, and language skills among individuals with PDD-NOS are intermediate to those with autistic disorder and Asperger syndrome (Walker et al., 2004). 


\section{Etiology of autism}

The underlying etiology for autism is still unidentified, which has led to a proliferation of possible causative theories. Of all the possible causes of autism, genetic factors are considered to play a major role in its occurrence. Genetic studies have shown more than $60 \%$ concordance for autism in monozygotic twin pairs as compared to $0 \%$ concordance in dizygotic twin pairs (Bailey et al., 1995). The occurrence of autism among siblings of individuals with the disorder is 215 times more frequent as compared to the general population (Ritvo et al., 1989). Role of environmental factors such as heavy metal pollutants in air (Windham et al., 2006), and prenatal, perinatal, and neonatal conditions (Juul-Dam et al., 2001) in causing autism has also been studied. It is generally considered that there is no single cause for autism, and that it occurs due to an interaction between genetic and environmental factors. It has been suggested that for environmental factors to trigger the occurrence of ASD, the presence of genetic predisposition is necessary (Szpir, 2006).

\section{Prevalence of autism}

Over the past two decades, there has been a significant increase in the prevalence and incidence of autism in the US (Barbaresi et al., 2005; Gurney et al., 2003; Newschaffer et al., 2005). In 1970 , the prevalence of autism was reported to be 0.7 per 10,000 among children between the ages 3-11 years in Wisconsin (Treffert, 1970). However, a recent study reported the prevalence rate to be $\sim 1.1 \%$ among children in the age group 3-17 years in the US (Kogan et al., 2009). It is estimated that 673,000 children in the US have autism (Kogan et al., 2009). The increase in the prevalence of autism has been attributed to multiple reasons. Some researchers attribute this 
increase to methodological factors (Fombonne, 2003; Rutter, 2005). In their study of trends in autism prevalence in the state of California between 1987 and 1994, Croen and colleagues (2002) attributed the increase to a greater recognition of autism among healthcare professionals, use of better screening and assessment tools, broadening of the diagnostic criteria, and substitution of children diagnosed with mental retardation (MR) to autism. In another study, Gurney and colleagues (2003) did not find recategorization of children with MR to autism as one of the factors causing an increase in the prevalence of autism. Instead, the authors attributed the increase in autism prevalence rate to improvements in identification and ascertainment resulting from administrative policy changes. Autism prevalence is higher among males as compared to females (Nicholas et al., 2008).

\section{Healthcare utilization and costs associated with autism}

The increasing prevalence of autism in the US has been accompanied by an increase in the healthcare burden and costs associated with the disorder. Several studies over the years have documented the significant healthcare utilization and costs associated with the disorder (Croen et al., 2006; Leslie \& Martin, 2007; Liptak et al., 2006; Mandell et al., 2006; Ruble et al., 2005; Shimabukuro et al., 2008). In their study of a nationally representative sample of children in the US, Liptak and colleagues (2006) reported that children with autism have greater number of outpatient visits, physician visits, and prescription medications as compared to children with typical development. The incremental direct medical cost incurred over the lifetime of an individual with autism is more than twice that of a typical American (Ganz, 2007). The average

lifetime societal cost of caring for an individual with autism in the US is estimated to be roughly $\$ 3.2$ million, with costs from lost productivity and adult care constituting the largest component 
(Ganz, 2007). The total economic burden, which includes direct medical, direct non-medical, and indirect costs, of autism in the US has been reported to be more than $\$ 35$ billion (Ganz, 2006).

\section{Treatment of autism}

To date, there is no established cure for autism, since the biological marker that causes autism is unidentified (Tsai, 1999). Given the commonly occurring impairments in children with autism, the treatment goal is to alleviate behavioral problems, and simultaneously develop academic skills, social interaction, and communication among these individuals (Fombonne, 2003). A multidimensional treatment approach is generally used to alleviate behavioral symptoms and improve functioning among children with autism. There is no standard treatment approach for autism, and treatment modalities are provided based on the presence of specific symptoms and parental discretion. A comprehensive treatment modality for autism generally includes behavioral therapy (applied behavior analysis [ABA]), speech therapy, special educational therapy, social skill learning, nutrition control, environmental control, physical therapy, and prescription medications.

One of the most important treatment components for autism is behavior therapy. The objective of using behavioral interventions is to alleviate behavioral symptoms such as aggression, hyperactivity, self-injury, repetition, and other maladaptive behaviors among children with autism. A pioneer study by Lovaas (1987) first demonstrated the usefulness of behavioral modification therapy in improving the level of functioning among children with autism. In that study, roughly half of the children with autism who were provided early intensive behavioral treatment attained intellectual capacity and educational functioning comparable to a 
normal child. Several studies conducted since then have shown that early intensive behavioral interventions such as $\mathrm{ABA}$, which is based on the principle that repetition of a behavior is more likely when it is rewarded than when it is ignored, could lead to significant improvements in functioning and alleviation of behavioral symptoms among children with autism (Ben-Itzchak \& Zachor, 2007; Eldevik et al., 2006; Eikeseth et al., 2007; McEachin et al., 1993; Remington et al., 2007). Long term outcomes are improved considerably among children with autism who receive early intensive behavior therapy, with many children showing similar results on tests of intelligence and adaptive behavior in comparison to average children (McEachin et al., 1993). Services such as speech therapy, nutritional therapy, physical therapy, and social skill learning are also commonly used to improve functioning among children with autism (Thomas et al., 2007). Other treatments that have been reported to be used are facilitated communications, secretin infusions, auditory integration training, intake of vitamins (vitamin $\mathrm{A}$, vitamin $\mathrm{B}_{6}$ ), gluten and casein free diets (Aman, 2005).

Many of the behavioral symptoms associated with autism are not alleviated by the use of non-pharmacological therapies, and therefore require pharmacological interventions.

Medications are generally used to treat behavioral symptoms such as aggressiveness, anxiety, hyperactivity, self-injury, social withdrawal, and tantrums in children with ASD (Findling, 2005; Kutcher, 1997). In their study of trends in the use of psychotropic prescription medications to treat individuals with autism, Aman and colleagues (2005) reported an increase in their use from $30.5 \%$ to more than $45 \%$ between 1993 and 2001. Similar results were reported by Mandell and colleagues (2008) who found $56 \%$ of children with autism enrolled in the Medicaid system to have at least one claim for psychotropic medication use. The most common drug classes used among individuals with autism are: antipsychotics/ neuroleptics, antidepressants, stimulants, 
anticonvulsants, benzodiazepines, and antihypertensive agents (Aman et al., 2005; Mandell et al., 2008).

\section{Caregiver and Caregiving}

Hileman and colleagues (1992) defined caregiver as an individual who helps with physical care or coping with an infirmity without being paid. The assistance or aid provided by one or more member of the family to another family member that is more than the assistance required as a part of regular everyday life can be conceptualized as family caregiving (Walker et al., 1995). Informal caregiving can be defined as the "activities and experiences involved in providing help and assistance to relatives or friends who are unable to provide for themselves" (Pearlin et al., 1990; p583).

\section{Caregiver burden}

Burden refers to the consequence of caring for a patient on the informal caregiver. Providing care to a patient could place employment, financial, physical, social, and time burden on the caregiver (Siegel et al., 1991). Caregiver burden can be categorized into two broad dimensions: objective burden and subjective burden (Hoenig \& Hamilton, 1966; Montgomery et al., 1985). Objective burden refers to the caring demands placed on the family members. Biegel and colleagues (1991, p 51) defined objective burden as "the time and effort required of one person to attend to the needs of another person." Following a review of the literature related to family burden, Sales (2003) described objective burden to include the dimensions of: tasks related directly to the provision of care, tasks related indirectly to the provision of care, dealing with patient's distress and concerns, and impact of caregiving on other life roles. Tasks related 
directly to the provision of care include the time spent by the caregiver to assist care recipient with daily living. Tasks related indirectly to the provision of care refers to those tasks that were being performed by the care recipient before the illness, but are then required to be performed by the caregiver. In addition to the previously described tasks, family caregivers have to spend time to attend to the concerns and distress among patients. Finally, objective burden is said to include the impact of caregiving on family financial situation, normal routine, work, social involvement, and leisure activities. Subjective burden refers to the distress experienced among caregivers as a result of the caregiving demands (George \& Gwyther, 1986; Montgomery et al., 1985). It refers to the emotional consequence of the provision of care on the caregiver. Worry, distress, stigma, shame, and guilt are common markers of subjective burden (Sales, 2003).

\section{Health-related quality of life (HRQOL)}

The World Health Organization (WHO; 1947) defines health as "a state of complete physical, mental, and social well-being and not merely the absence of disease or infirmity." This definition of health is more holistic and broad in nature and forms the underlying framework on which the concept of quality of life (QOL) and health-related quality of life (HRQOL) has been built. QOL is a multidimensional construct that has been defined and measured in different ways (Gill \& Feinstein, 1994; Gladis et al., 1999), and is related to the above mentioned WHO definition of health. In 1991, the WHO quality of life (WHOQOL) project was initiated to develop cross-culturally valid and sensitive QOL instruments. The WHOQOL group defined QOL as "an individual's perception of his/her position in life in the context of the culture and value systems in which he/she lives, and in relation to his/her goals, expectations, standards and concerns" (WHOQOL Group, 1994, p.43). In their review of studies that had described 
conceptual models of QOL, Felce and Perry (1995) arrived at five domains which together encompassed the different aspects of QOL commonly described in literature. The five domains reported were: physical well being (health, fitness, mobility, and physical activity), material well being (finance or income, quality of the environment in which the individual lives, possessions, meals or food, transport, privacy, security, and stability), social well being (relationship within family, with relatives, and with friends, and community involvement), development and activity (competence, choice, work, leisure, housework, education, and productivity), and emotional well being (positive affect, status, satisfaction, fulfillment, religious faith, and self-esteem).

A discrete component of QOL that has been described commonly in the literature is the HRQOL. HRQOL is based on the amalgamation of the concepts of health status and QOL. Different environmental, economic, political, and spiritual factors could affect an individual's QOL; however, these factors cannot be addressed directly by healthcare interventions, and are therefore not associated with HRQOL. HRQOL is considered to include physical, psychological, and social areas of health, and these domains are said to be influenced by an individual's experiences and perceptions (Testa \& Simonson, 1996). The measurement of HRQL is exemplified by two basic approaches: generic instruments including single indicators, health profiles, and utility measures and specific instruments (Patrick \& Deyo, 1989).

There are two subtypes of generic HRQOL measures. The first subtype includes instruments which assess the core domains of HRQOL i.e. physical, psychological, and social health. Instruments such as the Medical Outcomes Study Short Form-36 (SF-36: Ware et al., 1993) fall under this category. These instruments require an individual to report the presence and intensity of symptoms, behaviors, or feelings (Revicki, 1992). Individual scores on different core dimensions as well as global summary scores can be attained using these instruments. The 
main advantage of these instruments is that they can be used across different populations in different disease areas. However, a limitation of these instruments is that they do not provide information about an individual's preference to remain in a particular health state (Revicki, 1992).

The second type of generic HRQOL instruments assesses an individual preference for a particular health state (Guyatt et al., 1993). Commonly known as utility measures of HRQOL, the foundation of these instruments is based on economic and decision theory. Torrance (1987) defined utility as “a cardinal measure of strength of one's preference.” Using preference measurements, these instruments summarize HRQOL as a single number, which generally ranges from a state of perfect health (1.0) to death (0.0). The utilities therefore reflect both the health status and the value assigned to that status by an individual. There are several advantages of using utility based measures of HRQOL. First, from a societal and patient perspective, utility measures are useful to determine whether a new treatment strategy improves patient HRQOL or not, based on which the treatment can either be adopted or discarded. Second, utilities can be used in performing cost-utility analysis. Cost-utility analysis are a kind of economic analysis that are performed to determine the ratio between the cost of providing a particular health care intervention and the benefit produced by the intervention in terms of the number of years lived in good health. The denominator in cost-utility analysis is the quality adjusted life years (QALYs), which is estimated by combining utilities with survival data. Third, as economic resource becomes scarce, policy makers and administrators will adopt strategies/interventions which provide the maximum benefit for less cost. Since utilities provide an individual's preference for a particular health state, they are increasingly being used to distinguish between interventions and across diseases in making health care resource allocation decisions. Using cost per QALY 
as the underlying criteria, league tables have been created that rank interventions. These tables are useful in comparing distinct interventions, and allow policy makers to compare different programs competing for limited resources.

There are different approaches to measure health utilities. Individuals may be directly asked to rate the value of their current health state or a multi-attribute health status classification system can be used (Guyatt et al., 1993). Under the multi-attribute health status classification system, preference measures for health states derived from general community or other patients are used to score the information collected about an individual's health status. Instruments such as EuroQol (EQ-5D; EuroQol Group, 1990) and Health Utilities Index (HUI; Torrance et al., 1996) fall under the category of multi-attribute health status classification systems.

One of the main disadvantages of generic measures is that they cannot be used to assess particular domains of HRQOL that may be of interest in the study of a specific disease. For this purpose, researchers often use HRQOL instruments that are specific to a particular disease, population, function, or condition. However, these instruments cannot be used to make comparisons across different populations and conditions. The use of a generic or diseasespecific HRQOL instrument is governed by study objectives and purpose and the ability of the instrument to assess the domains of interest to the researcher.

\section{Caregiving Outcomes in Autism}

Given the fact that most of the children with autism live with their parents, there is a profound impact of caring for these children on caregivers' health and well-being and is a life altering experience for them. Several studies conducted over the years have consistently shown that parents or caregivers of children with autism have higher degree of stress as compared to parents 
of children with normal development or other developmental disorders (Bebko et al., 1987; Bouma \& Schweitzer, 1990; Duarte et al., 2005; Kasari \& Sigman, 1997; Sanders \& Morgan, 1997). Besides stress, studies have shown the significant financial burden associated with providing care to children with autism (Montes \& Halterman, 2008). Children with autism have higher healthcare utilization as compared to children without autism (Shimabukuro et al., 2008), which together with the provision of behavioral and other treatment services places an enormous financial burden on caregivers. Montes and Halterman (2008) estimated that families loose as high as $14 \%$ or $\$ 6,200$ of their annual income because of caring for a child with autism. Lefley (1996) listed 10 dimensions of caregiver burden: economic dependence of patient, disruption of routines, behavioral management, time and energy expended in dealing with health care system, negative interactions with services providers, financial cost of managing illness, neglect of other family member needs, restriction of social activities, impaired relations with non-family members, and lack in ability to find satisfactory care settings. These dimensions of caregiver burden have been reported to be relevant for families of children with autism (Burgess \& Gutstein, 2007).

Besides placing burden on caregivers, taking care of a child with a development disorder like autism could adversely affect caregiver health and well-being. Studies have shown that parents of children with ASD have high levels of anxiety and depression (Abbeduto et al., 2004; Hastings, 2003; Smith et al., 2008). Anxiety and depression are key markers of psychological well-being, which is one of the central domains of HRQOL. Though several studies have documented the adverse psychological impact of caregiving on autism caregivers, the impact on their HRQOL is still not fully understood. 
One of the first studies to measure the impact of caring for a child with autism on caregiver's HRQOL was conducted by Allik and colleagues (2006). Using a generic HRQOL instrument, the authors compared the HRQOL among parents of children with Asperger's syndrome and High-Functioning Autism to that of parents of children with typical development. The results of the study reflected poor physical HRQOL among mothers of children with Asperger's syndrome/High-Functioning Autism as compared to mothers of children with typical development. No differences in HRQOL were observed between fathers in the two groups. Within group differences were also observed in the study, with mothers of children with Asperger's syndrome/high-functioning autism reporting poorer physical HRQOL than fathers. HRQOL was found to be related to child behavioral problems. Though this study provided useful information about autism caregivers HRQOL, the small sample size of the study limited its usefulness. A thorough review of the literature did not reveal any study that had compared HRQOL among autism caregivers to those of the general population in the US. Further, the role played by different caregiving situational factors in impacting caregivers HRQOL is not known.

\section{Study Need}

\section{Need for qualitative examination of caregiving outcomes in autism}

To date, most of the research conducted to study caregiving outcomes in autism has been quantitative in nature, wherein a survey instrument has been used to collect data. A major limitation of quantitative research is that it does not provide an in-depth understanding of an individual's experiences and feelings. This limitation can be better addressed with the use of qualitative techniques like face-to-face- interviews or focus groups. In order to provide adequate support and assistance to autism caregivers, it is imperative that researchers and policy makers 
understand caregivers' self-perspective in terms of their caregiving experiences, needs, and concerns. There are a few qualitative studies that have assessed caregiving outcomes in autism, but much further work is needed to get a true understanding of the experiences of autism caregivers. One such qualitative study has been conducted by Phelps et al. (2009), who used open ended questions in a survey to collect their data. In their study, Phelps et al. (2009) provided a glimpse of caregivers' perspective on the implications of caregiving and their concerns.

Chapter 2 in this study builds upon the work conducted by Phelps et al. (2009) with the aim of collecting qualitative data to study the implications of caregiving on autism caregivers. Using focus group methodology, data concerning the health implications, needs, and concerns of primary caregivers of children with autism was collected and analyzed. This chapter provides a rich description of the true impact of autism caregiving as reported by caregivers.

\section{Need to determine burden experienced by autism caregivers using psychometrically valid instruments}

Though several instruments have been used to study burden experienced by caregivers of children with autism, the psychometric soundness of these instruments in this population is not known. A valid and reliable assessment of burden is necessary before interventions are employed to improve outcomes among autism caregivers. Unlike adult caregiving literature where several burden instruments have been developed and validated, no such instrument currently exists in autism. Until researchers develop an instrument that uniquely captures burden experienced by autism caregivers, this gap in the literature can be filled by using psychometrically sound burden instruments that are currently available. 
Chapter 3 tests the usefulness and validity of the Caregiver Strain Questionnaire (CGSQ) in assessing burden experienced by autism caregivers. The CGSQ was originally developed to assess burden experienced by caregivers of children with emotional and behavioral problems (Brannan et al., 1997). Based on a survey of primary caregivers of children with autism, relevant data was collected and analyzed. In this chapter, analyses concerning scale feasibility, factorial validity, construct validity, internal consistency reliability, and floor and ceiling effects of the CGSQ is presented.

\section{Need to assess the health-related quality of life of caregivers of children with autism} Besides assessing burden experienced by caregivers, there is a need to assess the impact of caregiving on their well-being (George \& Gwyther, 1986). HRQOL is one such measure of well-being that is being increasingly used to study the impact of caregiving. Poor HRQOL among caregivers may impact their ability to provide high quality care to the care recipient. Several studies have reported the occurrence of high levels of anxiety and depression among caregivers of children with autism; however, limited information currently exists regarding the impact on autism caregiver HRQOL. Chapter 4 bridges this gap in the literature by assessing HRQOL among primary caregivers of children with autism. Using survey methodology, relevant data for this chapter was collected. After adjusting for age and gender, the HRQOL of caregivers of children with autism is compared to that of general US population norms.

Knowledge concerning autism caregivers HRQOL is of limited use without an adequate understanding of the caregiving situational factors that impact HRQOL. Using a previously validated caregiver well-being model proposed by Chappell and Reid (2002) as a guiding framework, the role of primary stressors (care recipient functional status and extent of behavioral 
problems), mediators (social support, coping mechanisms, and family functioning), and burden in predicting autism caregivers HRQOL is studied in chapter 4. An understanding of the complexity of caregiving experience and the direct and indirect relationships that determine caregiver HRQOL could be used to design and tailor interventions aimed at improving their well-being.

This study aims to provide in-depth information concerning caregiving outcomes in autism by using both qualitative and quantitative research techniques. First, qualitative data concerning the impact of caregiving on caregivers of children with autism is collected through focus groups. This data enables us to understand the health implications, needs, and concerns of these caregivers from their personal perspective. Second, the study tests the validity and reliability of a burden instrument in caregivers of children with autism. This is intended to provide future researchers with a psychometrically sound instrument that could be used to assess burden in this growing population of caregivers. Finally, the study determines the HRQOL of caregivers of children with autism, and compares it to norm-based scores for the general US population. Also, the factors that impact caregiver HRQOL are identified using a theoretical model. Specifically, the model tests the relationship between care recipient level of functional impairment and extent of behavioral problems, family functioning, social support, caregiver coping mechanism, burden, and HRQOL. 


\section{Bibliography}

Abbeduto, L., Seltzer, M. M., Shattuck, P., Krauss, M. W., Orsmond, G., \& Murphy, M. M. (2004). Psychological well-being and coping in mothers of youths with autism, Down syndrome, or fragile X syndrome. American Journal of Mental Retardation, 109, 237-254.

Allik, H., Larsson, J. O., \& Smedje, H. (2006). Health-related quality of life in parents of schoolage children with Asperger Syndrome or High-Functioning Autism. Health and Quality of Life Outcomes, 4, 1.

Aman, M. G. (2005). Treatment planning for patients with autism spectrum disorders. Journal of Clinical Psychiatry, 66, 38-45.

Aman, M. G., Lam, K. S., \& Van Bourgondien, M. E. (2005). Medication patterns in patients with autism: temporal, regional, and demographic influences. Journal of Child and Adolescent Psychopharmacology, 15, 116-126.

Asperger, H. D. (1944). “Autistichen Psychopathen” Kindesalter. Arch Psychiatr Nervenkr, 117, 76-136.

Bailey, A., Le Couteur, A., Gottesman, I. et al. (1995). Autism as a strongly genetic disorder: evidence from a British twin study. Psychological Medicine, 25, 63-77.

Barbaresi, W. J., Katusic, S. K., Colligan, R. C., Weaver, A. L., \& Jacobsen, S. J. (2005). The incidence of autism in Olmsted County, Minnesota, 1976-1997: results from a populationbased study. Archives of Pediatrics and Adolescent Medicine, 159, 37-44.

Bebko, J. M., Konstantareas, M. M., \& Springer, J. (1987). Parent and professional evaluations of family stress associated with characteristics of autism. Journal of Autism and Developmental Disorders, 17, 565-576.

Ben-Itzchak, E., Zachor, D. A. (2007). The effects of intellectual functioning and autism severity on outcome of early behavioral intervention for children with autism. Research in Developmental Disabilities, 28, 287-303.

Biegel, D., Sales, E., \& Schulz, R. (1991). Family Caregiving in Chronic Illness. Newbury Park, CA: Sage Publications.

Bouma, R., \& Schweitzer, R. (1990). The impact of chronic childhood illness on family stress: a comparison between autism and cystic fibrosis. Journal of Clinical Psychology, 46, 722730.

Brannan, A. M., Heflinger, C. A. \& Bickman, L. (1997). The Caregiver Strain Questionnaire: Measuring the impact on the family of living with a child with serious emotional problems', Journal of Emotional and Behavioral Disorders, 5, 212-22.

Burgess, A. F., \& Gutstein, S. E. (2007). Quality of Life for People with Autism: Raising the Standard for Evaluating Successful Outcomes. Child and Adolescent Mental Health, 12, 80-86.

Chappell, N. L., \& Reid, R. C. (2002). Burden and well-being among caregivers: examining the distinction. Gerontologist, 42, 772-780.

Croen, L. A., Grether, J. K., Hoogstrate, J., \& Selvin, S. (2002). The changing prevalence of autism in California. Journal of Autism and Developmental Disorders, 32, 207-215.

Croen, L. A., Najjar, D. V., Ray, G. T., Lotspeich, L., \& Bernal, P. (2006). A comparison of health care utilization and costs of children with and without autism spectrum disorders in a large group-model health plan. Pediatrics, 118, e1203-1211.

Duarte, C. S., Bordin, I. A., Yazigi, L., \& Mooney, J. (2005). Factors associated with stress in mothers of children with autism. Autism, 9, 416-427. 
Eikeseth, S., Smith, T., Jahr, E., \& Eldevik, S. (2007). Outcome for children with autism who began intensive behavioral treatment between ages 4 and 7: a comparison controlled study. Behavior Modification, 31, 264-278.

Eldevik, S., Eikeseth, S., Jahr, E., \& Smith, T. (2006). Effects of low-intensity behavioral treatment for children with autism and mental retardation. Journal of Autism and Developmental Disorders, 36, 211-224.

EuroQol Group. (1990). EuroQol - a new facility for the measurement of health-related quality of life. Health Policy, 16, 199-208.

Felce, D., \& Perry, J. (1995). The extent of support for ordinary living provided in staffed housing - the relationship between staffing levels, resident characteristics, staff-resident interactions and resident activity patterns. Social Sciences and Medicine, 40, 799-810.

Findling, R. L. (2005). Pharmacologic treatment of behavioral symptoms in autism and pervasive developmental disorders. Journal of Clinical Psychiatry, 66, 26-31.

Fombonne, E. (2003). Epidemiological surveys of autism and other pervasive developmental disorders: an update. Journal of Autism and Developmental Disorders, 33, 365-382.

Ganz, M. L. (2006). The costs of autism. In: Moldin SO, Rubenstein JLR, eds. Understanding Autism: From Basic Neuroscience to Treatment. Boca Raton, Fla: Taylor and Francis Group.

Ganz, M. L. (2007). The lifetime distribution of the incremental societal costs of autism. Archives of Pediatrics and Adolescent Medicine, 161, 343-349.

George, L., \& Gwyther, L. P. (1986). Caregiver well-being: A multidimensional examination of family caregivers of demented adults. Gerontologist, 26, 253-259.

Gill, T. M., \& Feinstein, A. R. (1994). A critical appraisal of the quality of quality-of-life measurements. Journal of the American Medical Association, 272, 619-626.

Gladis, M. M., Gosch, E. A., Dishuk, N. M., \& Crits-Christoph, P. (1999). Quality of life: expanding the scope of clinical significance. Journal of Consulting and Clinical Psychology, 67, 320-331.

Gurney, J. G., Fritz, M. S., Ness, K. K., Sievers, P., Newschaffer, C. J., \& Shapiro, E. G. (2003). Analysis of prevalence trends of autism spectrum disorder in Minnesota. Archives of Pediatrics and Adolescent Medicine, 157, 622-627.

Guyatt, G. H., Feeny, D. H., \& Patrick, D. L. (1993). Measuring health-related quality of life. Annals of Internal Medicine, 118, 622-9.

Hastings, R. P. (2003). Child behavior problems and partner mental health as correlates of stress in mothers and fathers of children with autism. Journal of Intellectual Disability Research, 47, 231-237.

Hillman, R. E., Kanafani, N., Takahashi, T. N., \& Miles, J. H. (2000). Prevalence of autism in Missouri: changing trends and the effect of a comprehensive state autism project. Missouri Medicine, 97, 159-163.

Hoenig, J., \& Hamilton, M. (1966). The schizophrenic patient in the community and his effect on the household. International Journal of Social Psychiatry, 12, 165-176.

Juul-Dam, N., Townsend, J., \& Courchesne, E. (2001). Prenatal, perinatal, and neonatal factors in autism, pervasive developmental disorder-not otherwise specified, and the general population. Pediatrics, 107, E63.

Kanner, L. (1943). Autistic disturbances of affective contact. Nervous Child, 2, 217-250.

Kasari, C., \& Sigman, M. (1997). Linking parental perceptions to interactions in young children with autism. Journal of Autism and Developmental Disorders, 27, 39-57. 
Kogan, M. D., Blumberg, S. J., Schieve, L. A., et al. (2009). Prevalence of Parent-Reported Diagnosis of Autism Spectrum Disorder Among Children in the US, 2007. Pediatrics, 124, 1395-1403.

Kutcher, S. P. (1997). Psychopharmacologic treatment of autism and mental retardation. In: Child and Adolescent Psychopharmacology. Philadelphia, PA: WB Saunders Company.

Lefley, H. P. (1996). Family caregiving in mental illness. Thousand Oaks CA: Sage.

Leslie, D. L., \& Martin, A. (2007). Health care expenditures associated with autism spectrum disorders. Archives of Pediatrics and Adolescent Medicine, 161, 350-355.

Liptak, G. S., Stuart, T., \& Auinger, P. (2006). Health care utilization and expenditures for children with autism: data from U.S. national samples. Journal of Autism and Developmental Disorders, 36, 871-879.

Lovaas, O. I. (1987). Behavioral treatment and normal educational and intellectual functioning in young autistic children. Journal of Consulting and Clinical Psychology, 55, 3 Y9.

Mandell, D. S., Cao, J., Ittenbach, R., \& Pinto-Martin, J. (2006). Medicaid expenditures for children with autistic spectrum disorders: 1994 to 1999. Journal of Autism and Developmental Disorders, 36, 475-485.

Mandell, D. S., Morales, K. H., Marcus, S. C., Stahmer, A. C., Doshi, J., \& Polsky, D. E. (2008). Psychotropic medication use among Medicaid-enrolled children with autism spectrum disorders. Pediatrics, 121, e441-448.

McEachin, J. J., Smith, T., \& Lovaas, O. I. (1993). Long-term outcome for children with autism who received early intensive behavioral treatment. American Journal of Mental Retardation, 97, 359-372.

Montes, G., \& Halterman, J. S. (2008). Association of childhood autism spectrum disorders and loss of family income. Pediatrics, 121, e821-826.

Montgomery, R., Gonyea, J., \& Hooyman, N. (1985). Caregiving and the experience of subjective and objective burden. Family Relations, 34, 19-26.

Newschaffer, C. J., Croen, L. A., Daniels, J., et al. (2007). The epidemiology of autism spectrum disorders. Annual Review of Public Health, 28, 235-258.

Newschaffer, C. J., Falb, M. D., Gurney, J. G. (2005). National autism prevalence trends from United States special education data. Pediatrics, 115, e277-282.

Nicholas, J. S., Charles, J. M., Carpenter, L. A., King, L. B., Jenner, W., \& Spratt, E. G. (2008). Prevalence and characteristics of children with autism-spectrum disorders. Annals of Epidemiology, 18, 130-136.

Patrick, D. L., \& Deyo, R. A. (1989). Generic and disease-specific measures in assessing health status and quality of life. Medical Care, 27, S217-232.

Pearlin, L., Mullan, J., Semple, S., \& Skaff, M. (1990). Caregiving and the stress process: An overview of concepts and their measures. Gerontologist, 30, 583-594.

Phelps, K. W., Hodgson, J. L., McCammon, S. L., \& Lamson, A. L. (2009). Caring for an individual with autism disorder: a qualitative analysis. Journal of Intellectual and Developmental Disability, 34, 27-35.

Remington, B., Hastings, R. P., Kovshoff, H., et al. (2007). Early intensive behavioral intervention: outcomes for children with autism and their parents after two years. American Journal of Mental Retardation, 112, 418-438.

Revicki, D. A. (1992). Relationship between health utility and psychometric health status measures. Medical Care, 30, MS274-282. 
Ritvo, E. R., Jorde, L. B., Mason-Brothers, A., et al. (1989). The UCLA-University of Utah epidemiologic survey of autism: recurrence risk estimates and genetic counseling. American Journal of Psychiatry, 146, 1032-1036.

Ruble, L. A., Heflinger, C. A., Renfrew, J. W., \& Saunders, R. C. (2005). Access and service use by children with autism spectrum disorders in Medicaid Managed Care. Journal of Autism and Developmental Disorders, 35, 3-13.

Rutter, M. (2005). Incidence of autism spectrum disorders: changes over time and their meaning. Acta Paediatrica, 94, 2-15.

Sales, E. (2003). Family burden and quality of life. Quality of Life Research, 12, 33-41.

Sanders, J. L., \& Morgan, S. (1997). Family stress and adjustment as perceived by parents of children with autism or Down Syndrome: Implications for intervention. Child and Family Behavior Therapy, 19, 15-32.

Shimabukuro, T. T., Grosse, S. D., \& Rice, C. (2008). Medical expenditures for children with an autism spectrum disorder in a privately insured population. Journal of Autism and Developmental Disorders, 38, 546-52.

Siegel, C., Ravens, V. H., Houts, P., \& Mor, P. (1991). Caregiver burden and unmet patient needs. Cancer, 68, 1131-1140.

Smith, L. E., Seltzer, M. M., Tager-flusberg, H., Greenberg, J. S. \& Carter, A. S. (2008). A comparative analysis of well-being and coping among mothers of toddlers and mothers of adolescents with ASD. Journal of Autism and Developmental Disorders, 38, 876-889.

Szpir, M. (2006). Tracing the origins of autism: a spectrum of new studies. Environmental Health Perspective, 114, A412-418.

Testa, M. A., \& Simonson, D. C. (1996). Assesment of quality-of-life outcomes. New England of Journal Medicine, 334, 835-840.

The WHOQoL Group. (1994). The development of the World Health Organization Quality of Life Assessment Instrument (the WHOQoL). In J. Orley and W. Kuyken (Eds). Quality of Life Assessment: International Perspectives. Heidleberg: Springer-Verlag.

Thomas, K. C., Morrissey, J. P., McLaurin, C. (2007). Use of autism-related services by families and children. Journal of Autism and Developmental Disorders, 37, 818-829.

Torrance, G. W. (1987). Utility approach to measuring healthrelated quality of life. Journal of Chronic Diseases, 40, 593-600.

Torrance, G. W., Feeny, D. H., Furlong, W. J., Barr, R. D., Zhang, Y., \& Wang, Q. (1996). Multiattribute utility function for a comprehensive health status classification system. Health Utilities Index Mark 2. Medical Care, 34, 702-722.

Treffert, D. A. (1970). Epidemiology of infantile autism. Archives of General Psychiatry, 22, 431-438.

Tsai, L. Y. (1999). Psychopharmacology in autism. Psychosomatic Medicine, 61, 651-665.

Walker, D. R., Thompson, A., Zwaigenbaum, L., et al. (2004). Specifying PDD-NOS: a comparison of PDD-NOS, Asperger syndrome, and autism. Journal of the American Academy of Child and Adolescent Psychiatry 43, 172-180.

Walker, A. J., Pratt, C. C., \& Eddy, L. (1995). Informal caregiving to aging family members: A critical review. Family Relations, 44, 402-411.

Ware, J. E., Snow, K. K., Kosisnki, M., \& Gandek, B. (1993). SF-36 Health Survey Manual and Interpretation Guide. Boston: The Health Institute. 
Windham, G. C., Zhang, L., Gunier, R., Croen, L. A., \& Grether, J. K. (2006). Autism spectrum disorders in relation to distribution of hazardous air pollutants in the san francisco bay area. Environmental Health Perspective, 114, 1438-1444.

World Health Organization (WHO). (1947). The Constitution of The World Health Organization.World Health Organization Chronicle, Geneva, Switzerland. 
CHAPTER 2 


\section{CHAPTER 2:}

\section{A QUALITATIVE STUDY OF THE EXPERIENCES OF PRIMARY CAREGIVERS OF CHILDREN WITH AUTISM SPECTRUM DISORDERS}

\section{Introduction}

Autism spectrum disorders are a set of developmental disabilities characterized by social interaction and communication impairments, and restricted and repetitive behaviors (American Psychiatric Association, 2007). Three disorders - autistic disorder, Asperger's syndrome, and pervasive developmental disorder-not otherwise specified (PDD-NOS) - are classified under autism spectrum disorders (referred to as autism). In the past few decades, the prevalence of autism has increased markedly in the United States (US). In 1970, the prevalence of autism was estimated to be $0.7 / 10,000$ (Treffert, 1970); however, a more recent study reported prevalence in the US to be 110/10,000 among children 3-17 years of age (Kogan et al., 2009). Based on this current prevalence rate, it is estimated that there are 673,000 children 3-17 years of age with autism in the US (Kogan et al., 2009). Though the exact etiology of autism is still unknown, it has been suggested that it occurs due to an interaction of genetic and environmental factors (Hertz-Picciotto et al., 2006).

Unlike families of children with typical development, parents who have a child with autism also have to assume the role of a caregiver. A caregiver is an individual who helps another individual with physical care or coping with an infirmity without being paid (Hileman et al., 1992). Caring for a child with a chronic illness like autism can have a profound impact on the lives of caregivers. Several studies have documented the negative consequences of caring for a child with autism on the emotional health, physical health, social life, and financial status of 
caregivers (Allik et al., 2006; Davis \& Carter, 2008; Montes \& Halterman, 2008; Mugno et al., 2007; Smith et al., 2008). For example, a study by Smith et al. (2008) found that more than onethird of mothers of children with autism had scores on a depression scale higher than the clinical cut-off. The quality of life of parents of children with autism has been shown to be significantly lower than parents of children with mental retardation, cerebral palsy, and typical development (Mugno et al., 2007).

A majority of studies assessing caregiving outcomes in autism are quantitative in nature, and have used questionnaires for data collection. Though quantitative data collection through survey methodology provides answers to specific questions, it may not provide the researcher with the range and depth of people's feelings and opinions (Pill, 1995). Providing adequate support to caregivers to alleviate their burden requires a deeper understanding of their experiences. A richer understanding of caregivers' self-perspective can be attained through the use of qualitative research techniques. Qualitative methods of data collection are useful especially to describe a phenomenon from the "emic" perspective, which is the perspective of the problem from an individual's point of view (Morse \& Field, 1995). Understanding caregiver's perspective through qualitative research techniques could enable policy makers, researchers, and healthcare professionals to better address the needs of this growing population.

A literature search of qualitative studies assessing caregiving outcomes and experiences in autism revealed limited results. A recent study by Phelps and colleagues (2009) highlighted this lack of qualitative research in autism caregiving. Using a phenomenological research design, a qualitative technique which primarily focuses on human experience (Morse \& Field, 1995), the authors identified autism caregiving themes which included the psychological, familial, social, and financial implications of caring. In addition, they highlighted caregivers' 
experiences with service professionals and the use of spirituality as a coping mechanism. Other qualitative studies in autism have focused on studying coping mechanisms used by caregivers (Gray, 2006; Lin et al., 2008; Luong et al., 2009), experiences among grandparents (Margetts et al., 2006), and world views, values, and priorities among families of children with autism (King et al., 2006). In order to fully understand the experiences and specific needs of those caring for children with autism, more qualitative research is necessary.

This research builds upon the work of Phelps et al. (2009), with the aim of gathering information about caregivers' experiences in providing care to a child with autism. The purpose of this study is to determine caregivers' self-perspective on the health impact of caring. In addition, the study aims to gather data concerning caregivers' needs and concerns. Unlike Phelps et al. (2009) who had used open ended questions as a part of a broader survey to collect their information, we collected our data through focus groups. The focus group is a qualitative research method that can be used to obtain perceptions on a particular area of interest in a permissive and nonthreatening environment (Krueger \& Casey, 2000). Focus group is an efficient and effective way of collecting rich qualitative data, and enables researchers to access participants' perceptions, attitudes, and beliefs (Clarke, 1999).

\section{Methods}

Study design

The present study reports data from Phase I of a two-phase research project. This phase of the study incorporated qualitative methodology using focus groups of caregivers of children with autism for data collection. 


\section{Participants}

The ideal group size for focus groups is six to eight participants (Krueger \& Casey, 2000). In this study, a purposive sample of 20 participants was recruited for two focus groups by the site coordinators at the northern and southern offices of the West Virginia Autism Training Center (WV ATC). Purposive sampling allows researchers to choose participants for focus groups based on the study purpose, with the goal of generating the most productive discussions (Morgan, 1998). Participants were primary caregivers of children with autism. For study purpose, primary caregiver was defined as the individual in the family who had the primary responsibility for providing daily care to the child with autism. Participants were recruited in the study if the child with autism to whom they provided care was less than or equal to 18 years of age and there was no more than one child diagnosed with autism in the family. Twelve and seven caregivers participated in the first and second focus group discussions, respectively, and one caregiver recruited for the second focus group did not show up. Thus, a total of 19 participants were involved in two focus group discussions conducted in Fall 2009. The study was acknowledged by the Institutional Review Boards (IRB) of West Virginia University and Marshall University under exempt status.

\section{Procedure}

Site coordinators at the northern and southern office of the WV ATC identified and contacted families of children with autism. Using a structured telephonic guide (Appendix A), the site coordinators gained the interest for participation in the focus groups from the primary caregivers, and the suitable dates and times of their availability. A follow-up cover letter (Appendix B) detailing the final date and time of focus group was then mailed to caregivers who had agreed to 
participate during telephonic invitation. The two focus groups were held in conference rooms at the WV ATC north (Fairmont, WV) and south (Huntington, WV) office, respectively. Both focus groups were moderated by the primary author (RK), who had gained training in qualitative research methodology during graduate education.

Prior to data collection, an information sheet (Appendix C) that served the purpose of informed consent was presented to the participants. The information sheet highlighted voluntary participation. Further, it was emphasized that information shared during the discussion would be maintained confidential by study researchers at all times. However, it was also mentioned that study researchers could not bear any responsibility if participants were to share any information discussed during the focus group with others. The focus groups lasted between 2 and 3 hours and were audio taped for transcription. Numeric placards were placed around a round table, and each participant was given the choice to select any seat with a number. As a result, each participant had a number that was self-chosen, and was requested to report that number before providing an opinion during the discussion. There were two benefits of using this approach. First, it became easier to sift through multiple voices during transcription to determine the participant who had voiced his/her opinion. And second, it maintained participant anonymity during the discussion, data analysis, and report writing.

Before the discussion was initiated, participants were requested to complete a questionnaire (Appendix D) collecting basic demographic data. In accordance with IRB recommendation and the sensitivity of the topic, participants were also provided with a list of counseling facilities (Appendix E) that they could contact if they were to experience any emotional discomfort with the focus group discussion. A structured discussion guide (Appendix F) was used to collect data from participants. The questions in the discussion guide were 
modified (with permission) from the study conducted by Murphy, Christian, Caplin, and Young (2006) who had used them to assess the health implications of caring for children with disabilities on caregivers. Since we were interested in collecting similar information from caregivers of children with autism, the questions used by Murphy et al. (2006) fit well with our study purpose after modification. Questions were generally open ended, which provided participants with an opportunity to share their experiences in detail. There was an interactive discussion in both focus groups, and participants gave each other the opportunity to put forth an opinion. When appropriate, participant responses were further probed by the moderator to elicit in-depth discussion. A \$25 Wal-Mart gift card (Appendix G) was provided to each participant on completion of the focus group session as a token of appreciation for their time.

\section{Data analysis}

Data from focus group discussions recorded in audiotapes were transferred to Qualitative Solutions and Research (QSR) NVivo Version 8.0 software (QSR International Pty. Ltd., Doncaster, Victoria, Australia) for transcription and data analysis. Full verbatim transcripts were created, leading to 54 single-spaced pages of transcribed data. Qualitative content analysis of the caregiving experience shared by participants during focus group discussions was undertaken (Sandelowski, 2000). Content analysis allows a researcher to distil data into content-related categories (Elo \& Kyngas, 2008). Data analysis was driven by the purpose of the study (Krueger \& Casey, 2000), which was to determine the impact of caring for a child with autism on different aspects of a caregiver's life and their experiences in general. Data were read several times by the primary researcher. Based on content analysis approach, the data were classified into categories, which were then refined and grouped together into specific themes when appropriate (Pope et al., 
2000). The collapsing of categories into themes was undertaken based on discussions among members of the research team. The themes reflect the purpose of the study and collapse the information collected through study questions.

The trustworthiness of study research findings was established based on procedures outlined by Graneheim and Lundman (2003), and included the aspects of credibility, dependability, and transferability. Credibility (internal validity in quantitative parlance) refers to the accuracy of information. Credibility can be established by selecting an appropriate method of data collection and choosing participants with different experiences and perspectives. Given our study objectives, focus group methodology served a useful purpose in data collection, and we invited participants who had the primary responsibility of caring for a child with autism. Though the degree of contribution to the discussion varied, all except one participant shared his/her experiences and participated in the discussion. Another way of establishing study credibility is to ensure that themes include relevant data and are distinctive, which can be approached by the inclusion of participant quotes. Within each theme described below, participant quotes that best illustrate the theme have been included. Data triangulation (i.e. using multiple sources to gather data) is also an important mean of establishing credibility of a qualitative study (Lincoln \& Guba, 1985). We triangulated data by conducting two focus groups.

Dependability (reliability) was established by using the same discussion guide for each of the two focus groups and by preparing transcripts promptly. Further, a single researcher (primary author) transcribed the data, and the results were discussed among the research team to establish study dependability. Transferability (external validity) refers to the extent to which study findings can be transferred to other settings or groups (Lincoln \& Guba, 1985). It has been suggested that transferability is not a crucial issue for qualitative studies (Maxwell, 1996). The 
transferability of our findings was enhanced by the inclusion of participants who were primary caregivers of children with autistic disorder, Asperger's syndrome, and PDD-NOS.

\section{Results}

Participants $(n=19)$ were adult primary caregivers of children with autism. Eighteen participants were female (mother), and one participant was male (father). Participants' age ranged from 29 years to 50 years, and the average age was approximately 37 years $(\mathrm{SD}=5.5$ years). Seventeen participants were white, one was black, and one was hispanic. Fourteen participants were married, and five were divorced or separated. Two participants had graduated high school, six had attended college or technical school, and eleven were college graduates. With respect to occupation, twelve participants were employed (full-time or part-time), five were homemakers, one was a student, and one was a substitute. In terms of family income distribution, two participants reported their family income to be less than $\$ 25,000$, eleven reported income to be between $\$ 25,000$ and $\$ 49,999$, five reported income to be between $\$ 50,000$ and $\$ 99,999$, and one reported income equal or above $\$ 100,000$. As for the characteristics of children with autism to whom the participants provided care, sixteen were male and three were female. In terms of age distribution, one child was less than 5 years of age, nine were in the age group of 5 years-less than 10 years, six were between 10 years-less than 15 years, and three were between 15 years and 18 years of age. Ten children had autistic disorder, four had Asperger's syndrome, and five had PDD-NOS. Table 2.1 shows basic demographic characteristics of the participants.

Data gathered during focus group discussions were classified into six themes - impact on caregiver health, impact on relationships, objective burden, needs of caregiver, caregiver coping 
mechanisms, and caregiver concerns. The themes explained below cover the breadth of information discussed during the focus groups, and offer a glimpse of experiences, needs, and concerns among caregivers of children with autism. Participants have been referred to by two digits in this section. The first digit relates to focus group ( 1 or 2$)$ and the second to participant number (self-chosen) within that particular focus group. Names referred to by participants during the discussions have not been reported.

\section{Theme I: Impact on caregiver health}

Participants reported feeling both positive and negative emotional consequences of caring. In terms of negative emotional impact, participants reported feelings of stress, anxiety, depression, grief, guilt, and isolation. Though not always directed towards the child, feelings of frustration and anger were also reported. Some caregivers reported feeling emotionally numb. As one mother (2_6) described:

...there is that feeling of isolation. There are times when you could talk to someone else who is a parent, but you are so trying to figure it out in yourself in the moment before you can either do that, that you feel so isolated. You don't know what to do or you don't know how to deal with the feelings, that sort of thing. So I mean that's a feeling that comes and goes with me regularly, is feeling isolated.

Some shared the positive emotional consequences of caregiving. Feelings of joy, pride, enrichment, and excitement in caring were reported. Caregivers expressed strong emotional bond towards the child, which they felt gave them the internal strength and motivation to keep up with all the work that their role demands. In midst of all their responsibilities, caregivers described that they do enjoy special moments with their child and feel the happiness of being a 
parent. Small accomplishments, such as the child learning how to use the toilet or riding a bike, carry a lot of significance and are considered as victories in the fight against the disorder. Carers reported that they have learned to appreciate the unique qualities of the child. A father (1_10) who had a son with autism described:

...instead of asking why or if and asking the question - would I want things to be different or would I want the child [with autism] I have. I think I probably would take the child I have. It comes with a lot of....it comes with a lot of stress and a lot of... but there is something unique and special about him [child with autism] that if he was like every other kid it wouldn't be there.

Another participant (2_1) said:

In regards to stress and being overwhelmed, it is kind of ironic, because on one hand this is the most stressful job, the most stressful and overwhelming experience I have ever had, but at the same time it is the most enriching experience of my life.

A term that was commonly described during the discussions was "emotional rollercoaster." Participants described that there were highs and lows associated with caring, and that they experience opposite emotions on a regular basis. They attributed the emotional ups and downs to the unpredictability associated with symptom manifestation in autism. Since the occurrence and severity of behavioral and other social and medical symptoms among children with autism cannot be predicted, participants indicated feeling anxious and emotionally tense thinking about the next moment. As participant 1_9 said:

I think the way you feel everyday is that you have the worst feeling in the entire world and you have the best feeling. It's like an emotional roller coaster. You probably have to drug yourself and maintain a flat line. Then you miss out on all the 
fabulous things and you miss out all the horrible things you have to go through to appreciate the simple things.

Likewise, participant 1_3 reported:

I don't even know how to put into words the range of emotions that you go through in a day. You really can't let yourself get too cocky where you are in the spot in your life because you get your legs kicked really far.

In addition to the emotional consequences, participants reported adverse physical health effects of caring. Many participants felt overwhelmed and exhausted. Sleep deprivation was commonly reported. The negative impact on physical health was attributed primarily to the stress associated with caring. Among participants who had prior physical illnesses, stress was reported to aggravate symptoms associated with the illness. As one participant (2_7) said, "I was diagnosed with rheumatoid arthritis and they said it was stress related and I was on nine different medicines, chemotherapy and everything. But now I am up and walking now, but they said its stress related." Further, caregivers felt that time constraints makes it difficult for them to take care of their health or visit a health care provider when ill. Caregivers expressed that taking care of their own health is generally last on their list of priorities. Few participants described that the impact of caring on their physical health is further exacerbated because of a lack of availability of respite care. As one mother (2_2) described, "I actually have what they say is lupus, based on not taking care of myself for so many years. Not eating when I should be eating, not sleeping when I should be sleeping, not resting when I should be resting."

Given the physical demands placed on them, some carers reported undertaking steps to maintain their physical health. Caregivers said that they use preventive measures such as eating healthy and walking to maintain their physical health. Being the primary caregiver, these 
participants felt that it was imperative for them to remain physically healthy so as to be able to provide constant care to the child. As participant $1 \_5$ who was a single mother noted:

I was a smoker for probably 10 years and I loved it. It was the hardest thing I ever did to give it up. I still think about it a lot, but when I turned 30, I realized that it was probably just going to be me and my son forever. So if I didn't start taking care of myself, who was gonna take care of him [child with autism]. My parents would not be there forever and I don't have any brothers and sisters. So I started running.

\section{Theme 2: Impact on relationships}

The second theme reflects the impact of caring for a child with autism on relationships both within and outside the family. In their immediate family, participants described how autism had affected relationship between them and their spouse and also with siblings of the child with autism. Some reported receiving support from their spouse in care responsibilities, which provided them a much needed break from caregiving. These participants felt that autism had brought them closer to their spouse. A few mothers felt that though they were the one providing daily care to the child, their spouses were working to ensure that their child's future as an adult was secured. Participant 1_3 reported:

I don't want to think that our husbands are a negative thing. He [husband] has been my best team co-captain than I can ask for. He can tell when I need a break and I can tell when he needs a break.

However, some participants reported strain in the relationship with their spouse and attributed it to autism. Lack of time needed to maintain a healthy relationship and lack of support in caring were reported as reasons behind the strain. A participant $\left(2 \_1\right)$ who was 
divorced mentioned: "I am not embarrassed to say that I lost my marriage to autism and my exhusband is much more open to it now and embraces it more now than he did before." Another caregiver (1_2) reported: "If I could afford it, I probably would be divorced too. Can't afford it."

Several participants reported feeling guilty about not being able to give adequate time to the siblings because of caregiving. Since taking care of the child with autism requires full-time devotion, participants said that it becomes difficult for them to focus on the needs of the sibling. Caregivers felt that their relationship with the sibling had been 'sacrificed' because of the constant support that they had to provide to the child with autism. Participant 1_12 reported occurrence of negative health outcomes among the sibling: “.... matter of fact my older son has exhibited problems because of the 12 year old [child with autism] and he [sibling] is actually medicated too because he was having bouts of depression to the point where he could not meet."

Some caregivers also talked about the warmth in sibling relationship that had developed in their family. They mentioned that the siblings have gained compassion and understanding towards children with autism in general. They felt that siblings perception towards children with disabilities have changed in a positive way because of experiences at home. A few participants reported receiving support from siblings in caregiving. Participant $1 \_7$ reported:

She [sibling] is wonderful. She helps out tremendously. She gets [child with autism] to OT [occupational therapy]. I don't know how many 18 year olds who are freshman in college would bathe a 9 year old and wash their hair, take them OT, and work with them, and do the things that she does.

Participants also shared their experiences about the impact on relationships outside the family, including those with extended family members, friends, and the general public. Several participants felt that their relationships outside the family had been negatively affected. Multiple 
reasons were attributed for this: 1) lack of understanding among the extended family members and friends about the challenging situations caregivers face in their daily lives; 2) extended family members not wanting to deal with the behavioral issues of the child with autism and feeling embarrassed; and 3) ignorance of autism among the general public. For example, participant 1_4 expressed her frustration with lack of understanding among members of her church:

She [child with autism] can't go to church all those times and be with all those people. And what I have noticed is even with the church people, and I am not putting them down...and if you are thinking they are going to understand a lot better by sudden great enlightenment given by god that they are going to understand you better. But they are not.

Caregivers reported that their opportunities for socialization have diminished because of autism, which often makes them feel isolated. Participants reported avoiding social situations on several occasions because they are concerned that the child with autism will have a behavior 'meltdown' and that others will not be able to comprehend the situation. In line with socialization, some female caregivers also shared the difficulties they face in dating.

Though socialization opportunities were generally reported to have diminished, several participants said that autism had led to creation of new social networks for them. Participants described that they had developed relationships with their 'autism peers' who shared similar experiences and are more understanding of their situation than parents of children with typical development. Caregivers expressed that they tend to reach out to parents of newly diagnosed children with autism to help them navigate through the challenges that they themselves had faced in the past. As one participant (2_1) described: 
You have this sense of community. One of our responsibilities is to help new families, new moms, new whatever, come to terms with this... and kind of help them find their way through this maze to get to where they need to be.

\section{Theme 3: Objective burden}

The burden of autism was reported to extend beyond the negative emotional, physical, and social consequences. Caregivers felt that the effect of autism pervades through every minor aspect of their life. Several talked about the financial toll that autism has had on their family because of the out-of-pocket expenses associated with treatment. They mentioned that insurance paid for only limited treatment services, which left them with no choice but to incur those expenses. A female caregiver (2_2), describing the financial impact, stated:

As a parent if there is a service that waiver is not going to pay for, or insurance is not going to pay for, or grandma won't give you or even let you borrow, you are the one left to pay for your son. And when you start getting in debt that is another worry. It's all a spiral all the time.

Another aspect that was talked about was the impact on caregiver's career. Some mothers mentioned that they had to leave their job so that they could provide full-time care to the child with autism. As one mother (1_2) described: "I just recently left my job, I was working full time, so now I am stay at home mom." This was said to further add to the financial burden of autism on the family.

Besides finances and career, a few participants also described the impact of autism on their personal hygiene, self-attire, and immediate environment. Participants noted that they have to be careful about minor things such as the type of cleaning products they use, lighting in the 
house, and keeping sharp objects like knives in the kitchen. Though not as significant as the emotional or physical health consequence of caring, it does signify the all encompassing impact of autism on families. Participant 1_9 captured this feeling in her remark:

It affects every aspect of your life. There is not a point, unless you are like a superhero and you can put your mask on and go and do something fun over there and pretend this right here doesn't exist. You are over there playing superhero.

\section{Theme 4: Needs of caregiver}

Participants reported the need for: 1) respite care services; 2) support groups; 3) support from health care professionals and school system; and 4) insurance reform extending coverage of autism-related services. Need for respite services such as babysitters who are educated in autism-related issues and willing to take care of children with autism was expressed by several participants. They felt that regular babysitters or other paid respite care providers are generally not able to deal with the behavioral issues that are common among children with autism. Caregivers felt that the availability of respite care would not only provide them with some personal time and be beneficial for their physical and emotional health, but it would also improve family relationships. Participant 2_3 highlights this need in her remark

....we don't have staff. I choose that for a while but it would be nice to be able to just call someone that you could....a staff person that is employed by autism agency that you could trust may be for just like 2-4 hours so you could go for dinner and movie for the first time in over a year...I just...it will be nice to see whats its like to be married again.

Need for support group for both parents and siblings was also expressed by some 
participants. Support groups where participants could get information and advice about improving familial relationships were said to be needed. Carers felt that support groups would also help them 'vent their feelings' to those who share similar experiences. Some mentioned that even though they had support groups available near their area of residence, they could not use them because of lack of child care or play area accommodations: "You can't go to support groups and leave your child at home" (1_1). A few participants reported the need for support groups for siblings of children with autism. Caregivers felt that this would give siblings an opportunity to share their experiences and feelings to someone other than the parent.

Several participants expressed their frustration dealing with health care professionals and school system. Lack of understanding and limited informational support from health care professionals was a commonly reported feeling among caregivers. Caregivers reported receiving limited information from health care providers on issues related to autism. Some felt that health care professionals often attribute any occurrence of medical issues in the child to autism without making an adequate diagnosis. As one participant (2_8) described:

When we were talking about physicians, you go to the physician's office...like she [participant (2_1)] said the umbrella is just everything autism. They want to put your child on medication, that's like their solution to everything, not to find the underlying symptoms or problems with the child.

Some also remarked that health care visits are challenging for them because of the waiting time involved, which often results in exacerbation of behavioral issues in the child. Participant 2_6 describing an incident stated:

Little while back my son [with autism] had reaction to a medication they [physician] put him on. Took him to ER when he was having spasms, where his neck turned to 
the left....and took him into ER and they [health care professionals] are asking for insurance cards and all that. And he had meltdown right then and there.

Similar feelings of neglect and frustration were expressed with regards to the school system. Caregivers reported that Individualized Education Plan (IEP) in place for their children was not being adequately followed. Participants expressed concern that their children were not receiving a gainful educational experience, and reported lack of adequate resources in their school district. Some also spoke about the lack of inclusion of children with autism with their peers. Though a few caregivers were satisfied and appreciated the role of teachers, others felt that teachers need to be better educated about the issues surrounding autism. Expressing her frustration with the school system, participant 2 _ 7 remarked:

As far as school system, it is a constant fight, and you would think that they would be more work with you more as a team considering they already know your daily challenge, and I found it to be a constant fight.

Another area of need that was expressed by many caregivers was insurance reform. Most of the participants reported frustration in dealing with insurance to receive coverage for autism services. Availing autism services through the state Medicaid waiver program was also reported to be an issue by several caregivers. One caregiver (1_1) spoke about how she had to wait to avail services for her child through the Medicaid waiver program:

Waiver West Virginia. I applied for it 2-1/2 years ago. You have to wait 2 years to get the help. I am thankful is....that we got accepted for behavior support...2-1/2 years ago when I really needed it, we had to wait our 2 years before we get the help. Others expressed their frustration arising from lack of continuity of autism services through the Medicaid waiver program. Participant 1_12 described that her son was taken off the 
Medicaid waiver program:

You [referring to participant (1_1)] can be thrown off waiver. Make sure you do everything they [Medicaid waiver] ask you to do and on time because we lost our waiver and got it back through a lot of jumping through hoops.... They told me that [child with autism] was not autistic enough. I said, excuse me?

\section{Theme 5: Caregiver coping mechanisms}

When asked about how they coped with the high demands placed on them, participants revealed using different coping strategies. Some participants felt that work allows them to take their mind off the daily rigors. As participant $1 \_7$ stated, "I go to work. Work is my outlet. It really is." Another caregiver (1_11), who had a flexible work from home schedule, said: "Sometimes I pretend to go to work. And go in and shut my door and lock it...It is okay to get away from it. Kids are not in, shut the door and lock it, turn the music up." However, a couple of caregivers felt that work contributes to the stress that they already experience, and also leads to time constraints. Not surprisingly, faith was also described as a commonly used coping strategy. When experiencing high levels of stress, participants stated that they pray to God. They emphasized the role of faith in not only alleviating their stress but also in improving the functioning in their child with autism.

In general, participants reported using positive coping strategies such as relaxation, walking, reading, and exercising. As one caregiver (2_6) said: "Walk, walk a lot." Another said that she has a mentor who guides her and provides her with practical steps to manage caregivingrelated situations. Some reported 'venting' their feelings to their family members and friends. Participant 2_5 describing her coping strategy stated: 
I am calling to vent to friends if there is something off the wall. I have a list - first I call my mom, then I call my grandmother, then I call anybody else who has answered the phone and vent to them. And then about six people later I am ok.

\section{Theme 6: Caregiver concerns}

As has also been described in previous studies (Murphy et al., 2006; Phelps et al., 2009), concern for future care was expressed by most of the participants in this study. Lack of long term care facilities for individuals with autism was voiced as a source of concern by the caregivers. Since children with autism generally suffer from verbal impairments and have difficulty expressing their thoughts, carers felt that placing children with autism in group home may not ensure adequate care. One caregiver shared an incident where her uncle who had mental retardation was mistreated in a group home, which made her concerned thinking that it could also happen to her child. In comparison to children with typical development, caring for a child with autism requires significant emotional, physical, and financial investment from parents. Participants felt concerned thinking about the implications on caring if something were to happen to them or their spouse. Participant 2_2 stated:

I worry a lot about if something would happen to my husband or I, and we physically become disabled. Could the other pick up and do what both of us have been doing all this year. Could I pick up and go out and work and make the income my husband makes. I don't think so. If something would happen to me, then he [husband] wouldn't be able to work.

Another participant, who had an adolescent son with autism, was worried about the quality of life that her son would have as an adult. Some were worried about the uncertainty of 
health issues that their child with autism may face as an adult. For example, participant 2 _3 said: "Are they [children with autism] going to have autism and cancer, are they going to have autism, cancer, and Alzheimer. What if that happens to their bodies, if this [autism] is not resolved?" With limited informational support from health care professionals or experts in the field, some were concerned about whether they were taking appropriate and correct measures in caring for their children.

\section{Discussion}

The present study offers additional insight into the caregiving experiences in autism from the caregivers' self-perspective. Since data was collected from the perspective of primary caregivers, the results of the study provide a rich description of the realities associated with autism caregiving. Carers felt that every domain of their life is affected by autism, whether it is their emotional or physical health, family relationships, socialization, or finances. Some of our findings are well documented in autism literature, while others are unique to this study.

The positive and negative emotional consequence of caregiving as seen in our findings is not surprising. Previous literature in autism has reported two emotional aspects of caregiving. Feelings of stress, anxiety, and depression as reported by caregivers in the current study have been well documented previously (Davis \& Carter, 2008; Magana \& Smith, 2006; Smith et al., 2008; Stuart \&McGrew, 2009). Further, the positive emotions such as joy and pride shared by carers in this study have also been described in the autism literature (Myers et al., 2009; Phelps et al., 2009). Our data gives insight into the caregiver feeling of riding an emotional roller coaster because of the ever changing health and functional issues associated with autism. Carers felt that the negative emotional feelings associated with caring are interspersed with moments of 
happiness. A small improvement in functional status of the child is considered to be of immense satisfaction to carers. This signifies the importance of employing successful treatment interventions in improving functioning among children with autism. Such interventions could not only help improve the quality of life of those with the disorder, but also of caregivers.

Autism literature is replete with studies that have described the negative mental health consequence on caregivers; however, the impact on caregiver physical health is still not fully understood. Besides psychological health, it is also imperative to understand the affect of caregiving on physical health of autism caregivers. In our study, participants emphasized that stress had a significant role to play in the occurrence and exacerbation of physical illnesses in them. Caregiving studies in Alzheimer's have shown stress to affect physical health of caregivers (Haley, 1997). Stress is known to be a significant risk factor for chronic diseases (McEwen \& Stellar, 1993). Cardiovascular, immune, and endocrine functions can be altered as a result of prolonged distress evoked through chronic stressors such as caregiving (Rabin, 1999). A few studies have found the physical health of mothers of children with autism to be lower than that of mothers of children with typical development (Allik et al., 2006; Mugno et al., 2007). In their study of health-related quality of life among mothers of children with Asperger syndrome/high-functioning autism, Allik et al. (2006) found a significant relationship between physical health of mothers and prosocial behavior in the child with autism. Further research is needed to establish whether there is a relationship between stress and physical health in caregivers of children with autism, and the role played by caregiver characteristics (age, gender, income, education), care recipient characteristics (age, level of functioning, extent of behavioral problems), and the availability of family ecological resources (social support, family functioning) in this relationship. 
Though the awareness of autism among the general society has increased over the years, there is a significant understanding yet to be reached. The focus groups revealed that families face difficulties dealing with the public, and that the ignorance about autism is still prevalent. In his review of the literature on the relationship between social support and stress among mothers of children with autism, Boyd (2002) concluded that low levels of social support is a strong predictor of depression and anxiety among mothers. Diminished social opportunities compounds the strain already experienced by families of children with autism. Carers in this study felt that they are able to relate better to other parents of children with autism who face similar issues. It is recommended that professionally led support groups from experts in the field be made accessible to caregivers, where they could gain useful information about improving their quality of life, managing familial relationships, and interacting with other families with similar experiences. For a state like WV, which is mostly rural, it is imperative that these support groups be geographically accessible and located not only in certain central locations but all across the state.

As has also been documented in previous studies (Myer et al., 2009; Phelps et al., 2009), the participants in our study expressed frustration at the lack of information and support received from health care professionals and the school system. Studies have reported a lack of adequate training and knowledge about autism among health care professionals (Planche et al., 2004; Rhoades et al., 2007; Shah, 2001), which could be the reason for limited informational support received by caregivers in this study. Though not conclusively supported by their results, Rhoades et al. (2007) suggested that rural status may further result in delayed diagnosis and lack of information provided by health care professionals. Informational support from health care providers could go a long way in alleviating caregiver concerns about health issues in their child and measures they could take to improve caring. As per the school system, carers felt that they 
were involved in the development of IEP, but that the implementation of the plan falls short of the target. Teachers should be provided with the necessary educational tools, resources, and information needed to ensure that the IEP is meeting its goal.

The focus groups highlighted the need for support groups for siblings and insurance reform. The provision of support groups to siblings of children with autism could help them cope better with the demands placed on them. These support groups would also provide the siblings with an opportunity to share their feelings, which they otherwise may have kept to themselves and not shared with their family members. Carers reported concern about the lack of insurance coverage for autism services. In addition, the need for improvements in the state Medicaid waiver program was also expressed. Intervention strategies aimed at improving functioning in children with autism are expensive but necessary. Families of children with autism can spend as high as $\$ 100,000$ per year on treatments (Bartley, 2006). WV is one of the many states where insurance coverage for autism services is currently not mandated by law. As a result, several families have to bear the financial responsibility of paying for those services. In cases where the Medicaid waiver program bridges the gap, waiting times associated with the provision of services and the possibility of the child being taken off the program negates its purpose. The financial burden associated with autism is not restricted to therapies. Some mothers reported leaving their jobs to be full-time caregivers, which places further financial constraints on the families.

This study had several limitations which should be noted. The study sample was small, and the data reflected experiences of only those caregivers of children with autism who participated in our focus groups. This study does not capture the unique experiences and challenges facing male caregivers, since our focus groups consisted of only one male caregiver. 
However, in our initial contact with families, we had requested participation from primary caregiver, which not surprisingly turned out mostly to be females. We excluded families with more than one child with autism or where the child was more than 18 years of age. The challenges and experiences of caregivers who care for more than one child with autism or for an adult individual with autism may be different from those shared by our sample. Since caregivers were recruited by the WV ATC, they were likely to be engaged in support services and may not be representative of the caregiver population. Together, these factors limit the generalizability of our results.

This study is one of the few that uses focus group discussions to get rich perspectives on caregiving experiences from primary caregivers of children with autism. Caregiver feelings of riding an emotional roller coaster, impacting physical health, and needing support groups for siblings and insurance reform were some of the notable issues reported in this study. Future research is needed to fully understand the physical health impact of autism caregiving, and the role played by different caregiver and care recipient factors in affecting caregiver physical health. Limited qualitative data currently exists about the caregiving experiences, needs, and concerns among carers of adults who have the disorder. Future research should also extend the results of this study by gathering qualitative information from caregivers of adults with autism. 
Table 2.1. Descriptive characteristics of focus group participants.

\begin{tabular}{|c|c|}
\hline Characteristic & Frequency (n) \\
\hline \multicolumn{2}{|l|}{ Caregiver characteristics } \\
\hline \multicolumn{2}{|l|}{ Gender } \\
\hline Male & 1 \\
\hline Female & 18 \\
\hline Age in years (Mean [Range]) & 37 [29-50] \\
\hline \multicolumn{2}{|l|}{ Ethnicity } \\
\hline White & 17 \\
\hline Others $^{\mathrm{a}}$ & 2 \\
\hline \multicolumn{2}{|l|}{ Marital status } \\
\hline Married & 14 \\
\hline Divorced/separated & 5 \\
\hline \multicolumn{2}{|l|}{ Education } \\
\hline Graduated high school & 2 \\
\hline Attended college/technical school & 6 \\
\hline College graduate & 11 \\
\hline \multicolumn{2}{|l|}{ Occupation } \\
\hline Employed (full- or part-time) & 12 \\
\hline Homemaker & 5 \\
\hline Others $^{\mathrm{b}}$ & 2 \\
\hline \multicolumn{2}{|l|}{ Income } \\
\hline Less than $\$ 25,000$ & 2 \\
\hline$\$ 25,000-\$ 49,999$ & 11 \\
\hline$\$ 50,000-\$ 99,999$ & 5 \\
\hline Equal to or more than $\$ 100,000$ & 1 \\
\hline \multicolumn{2}{|l|}{ Care recipient characteristics } \\
\hline \multicolumn{2}{|l|}{ Gender } \\
\hline Male & 16 \\
\hline Female & 3 \\
\hline \multicolumn{2}{|l|}{ Age } \\
\hline Less than 5 years & 1 \\
\hline 5 years to less than 10 years & 9 \\
\hline 10 years to less than 15 years & 6 \\
\hline 15 years to 18 years & 3 \\
\hline \multicolumn{2}{|l|}{ Type of diagnosis } \\
\hline Autistic disorder & 10 \\
\hline Asperger's syndrome & 4 \\
\hline PDD-NOS & 5 \\
\hline
\end{tabular}

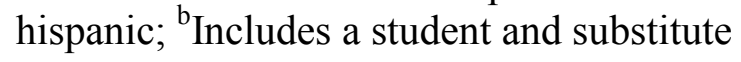




\section{Bibliography}

American Psychiatric Association. (2000). Diagnostic and statistical manual of mental disorders fourth edition text revision. Washington, D.C.: American Psychiatric Association.

Allik, H., Larsson, J. O., \& Smedje, H. (2006)._Health-related quality of life in parents of schoolage children with Asperger Syndrome or High-Functioning Autism. Health and Quality of Life Outcomes, 4, 1.

Bartley, J. J. (2006). An update on autism: science, gender, and the law. Gender Medicine, 3, 73 78.

Boyd, B. A. (2002). Examining the relationship between stress and lack of social support in mothers of children with Autism. Focus on Autism and Other Developmental Disabilities, 17, 208-215.

Clarke, A. (1999). Focus group interviews in health-care research. Professional Nurse, 14, 395 397.

Davis, N. O., \& Carter, A. S. (2008). Parenting stress in mothers and fathers of toddlers with autism spectrum disorders: associations with child characteristics. Journal of Autism and Developmental Disorders, 38, 1278-1291.

Elo, S., \& Kyngäs, H. (2008). The qualitative content analysis process. Journal of Advanced Nursing, 62, 107-115.

Graneheim, U. H., \& Lundman, B. (2004). Qualitative content analysis in nursing research: concepts, procedures and measures to achieve trustworthiness. Nurse Education Today, 24, 105-112.

Gray, D. E. (2006). Coping over time: the parents of children with autism. Journal of Intellectual Disability Research, 50, 970-976.

Haley, W. E. (1997). The family caregiver's role in Alzheimer's disease. Neurology, 48, S25S29.

Hertz-Picciotto, I., Croen, L. A., Hansen, R., Jones, C. R., van de Water, J., \& Pessah, I. N. (2006). The CHARGE study: an epidemiologic investigation of genetic and environmental factors contributing to autism. Environmental Health Perspectives, 114, 1119-1125.

Hileman, J., Lackey, N., \& Hassanein, R. (1992). Identifying the needs of home caregivers of patients with cancer. Oncology Nursing Forum, 19, 771-777.

King, G. A., Zwaigenbaum, L., King, S., Baxter, D., Rosenbaum, P., \& Bates, A. (2006). A qualitative investigation of changes in the belief systems of families of children with autism or Down syndrome. Child: Care, Health and Development, 32, 353-369.

Kogan, M. D., Blumberg, S. J., Schieve, L. A., Boyle, C. A., Perrin, J. M., Ghandour, R. M., et al. (2009). Prevalence of Parent-Reported Diagnosis of Autism Spectrum Disorder Among Children in the US, 2007. Pediatrics, 124, 1395-1403.

Krueger, R. A., \& Casey, M. A. (2000). Focus Groups: A Practical Guide for Applied Research. 3rd ed. Thousand Oaks, CA: Sage Publications.

Lin, C. R., Tsai, Y. F., \& Chang, H. L. (2008). Coping mechanisms of parents of children recently diagnosed with autism in Taiwan: a qualitative study. Journal of Clinical Nursing, 17, 2733-2740.

Lincoln, Y., \& Guba, E. (1985). Naturalistic inquiry. New York: Sage.

Luong, J., Yoder, M. K., \& Canham, D. (2009). Southeast Asian parents raising a child with autism: a qualitative investigation of coping styles. Journal of School Nursing, 25, 222229. 
Magana, S., \& Smith, M. J. (2006). Psychological distress and well-being of Latina and nonLatina White mothers of youth and adults with an autism spectrum disorder: cultural attitudes towards coresidence status. American Journal of Orthopsychiatry, 76, 346-357.

Margetts, J. K., Le Couteur, A., \& Croom, S. (2006). Families in a state of flux: the experience of grandparents in autism spectrum disorder. Child: Care, Health and Development, 32, 565-574.

Maxwell, J. A. (1996). Qualitative research design: An interactive approach (Vol. 41). Thousand Oaks, CA: Sage.

McEwen, B. S., \& Stellar, E. (1993). Stress and the individual. Mechanisms leading to disease. Archives of Internal Medicine, 153, 2093-2101.

Montes, G., \& Halterman, J. S. (2008). Association of childhood autism spectrum disorders and loss of family income. Pediatrics, 121, e821-826.

Morgan, D. L. (1998). Planning Focus Groups. Focus Group Kit 2. Sage Publications, Thousand Oaks.

Morse, J. M., \& Field, P. A. (1995). Qualitative research methods for health professionals (2nd ed.). Thousand Oaks, CA: Sage.

Mugno, D., Ruta, L., D'Arrigo, V. G., \& Mazzone, L. (2007). Impairment of quality of life in parents of children and adolescents with pervasive developmental disorder. Health and Quality of Life Outcomes, 5, 22.

Murphy, N. A., Christian, B., Caplin, D. A., \& Young, P. C. (2007). The health of caregivers for children with disabilities: caregiver perspectives. Child: Care, Health and Development, 33, 180-187.

Myers, B. J., Mackintosh, V. H., \& Goin-Kochel, R. P. (2009). "My greatest joy and my greatest heart ache:" Parents' own words on how having a child in the autism spectrum has affected their lives and their families' lives. Research in Autism Spectrum Disorders, 3, 670-684.

Phelps, K. W., Hodgson, J. L., McCammon, S. L., \& Lamson, A. L. (2009). Caring for an individual with autism disorder: a qualitative analysis. Journal of Intellectual and Developmental Disability, 34, 27-35.

Pill, R. (1995). Fitting the method to the question: The quantitative or qualitative approach? In R. Jones \& A. Kinmouth (Ed.), Critical reading for primary care (pp. 42-58). Oxford: Oxford University Press.

Planche, P., Lazartigues, A., \& Lemoniier, E. (2004). Identification of the early signs of autism spectrum disorder: Age at detection and conjectures about development. In Ryaskin O. T. (Ed.), Focus on Autism Research (pp. 103-123). New York: Nova Biomedical Books.

Pope, C., Ziebland, S., \& Mays, N. (2000). Qualitative research in health care. Analysing qualitative data. British Medical Journal, 320, 114-116.

Rabin, B. S. (1999). Stress, Immune Function, and Health: The Connection. New York, NY: Wiley-Liss \& Sons.

Rhoades, R. A., Scarpa, A., \& Salley, B. (2007). The importance of physician knowledge of autism spectrum disorder: results of a parent survey. BioMed Central Pediatrics, 7, 37.

Sandelowski, M. (2000). Focus on research methods: Whatever happened to qualitative description? Research in Nursing and Health, 23, 334-340.

Shah, K. (2001). What do medical students know about autism? Autism, 5, 127-133.

Smith, L. E., Seltzer, M. M., Tager-Flusberg, H., Greenberg, J. S., \& Carter, A. S. (2008). A comparative analysis of well-being and coping among mothers of toddlers and mothers of adolescents with ASD. Journal of Autism and Developmental Disorders, 38, 876-889. 
Stuart, M., \& McGrew, J. H. (2009). Caregiver burden after receiving a diagnosis of an autism spectrum disorder. Research in Autism Spectrum Disorder, 3, 86-97.

Treffert, D. A. (1970). Epidemiology of infantile autism. Archives of General Psychiatry, 22, 431-438. 
CHAPTER 3 


\section{CHAPTER 3:}

\section{PSYCHOMETRIC PROPERTIES OF THE CAREGIVER STRAIN QUESTIONNAIRE AMONG CAREGIVERS OF CHILDREN WITH AUTISM}

\section{Introduction}

Over the past four decades, there has been a substantial increase in the measured prevalence of autism in the United States (US) (Fombonne, 2005). Recent studies estimate autism prevalence to be $\sim 1.1 \%$ among children 3-17 years of age in the US (Kogan et al., 2009). Several studies have documented the adverse emotional, social, and financial consequences of caring for a child with autism on caregivers (Dunn et al., 2001; Estes et al., 2009; Konstantareas \& Papageorgiou, 2006; Montes \& Halterman, 2008; Orsmond et al., 2006; Sharpley et al., 1997; Stuart and McGrew, 2009). Mothers of children with autism have been shown to have a higher degree of parenting stress and psychological distress as compared to mothers of children with other developmental disabilities (Estes et al., 2009). On average, families of children with autism lose $14 \%$ of their annual income (Montes \& Halterman 2008). These studies highlight the tremendous burden placed by autism on different facets of caregivers' lives. In general, burden can be defined as the extent to which caregivers perceive that their emotional health, physical health, social life, and financial status has suffered as a result of providing care to the care recipient (Arai, 2004; Zarit et al., 1980). Burden can be further delineated into objective and subjective dimensions (Montgomery et al., 1985).

Objective burden relates to the tangible disruptions that occur as a result of caregiving. The impact of caregiving on a caregiver's financial situation, normal routine, work, social involvement, and leisure activities are markers of objective burden (Sales, 2003). Subjective 
burden refers to the emotional strain of caring on the caregiver (Montgomery et al., 1985). Feelings of worry, distress, stigma, shame, and guilt are some indicators of subjective burden (Sales, 2003). A high level of burden among caregivers could prevent them from functioning efficiently as a support system for care recipients. Care recipients are more likely to report unmet needs if there is a high level of burden on caregivers (Siegel et al., 1991). Further, burden affects quality of life and is a predictor for early mortality among caregivers (Schulz \& Beach, 1999).

Interventions aimed at improving outcomes among caregivers of children with autism must be preceded by a reliable and valid assessment of burden experienced by this growing population. Most of the caregiver burden-related studies in autism have utilized instruments that were not originally developed for this population. It is generally recognized that caregiving holds different meaning to different groups, and that the experience of caregiving may not be adequately captured if a researcher does not attend to these group differences (John et al., 2001). As such, there is a need to use psychometrically validated burden instruments for the population of interest. A thorough review of the literature did not reveal any burden instrument developed specifically to assess autism-related caregiving experiences. Until such a scale is developed, this gap in the literature can be narrowed by identifying instruments that provide a reliable and valid assessment of caregiver burden in autism.

The Caregiver Strain Questionnaire (CGSQ) is one such instrument that may be useful in studying the burden associated with caring for a child with autism. This scale was originally developed to assess burden experienced by parents of children and adolescents with serious emotional and behavioral disorders (Brannan et al., 1997). The CGSQ includes 21-items that are rated on a five-point scale ranging from 1 (not at all a problem) to 5 (very much a problem) 
(Brannan et al., 1997). In the original target population, factor analysis revealed CGSQ to have three dimensions: objective strain, internalized subjective strain, and externalized subjective strain. The objective caregiver strain subscale includes 11-items that capture the negative consequences of caregiving such as disruption of personal time, financial burden, effect on work, and social isolation. The internalized subjective caregiver strain dimension consists of six items that capture negative feelings such as worry, guilt, and unhappiness, which are internal to a caregiver. The externalized subjective caregiver strain dimension is made up of four items that include negative feelings directed towards the child such as anger, embarrassment, resentment, and relating poorly with the child. Scores for each of the three subscales are calculated as the mean of the items in the subscale. An overall burden score is calculated by summing the three subscale scores.

Since being developed, the CGSQ has been used to assess burden among caregivers of children with attention-deficit/hyperactivity disorder (Bussing et al., 2003), brain tumor (Hutchinson et al., 2009), cancer (Booner et al., 2007), obsessive-compulsive disorder (Storch et al., 2009), substance abuse disorder (Heflinger \& Brannan, 2005), and Tourette's syndrome (Schoeder \& Remer, 2007). The CGSQ has also been used to assess burden among caregivers of children with autism (Stuart \& McGrew, 2009). Though the overall instrument was found to be reliable in measuring caregiver burden in autism (Stuart \& McGrew, 2009), its validity in this population has not yet been established. Therefore, the purpose of this study was to determine the psychometric soundness of the CGSQ among caregivers of children with autism. The present study evaluates the factorial validity, convergent validity, discriminant validity, internal consistency reliability, and floor and ceiling effects of the CGSQ. 


\section{Methods}

\section{Participants and procedure}

Study participants were primary caregivers of children with autism. For study purposes, primary caregiver was defined as the individual in the family who had the main responsibility for providing daily care to the child with autism. The participants were recruited from families registered with the West Virginia Autism Training Center (WV ATC). Families were selected based on two inclusion criteria: (1) the child with autism is less than or equal to 18 years of age; and (2) there is no more than one child diagnosed with autism in the family. A total of 1,039 families qualified for inclusion, which were targeted for the study.

The study involved cross-sectional data collection using survey methodology. A comprehensive survey packet that included a cover letter describing the study purpose, a survey booklet consisting of study measures, and a pre-paid business reply envelope was mailed to the selected families (see Appendix H). The survey booklet also consisted of an acknowledgment statement. The cover letter described the study purpose and requested participation from the primary caregiver of the child with autism. Caregivers were requested to return the completed survey along with the acknowledgment statement to receive a $\$ 5$ Wal-Mart gift card. A total of three mailings were undertaken over a period of two months to maximize the survey response rate. The study was acknowledged under exempt status by the Institutional Review Boards of West Virginia University and Marshall University, respectively.

\section{Measures}


Caregiver burden. All 21 items of the CGSQ were used in this study. As described previously, each item is measured on a five-point Likert scale, with end points of 'not at all a problem' to 'very much a problem' (Brannan et al., 1997).

Caregiver health-related quality of life (HRQOL). The Health Survey Short Form-12 version 2 (SF-12 v2) was used to assess the HRQOL of participants (Ware et al., 2002). The SF-12 is a generic HRQOL instrument developed on the basis of the widely used SF-36. The SF-12v2 consists of 12 items that assess health and functioning of an individual during the past four weeks, and provides summary physical and mental health scores. Norm-based scores for the physical and mental component were calculated using the survey score guide. For both the physical and mental component, higher scores indicate better health state. The instrument has been shown to have acceptable psychometric properties (Ware et al., 1996).

Caregiver coping mechanisms. The Brief Coping Orientation to Problem Experiences (Brief COPE) scale was used to assess the coping mechanism employed by participants to deal with caregiving demands. The Brief COPE is a 28-item self-report questionnaire that measures 14 different adaptive and problematic coping skills (Carver, 1997). The 14 different coping reactions assessed by the Brief COPE are: active coping, planning, positive reframing, acceptance, humor, religion, use of emotional support, use of instrumental support, selfdistraction, denial, venting, substance use, behavioral disengagement, and self-blame. Each of the 14 different subscales is assessed by two items, with each item being measured on a fourpoint scale ranging from 1 (I haven't been doing this at all) to 4 (I've been doing this a lot). The 14 subscales can be reduced into two composite measures: (1) adaptive coping composed of 
active coping, planning, positive reframing, acceptance, humor, religion, use of emotion support, and use of instrumental support subscale; and (2) maladaptive coping composed of selfdistraction, denial, venting, substance use, behavioral disengagement, and self-blame subscale (Meyer, 2001). As recommended by the Institutional Review Board, the two items related to the substance use subscale were excluded from the study. We did not expect a significant impact of the removal of two substance use-related items on the measurement of maladaptive coping construct. The validity and reliability of the Brief COPE has been previously established (Carver, 1997; Carver et al., 1989)

Social support. The Multidimensional Scale of Perceived Social Support (MSPSS) was used to determine participants' perceived level of social support. The MSPSS is a 12-item instrument that assesses an individual's perception of social support adequacy. The instrument measures adequacy of support from three sources: friends (four items), family (four items), and significant other (four items) (Zimet et al., 1988). Each item is measured on a seven-point Likert scale ranging from 1 (very strongly agree) to 7 (very strongly disagree). A total score is calculated by averaging the scores of all individual items, with higher scores reflecting greater perceived social support. The instrument has been shown to be psychometrically sound across different populations (Zimet et al., 1988, 1990).

Family functioning. The Family Assessment Device General Functioning Scale (FAD-GFS) was used to assess family functioning. The GFS is a 12 -item questionnaire derived from the McMaster FAD that assesses the psychological adjustment of families (Epstein et al., 1983). The GFS provides a global assessment of family functioning (Byles et al., 1988). Each item is 
scored on a scale from 1 (strongly agree) to 4 (strongly disagree). An overall score is calculated by summing the scores for the 12 -items. A higher score indicates greater problem in family functioning. The GFS is reported to have good reliability and validity (Byles et al., 1988).

Care recipient autism severity. The Childhood Autism Rating Scale-Parent version (CARS-P) was used to assess participant's perception of the level of functional impairment in the care recipient. The CARS-P is a self-report instrument that assesses the level of functional impairment among children with autism as perceived by their parents (Bebko et al., 1987). The instrument is an adaptation of the original CARS (Schopler et al., 1980), which is commonly used to identify children with autism. CARS-P assesses a child's level of functioning across 14 domains: (1) relating with people; (2) imitation; (3) emotional response; (4) body use; (5) object use; (6) adaptation to change; (7) visual responsiveness; (8) listening responsiveness; (9) taste, smell, and touch response and use; (10) anxiety; (11) verbal communication; (12) non-verbal communication; (13) activity level; and (14) level and consistency of intellectual response. An individual score for each domain is measured using a single item, with endpoints ranging between 1 (normal for child's age) and 4 (severely abnormal for child's age). An overall functioning score is calculated by summing the score on the 14-items. Higher scores indicate greater autistic behavior in the child. The instrument is reported to be valid and reliable (Freeman et al., 1991; Tobing \& Glenwick, 2002).

Care recipient extent of behavioral problem. The Developmental Behavior Checklist Parent version Short Form (DBC-P24) was used to assess the extent of behavioral and emotional problems in the care recipient as perceived by the caregiver. The DBC-P24 is a short form 
version of the original 96-items DBC-P (Taffe et al., 2007). The DBC-P24 consists of 24-items to be completed by the caregiver, with each item scored on a three-point scale ranging from 0 (not true) to 2 (very true). The DBC-P24 provides a total behavior problem score, with higher scores indicating a greater problem. The short form has been shown to have low bias and high precision among cross-validation samples, and is reported to achieve high sensitivity and specificity with the full DBC-P in making case decisions (Taffe et al., 2007).

\section{Analysis}

Factorial validity. To establish the factorial validity of the CGSQ, we used both confirmatory factor analysis (CFA) and exploratory factor analysis (EFA). CFA is a statistical technique that allows a researcher to verify the factor structure of a set of observed variables (Suhr, 2006). We used CFA to observe the fit between the original three-subscale model of the CGSQ and sample data. Several fit indices were computed. The chi-square test, which is one of the most commonly used fit indexes, was determined in the study. A significant chi-square index means that the observed matrix is significantly different from the expected matrix, and reflects a poor fit (DiLalla, 2008). Other fit indices including the Comparative Fit Index (CFI), Goodness of Fit Index (GFI), and Adjusted Goodness of Fit Index (AGFI) were also determined. Scores $>0.80$ for AGFI and $>0.90$ for CFI and GFI indicate a good fit (Clara et al., 2001). The root mean square error of approximation (RMSEA) index was also studied, with scores $<0.05$ indicating a good model fit (Hu \& Bentler, 1999).

It is suggested that exploratory analysis be used when the goodness-of-fit indices from the CFA indicate a poor fit between the observed factor structure and the theoretical structure (Ozer et al., 2009). Principal component analysis with promax rotation was used to determine 
the factor structure of the CGSQ among caregivers of children with autism. Factors extracted were retained based on eigenvalues (Kaiser-Guttman criteria) and scree plot. Eigenvalues describe the variance explained by each underlying component. Components with an eigenvalue greater than 1.0 were retained. In a scree plot, eigenvalues are plotted in a descending order, and break is determined between the components with large eigenvalues and those with small eigenvalues (Hatcher, 1994). Components that appeared before the break on the scree plot were retained. Items that had factor loading $<0.4$ were removed from the analysis. The principal components solution is said to be better when the proportion of variance explained is high (Swisher et al., 2004). Therefore, the success of the principal components analysis was determined based on the amount of variance explained.

Convergent validity. Convergent validity of the CGSQ was examined based on correlation of its subscales with caregiver mental HRQOL, maladaptive coping, adaptive coping, social support, family functioning, care recipient level of functional impairment and extent of behavioral problems. It is expected that caregivers who experience greater burden would have lower mental health status. Therefore, a negative relationship between burden assessed using CGSQ and mental component score derived from SF-12v2 is hypothesized. Studies in autism have found the use of emotion-focused coping to be associated with poor psychological well-being among caregivers (Hastings \& Johnson, 2001; Smith et al., 2008). It is hypothesized that the burden would be positively associated with maladaptive coping. However, a negative correlation between burden subscales and adaptive coping is expected. Social support has been shown to buffer the impact of stressors on negative outcomes among caregivers of children with autism (Dunn et al., 2001). Studies have reported that greater availability of social support results in 
lower levels of anxiety, depression, and stress among caregivers of children with autism (Sharpley et al., 1997). It is therefore expected that burden will be negatively correlated with social support. Stress among caregivers of children with disabilities has been reported to be negatively correlated to caregivers' appraisal of family functioning, with lower stress found among caregivers who perceive more positive family relationships (Dyson, 1997). Since higher scores on the family functioning scale used in the study indicates greater dysfunction, we expect a positive correlation between caregiver burden and family functioning construct. Studies have reported poor functional status and greater behavioral problems in the care recipient to be associated with higher burden among caregivers (Davis \& Carter, 2008; Konstantareas \& Papageorgiou, 2006). Therefore, a positive correlation is expected between caregiver burden and care recipient level of functional impairment and extent of behavioral problems, respectively.

Discriminant validity. The discriminant validity of the CGSQ was examined based on correlation of burden with caregiver physical HRQOL. Since physical health and burden are subjectively different dimensions, a low negative correlation is hypothesized between the two constructs.

Internal consistency reliability. Internal consistency of the overall instrument and the subscales were determined using Cronbach's alpha. A Cronbach's alpha value of 0.7 is considered to be satisfactory, greater than 0.7 to 0.9 as adequate, and greater than 0.9 as excellent (Nunnally, 1978). 
Floor and ceiling effects. The percentage of participants who received the lowest or highest possible scores on the CGSQ were determined to explore floor and ceiling effects, respectively. Presence of floor or ceiling effects indicates a limited ability of the instrument to discriminate between participants. Floor and ceiling effects were considered to be present if more than $20 \%$ of the participants had lowest or highest possible scores, respectively (Holmes \& Shea, 1997).

Means and standard deviations were reported for continuous variables. Frequency and proportions were reported for categorical variables. The CFA was conducted with AMOS version 18.0 using the maximum likelihood estimation technique. All other analyses were conducted using SPSS version 18.0 (SPSS Inc., Chicago, IL).

\section{Results}

\section{Participant characteristics}

Of the 1,039 surveys mailed to families that met the inclusion criteria, 166 were returned due to incomplete address. A total of 317 responses were received after three mailings. However, 13 responses were removed because of $>15 \%$ missing data. Therefore, 304 responses $(\sim 35 \%$ response rate) were retained for the final analysis. Table 3.1 shows the demographic characteristics of the participants and the child with autism to whom they provided care. In terms of gender, a large majority of the participants were female ( $\sim 93 \%)$. Further, $88.8 \%$ of the participants were mothers and $5.6 \%$ were fathers. The average age of the participants was 38.9 years $( \pm 8.0)$. More than $95 \%$ of the participants were white. Roughly three-fourths of the participants were married. Most of the participants had a high school education (95.1\%). The proportion of participants either employed full-time (38.2\%) or homemakers (38.2\%) was the 
same. Slightly more than one-third (33.9\%) of the participants had an annual household income between $\$ 50,000$ and $\$ 99,999,29.9 \%$ had an income of less than $\$ 25,000,25.0 \%$ had an income between $\$ 25,000$ and $\$ 49,999$, and $10.5 \%$ had an income equal to or greater than $\$ 100,000$. As per the care recipient characteristics, most were males (81.6\%) and in the age group between 5 years and less than 15 years old (85.5\%). More than half (52.3\%) of the children had a diagnosis of autistic disorder, 25.3\% had Asperger's syndrome, and 21.4\% had PDD-NOS.

\section{Factorial validity}

Table 3.2 summarizes the descriptive characteristics of the 21-items CGSQ. As with the original article, burden concerning the child's future had the highest average score among the CGSQ items. When testing the original 21-item three-factor model of the CGSQ using CFA, all goodness-of-fit indices indicated a poor fit with the data. The chi-square index test was significant (701.02; $p<0.001)$. Scores for CFI $(0.87)$ and GFI $(0.81)$ were $<0.90$, and the score for AGFI (0.76) was $<0.80$. Poor fit was also indicated by the RMSEA criterion (RMSEA $=$ $0.09)$.

Since the original three-factor model of the CGSQ did not fit with the data, EFA was conducted to determine the factor structure of the instrument among caregivers of children with autism. The result from principal component analysis using promax rotation for the 21-item CGSQ indicated three-factors based on eigenvalues $(>1)$ and scree plot. The total variance explained by the three factors was $63.36 \%$. Item 6 failed to load on any of the three factors (factor loadings less than 0.4). Further examination of the factor loadings revealed items 12, 20, and 21 to load on the same factor as items 1-5 and 7-11. In the original factor structure of the CGSQ, items 12, 20, and 21 represented subjective internalized strain, while items 1 to 11 
represented objective strain (Brannan et al., 1997). When looking at inter-item correlation, it was found that item 12 correlated strongly with item $11(\mathrm{r}=0.74)$ and item 20 correlated strongly with item $21(\mathrm{r}=0.79)$, respectively, suggesting some item redundancy. We decided to exclude items 6,12 , and 20, and perform principal component analysis with the remaining 18 items.

When performing EFA with items 6, 12 and 20 removed, a three-factor solution emerged that explained $65.80 \%$ of the variance. This 18 -item three-factor solution for the CGSQ was accepted in this study, and is depicted in Table 3.3. Items 1-5 and 7-11 that loaded on the first factor were those that related to objective strain in the original questionnaire. In addition, item 21 also loaded on the first factor. Factor two in our study was similar to the subjective externalized strain factor in the original study (Brannan et al., 1997), and included items 13, 14, 15, and 19. The third factor (subjective internalized strain) observed in our results included items 16,17 , and 18 whereas in the original questionnaire this factor included items $12,16,17$, 18, 20, and 21 (Brannan et al., 1997).

\section{Convergent validity}

All three subscales derived from EFA of the 18-item CGSQ had significant $(p<0.01)$ negative correlation with caregiver mental HRQOL that ranged from $r=-0.28$ to -0.57 . As expected, the three subscales had significant $(p<0.01)$ positive correlation with maladaptive coping. However, the correlation between CGSQ subscales and adaptive coping was positive but not significant $(p>0.05)$. There was a low to moderate negative correlation between CGSQ subscales and social support $(p<0.01)$, with coefficients ranging from -0.16 to -0.42 . As hypothesized, the three subscales had positive correlation with family dysfunction $(\mathrm{p}<0.01)$. 
Convergent validity of the instrument based upon its correlation with care recipient autism severity and extent of behavioral problems was adequate. The three subscales had low to moderate positive correlation with care recipient level of autism severity $(p<0.05$ for subjective externalized strain; $p<0.01$ for other two subscales). There was a moderate positive correlation between CGSQ subscales and care recipient extent of behavioral problems $(p<0.01)$. Table 3.4 lists the correlation of the 18-item CGSQ subscales (objective strain, subjective externalized strain, and subjective internalized strain) with other caregiving situational factors.

\section{Discriminant validity}

Consistent with our expectations, CGSQ subscales had low correlation with caregiver physical HRQOL. The correlation between objective strain and physical HRQOL was statistically significant $(p<0.05)$ but small (Table 3.4).

\section{Internal consistency reliability}

The 18-item CGSQ scale had internal consistency reliability (Cronbach's alpha) of 0.93. Cronbach's alpha values were $0.94,0.75$, and 0.74 for objective strain, subjective externalized strain, and subjective internalized strain, respectively.

\section{Floor and ceiling effects}

Floor and ceiling effects were not present for any of the three subscales. Each of the three CGSQ subscales could have the lowest possible score of 1 and highest possible score of 5. For objective strain, $3.6 \%$ of the cases had the minimum score and only $0.01 \%$ had the maximum score. When examining the responses for subjective externalized strain, $14.8 \%$ of the cases had 
the minimum score and none had maximum score. Finally, for the subjective internalized strain, $1.3 \%$ of the cases had the minimum score and $14.8 \%$ had the maximum score.

\section{Discussion}

This study assesses the psychometric properties of a burden instrument among caregivers of children with autism. In this study, we evaluated the factorial validity, convergent validity, discriminant validity, internal consistency reliability, and floor and ceiling effects of the CGSQ among caregivers of children with autism. Though originally developed for caregivers of children with serious emotional and behavioral disorders, the CGSQ was found to be a useful tool to determine caregiver burden in autism.

When evaluating the validity of the original 21 -item three-factor solution of the CGSQ using CFA, poor fit was observed between the model and our sample data. This indicated that the original factor solution of the CGSQ may not hold true for caregivers of children with autism. When performing EFA, some interesting patterns emerged. As with the original study of CGSQ (Brannan et al., 1997), we also obtained a three-factor structure in our sample. However, item 6 failed to load on any of the three-factors that emerged in the EFA, and was subsequently removed. Though not reported in the results, it was also found that item 6 had low item-total correlation (0.4), which further justified its exclusion. Item 6 measures the burden with respect to the child (care recipient) getting into trouble with neighbors, school, community, or law. When examining the response to item 6 , it was seen that $61.5 \%$ of the participants reported that this was not at all a problem, 18.1\% reported it to be a little of a problem, 9.5\% reported it to be somewhat of a problem, $7.9 \%$ reported it to be quite a bit of a problem, and $3.0 \%$ reported it to be very much of a problem. This shows that the majority of caregivers of 
children with autism did not perceive any burden associated with this issue. The response to this item is likely to be influenced by age and symptom severity of the child. In the original study, there were no children less than 5 years of age (Brannan et al., 1997); whereas, 7.3\% of children in our sample were less than 5 years of age. Given their young age, these children were less likely to get into trouble with neighbors, school, community, or law. Further, the sample of children in the original study had severe emotional and behavioral disorders, and all of them were receiving formal mental health treatment (Brannan et al., 1997). In contrast, our sample included children along the spectrum of autism disorders, with varying levels of functional and behavioral impairment. To see whether the responses to item 6 varied by functional impairment and behavioral problems among the children, we conducted a one-way ANOVA analysis. With respect to functional impairment, there was no significant difference observed; however, response to item 6 varied by extent of behavioral problems in the child $(\mathrm{p}<0.001)$. Caregivers who responded that their child getting into trouble with neighbors, school, community, and law was 'quite a bit' or 'very much' a problem also reported a higher average behavioral problem scores as compared to caregivers who responded to this as being 'not at all' or 'a little' of a problem. Therefore, item 6 could be considered to measure a facet of burden that is very specific to caregivers of children with severe behavioral problems, which may explain why it did not fit well in the current study.

In the EFA for the 21-item instrument, it was also observed that items 12, 20, and 21 loaded with items 1-5 and 7-11 on the factor similar to objective strain. In the original study, these three items had loaded on the subjective internalized strain (Brannan et al., 1997). When examining the content of items 12 and 20 (see Table 3.2), it can be clearly seen that they represent feelings that are internal to a caregiver, and would ideally be expected to load on the 
subjective internalized strain factor along with items 16,17 , and 18. Given the broad tone of item 21, it can be expected to load on either the objective or subjective strain. An examination of inter-item correlation revealed that item 12 correlated highly $(\mathrm{r}=0.74)$ with item 11 , indicating that these items are conceptually similar. Item 12 assessed caregiver feelings of sadness and unhappiness, while item 11 assessed feeling of social isolation. Studies have reported the occurrence of feelings of sadness and isolation among caregivers of children with autism (Myers et al., 2009; Phelps et al., 2009). It has been suggested that despite receiving social support, parents of children with autism could have feelings of isolation (Dunn et al., 2001). It is plausible that feeling socially isolated may lead to sadness among caregivers, which would explain the high correlation among the two items. We therefore decided to exclude item 12 from subsequent analysis. A high inter-item correlation was also observed between item 20 and item $21(\mathrm{r}=0.79)$, indicating item redundancy. Item 20 assessed caregiver feelings of being tired or strained, while item 21 assessed the overall toll on the family. Given the significance of establishing the overall burden of caregiving on the family, we decided to retain item 21 and exclude item 20 .

When conducting EFA with items 6,12 and 20 removed, we obtained a three-factor structure that explained a greater proportion of variance as compared to including all 21 -items, and therefore was accepted as the final solution. Despite differences observed in CGSQ item loading in our sample and that reported by Brannan et al. (1997), the final 18-item factor solution of the CGSQ in this study supported the existence of objective strain, subjective internalized strain, and subjective externalized strain. The CGSQ is a well-established scale that has been used successfully across different caregiver groups. Future researchers who aim to use this 
instrument to assess burden among caregivers of children with autism are recommended to include all 21-items and evaluate closely the response to items 6,12 , and 20.

The convergent validity of the 18-item CGSQ was well supported in this study. The three subscales correlated well with other caregiving situational constructs including mental HRQOL, maladaptive coping, social support, family functioning, and care recipient level of functional impairment and extent of behavioral problems. However, CGSQ subscales had small statistically insignificant correlation with adaptive coping. When studying the relationship between coping and psychological well-being among mothers of adults with intellectual disability and mental illness, Kim et al. (2003) found that problem-solving coping mechanisms do not alleviate feelings of subjective burden. Similar results have also been reported in autism. In their study of coping strategies among parents of children with autism, Hastings et al. (2005) found no relationship between problem-focused coping and parental stress or mental health. It has been suggested that problem-focused coping may not always lead to successful outcomes and that the success of a coping strategy in terms of leading to positive outcomes is contingent on the demands and constraints being placed on an individual, and the skill with which it is applied (Folkman et al., 1986). Therefore, the lack of relationship between the CGSQ subscales and adaptive coping observed in our study could be due to the lack of effectiveness of adaptive coping strategies in alleviating caregiver burden. The weak association between the CGSQ subscales and caregiver physical HRQOL provide evidence of the instrument's discriminant validity.

The homogeneity of the 18-item CGSQ in this study was excellent (Cronbach's alpha = $0.93)$, and similar to that reported for the original 21-item instrument (Cronbach's alpha $=0.93$ ) (Brannan et al., 1997). The reliability of the three subscales was also good, and exceeded the 
recommended 0.7 (Cronbach's alpha) criteria (Nunnally, 1978). The internal consistency of objective strain (Cronbach's alpha $=0.94)$ and subjective externalized strain (Cronbach's alpha $=$ 0.75) observed in the current study was similar to that reported in the original study (Cronbach's alpha of 0.92 and 0.74, respectively) (Brannan et al., 1997). However, the internal consistency of the subjective internalized strain subscale (Cronbach's alpha $=0.74)$ in the present study was lower than the original study (Cronbach's alpha $=0.86)($ Brannan et al., 1997). The size of Cronbach's alpha coefficient is determined by both the number of items and mean inter-item correlations (Gliem \& Gliem, 2003). In the 18-item CGSQ considered in this study, the subjective internalized strain subscale was composed of three items, while in the original study this subscale was measured by six items. The lower Cronbach's alpha for subjective internalized strain observed in the current study, as compared to the original study could be the result of the lower number of items representing this subscale. For each of the three subscales, less than $20 \%$ of the participants had a minimum or maximum score, indicating that there were no floor and ceiling effects.

The study has a few limitations. In this study, we tested the factorial, convergent, and discriminant validity of the instrument, all of which are indicators of construct validity and suitable for a cross-sectional study like ours; however, we did not include assessment of criterion validity of the CGSQ. Using a longitudinal study design, investigators could examine the predictive validity (a type of criterion validity) of the CGSQ by determining its ability to predict future health outcomes among caregivers. Also, we were not able to examine the test-retest reliability of the CGSQ. Future researchers could assess test-retest reliability of this instrument to determine its stability over time. 
In conclusion, this study assesses the psychometric soundness of the CGSQ among caregivers of children with autism. Based upon assessment of factorial validity, convergent validity, discriminant validity, internal consistent reliability, and floor and ceiling effects it can be concluded that the CGSQ is a useful and valid tool to determine caregiver burden in autism. In order to provide effective support services to caregivers of children with autism, it is essential to understand the burden that they experience. Until researchers develop a burden instrument specific to caregivers of children with autism, the CGSQ provides a valid alternative to capture caregiving experiences in this population. 
Table 3.1. Socio-demographic characteristics of survey participants.

\begin{tabular}{|c|c|}
\hline Characteristics & $\mathbf{N}(\%)^{a}$ \\
\hline \multicolumn{2}{|l|}{ Characteristics of caregiver participants } \\
\hline \multicolumn{2}{|l|}{ Gender: } \\
\hline Male & $19(6.3 \%)$ \\
\hline Female & $283(93.1 \%)$ \\
\hline \multicolumn{2}{|l|}{ Relationship to child: } \\
\hline Mother & $270(88.8 \%)$ \\
\hline Father & $17(5.6 \%)$ \\
\hline Other & $15(4.9 \%)$ \\
\hline \multicolumn{2}{|l|}{ Age (Years): } \\
\hline Mean (SD) [Range] & $38.9(8.0)[22-77]$ \\
\hline \multicolumn{2}{|l|}{ Ethnicity: } \\
\hline White & $291(95.7 \%)$ \\
\hline Others & $10(3.3 \%)$ \\
\hline \multicolumn{2}{|l|}{ Marital status: } \\
\hline Never married & $15(4.9 \%)$ \\
\hline Married & $225(74.0 \%)$ \\
\hline Divorced/Separated & $47(15.5 \%)$ \\
\hline Widowed/living with partner & $15(4.9 \%)$ \\
\hline \multicolumn{2}{|l|}{ Education: } \\
\hline Less than high school & $12(3.9)$ \\
\hline Graduated high school & $78(25.7 \%)$ \\
\hline Attended college/technical school & $83(27.3 \%)$ \\
\hline College graduate & $128(42.1 \%)$ \\
\hline \multicolumn{2}{|l|}{ Occupation: } \\
\hline Employed full-time & $116(38.2 \%)$ \\
\hline Employed part-time & $35(11.5 \%)$ \\
\hline Home-maker & $116(38.2 \%)$ \\
\hline Retired/student/seeking work/other occupation & $32(10.5 \%)$ \\
\hline \multicolumn{2}{|l|}{ Annual household income: } \\
\hline$<\$ 25,000$ & $91(29.9 \%)$ \\
\hline$\$ 25,000-\$ 49,999$ & $76(25.0 \%)$ \\
\hline$\$ 50,000-\$ 99,999$ & $103(33.9 \%)$ \\
\hline$\geq \$ 100,000$ & $32(10.5 \%)$ \\
\hline \multicolumn{2}{|l|}{ Characteristics of children with autism } \\
\hline \multicolumn{2}{|l|}{ Gender: } \\
\hline Male & $248(81.6 \%)$ \\
\hline Female & $51(16.8 \%)$ \\
\hline \multicolumn{2}{|l|}{ Age group: } \\
\hline$<5$ years & $22(7.2 \%)$ \\
\hline 5 years - less than 10 years & $134(44.1 \%)$ \\
\hline 10 years - less than 15 years & $126(41.4 \%)$ \\
\hline
\end{tabular}




$\begin{array}{lc}15 \text { years - } 18 \text { years } & 20(6.6 \%) \\ \text { Type of diagnosis: } & 159(52.3 \%) \\ \text { Autistic disorder } & 77(25.3 \%) \\ \text { Asperger's syndrome } & 65(21.4 \%) \\ \text { Pervasive developmental disorder not otherwise specified } & \end{array}$

${ }^{\mathrm{a}}$ Percentages may not always add to 100 because of missing data. 
Table 3.2. Summary statistics of the Caregiver Strain Questionnaire (CGSQ).

\begin{tabular}{|c|c|c|c|c|}
\hline $\begin{array}{c}\text { Item } \\
\text { number }\end{array}$ & Item description & Mean (SD) & $\begin{array}{c}\text { Original } \\
\text { article } \\
\text { mean } \\
(\mathrm{SD})^{\mathrm{a}}\end{array}$ & $\begin{array}{c}\text { Original } \\
\text { factor } \\
\text { structure }\end{array}$ \\
\hline 1 & Interruption of personal time & $3.17(1.19)$ & $2.50(1.31)$ & OS \\
\hline 2 & Missing work or neglecting other duties & $2.54(1.24)$ & $2.22(1.26)$ & OS \\
\hline 3 & Disruption of family routines & $2.75(1.18)$ & $2.53(1.31)$ & OS \\
\hline 4 & $\begin{array}{l}\text { Any family member having to do without } \\
\text { things }\end{array}$ & $2.32(1.24)$ & $1.53(1.00)$ & OS \\
\hline 5 & $\begin{array}{l}\text { Any family member suffering negative mental } \\
\text { or physical health effects }\end{array}$ & $2.26(1.24)$ & $1.82(1.18)$ & OS \\
\hline 6 & $\begin{array}{l}\text { Child getting into trouble with the neighbors, } \\
\text { the school, the community, or law enforcement }\end{array}$ & $1.72(1.10)$ & $1.79(1.19)$ & OS \\
\hline 7 & Financial strain & $2.38(1.38)$ & $1.62(1.10)$ & OS \\
\hline 8 & Less attention paid to other family members & $2.90(1.31)$ & $2.11(1.25)$ & OS \\
\hline 9 & $\begin{array}{l}\text { Disruption or upset of relationships within the } \\
\text { family }\end{array}$ & $2.74(1.30)$ & $2.37(1.37)$ & OS \\
\hline 10 & Disruption of family' social activities & $2.90(1.35)$ & $2.15(1.33)$ & OS \\
\hline 11 & Feeling socially isolated & $2.83(1.33)$ & $1.96(1.26)$ & OS \\
\hline 12 & Feeling sad or unhappy & $2.99(1.25)$ & $3.57(1.31)$ & SIS \\
\hline 13 & Feeling embarrassed & $2.23(1.23)$ & $2.12(1.35)$ & SES \\
\hline $14^{\mathrm{b}}$ & Relation with child & $1.98(0.89)$ & $2.54(1.12)$ & SES \\
\hline 15 & Feeling angry toward child & $1.94(1.02)$ & $2.59(1.33)$ & SES \\
\hline 16 & Feeling worried about child's future & $4.26(0.97)$ & $4.17(1.13)$ & SIS \\
\hline 17 & Feeling worried about family's future & $3.48(1.31)$ & $3.25(1.49)$ & SIS \\
\hline 18 & Feeling guilty about child's problem & $3.07(1.43)$ & $2.92(1.48)$ & SIS \\
\hline 19 & Feeling resentful towards child & $1.50(0.94)$ & $1.91(1.21)$ & SES \\
\hline 20 & Feeling tired or strained & $3.46(1.23)$ & $3.27(1.48)$ & SIS \\
\hline 21 & Toll taken on family & $3.31(1.16)$ & $3.21(1.30)$ & SIS \\
\hline
\end{tabular}

OS Objective strain; SIS Subjective internalized strain; SES Subjective externalized strain;

${ }^{\mathrm{a}}$ Values as reported in Brannan et al. (1997); ${ }^{\mathrm{b}}$ Item reverse scored 
Table 3.3. The 18-item three-factor solution of the Caregiver Strain Questionnaire (CGSQ) based on principal component analysis with promax rotation.

\begin{tabular}{|c|c|c|c|c|c|}
\hline $\begin{array}{c}\text { Item } \\
\text { number }\end{array}$ & $\begin{array}{l}\text { Original } \\
\text { factor } \\
\text { structure }\end{array}$ & Item description & $\begin{array}{l}\text { Factor } 1- \\
\text { Objective } \\
\text { strain }\end{array}$ & $\begin{array}{c}\text { Factor } 2- \\
\text { Subjective } \\
\text { externalized } \\
\text { strain } \\
\end{array}$ & $\begin{array}{c}\text { Factor } 3- \\
\text { Subjective } \\
\text { internalized } \\
\text { strain } \\
\end{array}$ \\
\hline 1 & OS & Interruption of personal time & 0.87 & -0.03 & 0.00 \\
\hline 2 & OS & $\begin{array}{l}\text { Missing work or neglecting } \\
\text { other duties }\end{array}$ & 0.90 & -0.17 & 0.01 \\
\hline 3 & OS & Disruption of family routines & 0.82 & 0.07 & -0.03 \\
\hline 4 & OS & $\begin{array}{l}\text { Any family member having to } \\
\text { do without things }\end{array}$ & 0.87 & -0.06 & -0.06 \\
\hline 5 & OS & $\begin{array}{l}\text { Any family member suffering } \\
\text { negative mental or physical } \\
\text { health effects }\end{array}$ & 0.63 & 0.23 & -0.07 \\
\hline 7 & OS & Financial strain & 0.78 & -0.39 & 0.12 \\
\hline 8 & OS & $\begin{array}{l}\text { Less attention paid to other } \\
\text { family members }\end{array}$ & 0.91 & 0.07 & -0.17 \\
\hline 9 & OS & $\begin{array}{l}\text { Disruption or upset of } \\
\text { relationships within the family }\end{array}$ & 0.75 & 0.18 & -0.04 \\
\hline 10 & OS & $\begin{array}{l}\text { Disruption of family' social } \\
\text { activities }\end{array}$ & 0.81 & 0.08 & 0.03 \\
\hline 11 & OS & Feeling socially isolated & 0.57 & 0.11 & 0.26 \\
\hline 13 & SES & Feeling embarrassed & 0.06 & 0.53 & 0.27 \\
\hline $14^{\mathrm{a}}$ & SES & Relation with child & 0.01 & 0.59 & 0.01 \\
\hline 15 & SES & Feeling angry toward child & -0.01 & 0.87 & -0.03 \\
\hline 16 & SIS & $\begin{array}{l}\text { Feeling worried about child's } \\
\text { future }\end{array}$ & -0.02 & -0.08 & 0.88 \\
\hline 17 & SIS & $\begin{array}{l}\text { Feeling worried about family's } \\
\text { future }\end{array}$ & 0.07 & -0.04 & $\mathbf{0 . 8 0}$ \\
\hline 18 & SIS & $\begin{array}{l}\text { Feeling guilty about child's } \\
\text { problem }\end{array}$ & -0.11 & 0.16 & 0.75 \\
\hline 19 & SES & Feeling resentful towards child & -0.06 & 0.88 & -0.05 \\
\hline 21 & SIS & Toll taken on family & 0.70 & 0.15 & 0.11 \\
\hline \multicolumn{3}{|c|}{ Percentage of variance explained (before rotation) } & 48.14 & 10.48 & 7.18 \\
\hline
\end{tabular}

$O S$ Objective strain; SIS Subjective internalized strain; SES Subjective externalized strain; ${ }^{\mathrm{a}}$ Item reverse scored 
Table 3.4. Correlation of Caregiver Strain Questionnaire (CGSQ) subscales with other caregiving situational constructs.

\begin{tabular}{|c|c|c|c|}
\hline Construct & $\begin{array}{c}\text { Factor } 1 \text { - } \\
\text { Objective } \\
\text { strain }\end{array}$ & $\begin{array}{c}\text { Factor } 2- \\
\text { Subjective } \\
\text { externalized } \\
\text { strain } \\
\end{array}$ & $\begin{array}{c}\text { Factor } 3- \\
\text { Subjective } \\
\text { internalized } \\
\text { strain } \\
\end{array}$ \\
\hline \multicolumn{4}{|l|}{ Convergent validity } \\
\hline Caregiver mental HRQOL & $-0.57^{* *}$ & $-0.28^{* *}$ & $-0.47^{* *}$ \\
\hline Maladaptive coping & $0.34^{* *}$ & $0.45^{* *}$ & $0.44^{* *}$ \\
\hline Adaptive coping & 0.08 & -0.01 & 0.03 \\
\hline Social support & $-0.42^{* *}$ & $-0.16^{* *}$ & $-0.25^{* *}$ \\
\hline Family functioning & $0.38^{* *}$ & $0.31^{* *}$ & $0.30^{* *}$ \\
\hline Care recipient level of functional impairment & $0.47^{* *}$ & $0.13^{*}$ & $0.37^{* *}$ \\
\hline Care recipient extent of behavioral problem & $0.57^{* *}$ & $0.33^{* *}$ & $0.44^{* *}$ \\
\hline \multicolumn{4}{|l|}{ Discriminant validity } \\
\hline Caregiver physical HRQOL & $-0.13^{*}$ & 0.05 & -0.05 \\
\hline
\end{tabular}




\section{Bibliography}

Arai, Y. (2004). Family caregiver burden in the context of the long-term care insurance system. Journal of Epidemiology, 14, 139-142.

Bebko, J.M., Konstantareas, M.M. \& Springer, J. (1987). Parent and professional evaluations of family stress associated with characteristics of autism. Journal of Autism and Developmental Disorders, 17, 565-576.

Bonner, M.J., Hardy, K.K., Willard, V.W . \& Hutchinson, K.C. (2007). Brief report: psychosocial functioning of fathers as primary caregivers of pediatric oncology patients. Journal of Pediatric Psychology, 32, 851-856.

Brannan, A.M., Heflinger, C.A. \& Bickman, L. (1997). The Caregiver Strain Questionnaire: Measuring the impact on the family of living with a child with serious emotional problems. Journal of Emotional and Behavioral Disorders, 5, 212-222.

Bussing, R., Gary, F.A., Mason, D.M., Leon, C.E., Sinha, K. \& Garvan, C.W. (2003). Child temperament, ADHD, and caregiver strain: exploring relationships in an epidemiological sample. Journal of the American Academy of Child and Adolescent Psychiatry, 42, 184-192.

Byles, J., Byrne, C., Boyle, M.H. \& Offord, D.R. (1988). Ontario Child Health Study: reliability and validity of the general functioning subscale of the McMaster Family Assessment Device. Family Process, 27, 97-104.

Carver, C.S. (1997). You want to measure coping but your protocol's too long: Consider the Brief COPE. International Journal of Behavioral Medicine, 4, 92-100.

Carver, C.S., Scheier, M.F. \& Weintraub, J.K. (1989). Assessing coping strategies: A theoretically based approach. Journal of Personality and Social Psychology, 56, 267-283.

Clara, I.P., Cox, B.J. \& Enns, M.W. (2001). Confirmatory factor analysis of the DepressionAnxiety-Stress Scales in depressed and anxious patients. Journal of Psychopathology and Behavioral Assessment, 23, 61-67.

Davis, N.O. \& Carter, A.S. (2008). Parenting stress in mothers and fathers of toddlers with autism spectrum disorders: associations with child characteristics. Journal of Autism and Developmental Disorders, 38, 1278-1291.

Dilalla, L.F. (2008). A structural equation modeling overview for medical researchers. Journal of Developmental and Behavioral Pediatrics, 29, 51-54.

Dunn, M.E., Burbine, T., Bowers, C.A. \& Tantleff-Dunn, S. (2001). Moderators of stress in parents of children with autism. Community Mental Health Journal, 37, 39-52.

Dyson, L.L. (1997). Fathers and mothers of school-age children with developmental disabilities: parental stress, family functioning, and social support. American Journal of Mental Retardation, 102, 267-279.

Estes, A., Munson, J., Dawson, G., Koehler, E., Zhou, X.H. \& Abbott, R. (2009). Parenting stress and psychological functioning among mothers of preschool children with autism and developmental delay. Autism, 13, 375-387.

Epstein, N.B., Baldwin, L.M. \& Bishop, D.S. (1983). The McMaster Family Assessment Device. Journal of Marital and Family Therapy, 9, 171-180.

Folkman, S., Lazarus, R., Dunkel-Schetter, C., Delongis, A. \& Gruen, R. (1986). Dynamics of a stressful encounter: cognitive appraisal, coping, and encounter outcomes. Journal of Personality and Social Psychology, 50, 992-1003.

Fombonne, E. (2005). Epidemiology of autistic disorder and other pervasive developmental disorders. Journal of Clinical Psychiatry, 66, 3-8. 
Freeman, N.L., Perry, A. \& Factor, D.C. (1991). Child behaviours as stressors: replicating and extending the use of the CARS as a measure of stress: a research note. Journal of Child Psychology and Psychiatry, 32, 1025-1030.

Gliem, J.A. \& Gliem R.R. (2003). Calculating, interpreting, and reporting Cronbach's alpha reliability coefficient for likert-type scales. In Proceedings of the 2003 Midwest Research-toPractice Conference in Adult, Continuing, and Community Education, Columbus, OH, The Ohio State University, pp. 82-88.

Hastings, R.P. \& Johnson, E. (2001). Stress in UK families conducting intensive home-based behavioral intervention for their young child with autism. Journal of Autism and Developmental Disorders, 31, 327-336.

Hastings, R.P., Kovshoff, H., Brown, T., Ward, N.J., Espinosa, F.D. \& Remington, B. (2005). Coping strategies in mothers and fathers of preschool and school-age children with autism. Autism, 9, 377-391.

Hatcher, L. (1994). A step-by-step approach to using the SAS system for factor analysis and structural equation modeling. Cary, NC: SAS Institute Inc.

Heflinger, C.A. \& Brannan, A.M. (2005). Differences in the experience of caregiver strain between families caring for youth with substance use disorders and families of youth with mental health problems. Journal of Child and Adolescent Substance Abuse, 15, 83-104.

Holmes, W. \& Shea, J. (1997). Performance of a new, HIV/AIDS-targeted quality of life (HATQOL) instrument in asymptomatic sero-positive individuals. Quality of Life Research, 6, 561-571.

Hu, L. \& Bentler, P.M. (1999). Cutoff criteria for fit indexes in covariance structure analysis: Coventional criteria versus new alternatives. Structural Equation Modeling, 6, 1-55.

Hutchinson, K.C., Willard, V.W., Hardy, K.K. \& Bonner, M.J. (2009). Adjustment of caregivers of pediatric patients with brain tumors: a cross-sectional analysis. Psychooncology, 18, 515-523.

John, R., Hennessy, C.H., Dyeson, T.B. \& Garrett, M.D. (2001). Toward the conceptualization and measurement of caregiver burden among Pueblo Indian family caregivers. Gerontologist $41,210-219$.

Kim, H.W., Greenberg, J.S., Seltzer, M.M. \& Krauss, M.W. (2003). The role of coping in maintaining the psychological well-being of mothers of adults with intellectual disability and mental illness. Journal of Intellectual Disability Research, 47, 313-327.

Kogan, M.D., Blumberg, S.J., Schieve, L.A., Boyle, C.A., Perrin, J.M., Ghandour, R.M., Singh, G.K., Strickland, B.B., Trevathan, E. \& Van Dyck, P.C. (2009). Prevalence of parentreported diagnosis of autism spectrum disorder among children in the US, 2007. Pediatrics, 124, 1395-1403.

Konstantareas, M.M. \& Papageorgiou, V. (2006). Effects of temperament, symptom severity and level of functioning on maternal stress in Greek children and youth with ASD. Autism, 10, 593-607.

Meyer, B. (2001). Coping with severe mental illness: relations of the brief COPE with symptoms, functioning, and wellbeing. Journal of Psychopathology and Behavioral Assessment, 23, 265-278.

Myers, B. J., Mackintosh, V. H. \& Goin-Kochel, R. P. (2009). My greatest joy and my greatest heart ache: Parents' own words on how having a child in the autism spectrum has affected their lives and their families' lives. Research in Autism Spectrum Disorders, 3, 670-684. 
Montes, G. \& Halterman, J.S. (2008). Association of childhood autism spectrum disorders and loss of family income. Pediatrics, 121, e821-826.

Montgomery, R., Gonyea, J. \& Hooyman, N. (1985). Caregiving and the experience of subjective and objective burden. Family Relations, 34, 19-26.

Nunnally, J.C. (1978). Assessment of Reliability. Psychometric Theory. 2nd Edition. New York: MacGraw-Hill Series, 225-255.

Orsmond, G.I., Seltzer, M.M., Greenberg, J.S. \& Krauss, M.W. (2006). Mother-child relationship quality among adolescents and adults with autism. American Journal of Mental Retardation, 111, 121-137.

Ozer, Z.C., Firat, M.Z. \& Bektas, H.A. (2009). Confirmatory and exploratory factor analysis of the caregiver quality of life index-cancer with Turkish samples. Quality of Life Research, 18, 913-921.

Phelps, K. W., Hodgson, J. L., Mccammon, S. L. \& Lamson, A. L. (2009). Caring for an individual with autism disorder: a qualitative analysis. Journal of Intellectual and Developmental Disability, 34, 27-35.

Sales, E. (2003). Family burden and quality of life. Quality of Life Research, 12, 33-41.

Schoeder, C.E. \& Remer, R. (2007). Perceived Social Support and Caregiver Strain in Caregivers of Children with Tourette's Disorder. Journal of Child and Family Studies, 16, 888-901.

Schopler, E., Reichler, R.J., De Vellis, R.F. \& Dally, K. (1980). Toward objective classifications of childhood autism: Childhood Autism Rating Scale (CARS). Journal of Autism and Developmental Disorders, 10, 91-103.

Schulz, R. \& Beach, S.R. (1999). Caregiving as a risk factor for mortality: the Caregiver Health Effects Study. Journal of American Medical Association, 282, 2215-219.

Sharpley, C., Bitsika, V. \& Efremidis, B. (1997). Influence of gender, parental health, and perceived expertise of assistance upon stress, anxiety, and depression among parents of children with autism. Journal of Intellectual and Developmental Disability, 22, 19-28.

Siegel, C., Ravens, V.H., Houts, P. \& Mor, P. (1991). Caregiver burden and unmet patient needs. Cancer, 68, 1131-140.

Smith, L.E., Seltzer, M.M., Tager-Flusberg, H., Greenberg, J.S. \& Carter, A.S. (2008). A comparative analysis of well-being and coping among mothers of toddlers and mothers of adolescents with ASD. Journal of Autism and Developmental Disorders, 38, 876-889.

Storch, E. A., Lehmkuhl, H., Pence, S. L., JR., Geffken, G. R., Ricketts, E. \& Murphy, T. K. (2009). Parental experiences of having a child with obsessive-compulsive disorder: Associations with clinical characteristics and caregiver adjustment. Journal of Child and Family Studies, 18, 249-258.

Stuart, M. \& Mcgrew, J.H. (2009). Caregiver burden after receiving a diagnosis of an autism spectrum disorder. Research in Autism Spectrum Disorder, 3, 86-97.

Suhr, D.D. (2006). Exploratory or Confirmatory Factor Analysis?. SAS User Group International San Francisco, CA: SAS Institute Inc.

Swisher, L.L., Beckstead, J.W. \& Bebeau, M.J. (2004). Factor analysis as a tool for survey analysis using a professional role orientation inventory as an example. Physical Therapy, 84, 784-799.

Taffe, J.R., Gray, K.M., Einfeld, S.L., Dekker, M.C., Koot, H.M., Emerson, E., Koskentausta, T. \& Tonge, B.J. (2007). Short form of the developmental behaviour checklist. American Journal of Mental Retardation, 112, 31-39. 
Tobing, L.E. \& Glenwick, D.S. (2002). Relation of the childhood autism rating scale-parent version to diagnosis, stress, and age. Research in Developmental Disabilities, 23, 211-223.

Ware, J.E., Kosinski, M. \& Keller, S.D. (1996). A 12-item short-form health survey: construction of scales and preliminary tests of reliability and validity. Medical Care, 34, 220-233.

Ware, J. E., Kosinski, M., Turner-Bowker, D. M. \& Gandek, B. (2002). How to score version 2 of the SF-12 Health Survey. Lincoln, RI: Quality Metric Incorporated.

Zarit, S.H., Reever, K.E. \& Bach-Peterson, J. (1980). Relatives of the impaired elderly: correlates of feelings of burden. Gerontologist, 20, 649-655.

Zimet, G.D., Dahlem, N.W., Zimet, S.G. \& Farley, G.K. (1988). The Multidimensional Scale of Perceived Social Support. Journal of Personality Assessment, 52, 30-41.

Zimet, G.D., Powell, S.S., Farley, G.K., Werkman, S. \& Berkoff, K.A. (1990). Psychometric characteristics of the Multidimensional Scale of Perceived Social Support. Journal of Personality Assessment, 55, 610-617. 
CHAPTER 4 


\section{CHAPTER 4:}

\section{ASSESSMENT OF HEALTH-RELATED QUALITY OF LIFE AMONG PRIMARY CAREGIVERS OF CHILDREN WITH AUTISM SPECTRUM DISORDERS}

\section{Introduction}

Autism spectrum disorders are a group of developmental disabilities characterized by deficiencies in social interaction and communication and restricted and repetitive behaviors (American Psychiatric Association, 2000). Three conditions are included under autism spectrum disorders (or autism): autistic disorder, Asperger disorder, and pervasive developmental disordernot otherwise specified (PDD-NOS). Recent studies have estimated the prevalence of autism to be $\sim 1 \%$ among children (Centers for Disease Control and Prevention, 2009; Kogan et al., 2009). Caring for a child with autism is a life-altering experience for parents, who have to assume the role of a caregiver. Several studies have documented the occurrence of negative outcomes such as stress, anxiety, and depression among caregivers of children with autism (Abbeduto et al., 2004; Bouma \& Schweitzer, 1990; Davis \& Carter, 2008; Kasari \& Sigman, 1997; Magana \& Smith, 2006; Smith et al., 2008). However, limited literature currently exists regarding the effect on caregiver's health-related quality of life (HRQOL). In one such study, Allik et al. (2006) found that mothers of children with Asperger disorder and high-functioning autism had lower physical HRQOL as compared to mothers of children with typical development. It was further reported that HRQOL among mothers of children with Asperger disorder and high-functioning autism was related to the extent of behavioral problems among the child. Though the study by Allik et al. (2006) shed some light on the HRQOL among caregivers of children with autism, the small sample size of the study limited its usefulness and generalizability. Furthermore, Allik et 
al. (2006) did not explore in detail the caregiving-related factors that impact caregivers' HRQOL.

The construct of HRQOL synthesizes the concepts of health status and quality of life (QOL) (Donohue, 2002). QOL is a broad and expansive construct, and includes both healthrelated and non-health-related components. According to the World Health Organization, QOL can be defined as an "individual's perception of their position in life in the context of the culture and value systems in which they live, and in relation to their goals, expectations, standards and concerns" (WHOQOL Group 1995, p.1405). Felce and Perry $(1995,1996)$ outlined five domains of QOL: (1) physical well-being, which includes fitness, health, and physical safety; (2) material well-being, which includes finances, transport, neighborhood, security, and stability; (3) social well-being, which includes relationships with immediate and extended family members and friends and community involvement; (4) development and activity, which includes competence, productivity, work, leisure, and education; and (5) emotional well-being, which includes mood, satisfaction, self-esteem, respect, and religious faith. HRQOL is a subset of QOL which relates directly to an individual's health. The term HRQOL is considered to represent the physical, psychological, and social domains of health that can be influenced by an individual's perceptions (Testa \& Simonson, 1996). Measuring HRQOL among caregivers of children with autism is important considering that there could be direct implications on the quality of care provided to the child. In the current study, we aimed to assess the HRQOL among caregivers of children with autism and compare it to that of the general US population.

The success of interventions targeted to improve caregiver outcomes in autism is contingent upon an in-depth understanding of the complexity of the caregiving experience and the factors that affect caregiver HRQOL. Using Chappell and Reid (2002) stress-appraisal 
model as a guiding framework, we tested an autism caregiving model to identify factors impacting HRQOL of caregivers of children with autism. The model proposed by Chappell and Reid (2002) modified a prior stress-appraisal model proposed by Yates et al. (1999), and was validated in caregivers of adults with Alzheimer's and other dementia. The model consists of five core components: (1) primary stressors that included care recipients cognitive status and behavioral problems; (2) primary appraisal that included the number of hours devoted to informal caregiving by the caregiver; (3) mediators that included perceived social support, use of formal/respite service, and frequency of getting a break; (4) secondary appraisal that included subjective burden; and (5) outcome that referred to caregiver well-being. Appraisal refers to the caregiver response to the disability. While primary appraisal refers to the caregiver's perception of the caregiving work, secondary appraisal refers to the caregiver's perception of being overwhelmed or overloaded (Yates et al., 1999). This model has also been used to study the caregiving process in Parkinson's disease (Goldsworthy \& Knowles, 2008). The caregiving process and factors influencing outcomes are likely to be unique to caregiver groups (Goldsworthy \& Knowles, 2008). Since the focus of this study was to study HRQOL among caregivers of children with autism, we adapted the model proposed by Chappell and Reid (2002) to capture the caregiving processes unique to this population. A thorough review of the literature did not reveal any prior caregiving model aimed at studying HRQOL among caregivers of children with autism.

The model proposed in this study consists of four core components: primary stressors, mediators, secondary appraisal, and outcome. Figure 4.1 depicts the caregiver HRQOL model tested in the present study. Care recipient's functional impairment and extent of behavioral problems were included as primary stressors. Studies have consistently found that greater 
symptom severity and extent of behavioral problems among children with autism are related to greater burden and poor health among caregivers (Allik et al., 2006; Bromley et al., 2004; Hastings et al., 2005a; Herring et al., 2006; Orsmond et al., 2006; Rao \& Beidel, 2009; Stuart \& McGrew, 2009).

The second component included in the model was the mediators, which included social support, family functioning, and coping mechanisms. Social support broadly refers to the availability of helping relationships that an individual can draw upon during stressful times (Leavy, 1983). Greater social support is associated with lower caregiver anxiety, depression, and stress (Sharpley et al., 1997). Family functioning can generally be defined as the relationships and interactions that occur among family members (Kavanagh, 1992). Greater family cohesion and adaptability have been shown to provide a buffer against the potential negative effects of caring for a child with greater behavioral problems (Ievers et al., 1998). The third mediator included in the model was caregiver coping mechanisms. Coping refers to an individual's cognitive and behavioral attempt to manage the demands placed on him/her due to a stressful event (Folkman \& Lazarus, 1980). Coping is said to mediate the impact of autism symptoms on maternal well-being (Smith et al., 2008). There are two types of coping strategies: problemfocused coping and emotion-focused coping. Problem-focused coping involves strategies that are employed to directly address the problem causing distress, whereas emotion-focused coping involves strategies aimed at regulating the distress associated with the problem (Folkman \& Lazarus, 1980). Studies in autism have reported the use of emotion-focused coping to be associated with poor well-being among parents (Hastings et al., 2005b; Smith et al., 2008). In their study of family functioning and coping mechanisms among parents of children with autism, Altiere and von Kluge (2009) found an increasing level of cohesion in families to be related to 
increased use of coping behaviors. Specifically, the authors found that individuals who reported their families to be more connected and enmeshed were more likely to use positive coping mechanisms than disengaged families. Further, the study also found that individuals in enmeshed families perceived greater social support from family and friends. These results suggest that family functioning may have an influence on social support and coping among caregivers of children with autism. Therefore, in our model we included a direct path from family functioning to coping mechanism and social support.

Caregiver burden was included as the secondary appraisal in the proposed model. Burden refers to the stress or strain experienced among caregivers related to the problems and challenges they encounter because of care recipient status (Buhse, 2008). Caregiver burden can be differentiated into two dimensions: objective burden, which relates to the observable and tangible impact of caring on the caregiver (such as the impact on caregiver finances, work, and leisure activities), and subjective burden, which relates to the emotional consequence of caring on the caregiver (such as the feeling of worry, distress, and fatigue) (Buhse, 2008; Montgomery et al., 1985; Sales, 2003). Stuart and McGrew (2009) identified care recipients' symptom severity, social support, pile-up demands, negative appraisal (caregiver's perception of the implications of having a child with autism), and use of passive avoidant strategies to be associated with burden experienced by caregivers of children with a recent diagnosis of autism. In our model, we included a direct path from each of the primary stressors and mediators to caregiver burden. In terms of the relationship between caregiver burden and HRQOL, studies have found burden to be a significant predictor of caregiver HRQOL (Hughes et al., 1999; Morimoto et al., 2003; Saunders, 2009; Serrano-Aguilar et al., 2006). In one of the first studies to examine the relationship between caregiver burden and HRQOL, Hughes et al. (1999) found 
the two constructs to be inversely related, with higher burden associated with lower HRQOL. Burden explained a significant amount of variance in caregiver HRQOL in that study. Both objective and subjective burden were shown to predict caregiver HRQOL (Hughes et al., 1999). Similar findings of an inverse relationship between burden and HRQOL have been observed in caregivers of individuals with Alzheimer's (Serrano-Aguilar et al., 2006), heart failure (Saunders, 2009), and stroke (Morimoto et al., 2003). While Chappell and Reid (2002) considered only subjective burden as the secondary appraisal in their model, we included an overall burden (including objective and subjective burden) measure in the proposed model. Finally, in contrast to Chappell and Reid (2002), who had measured caregiver well-being using a life-satisfaction measure, we used HRQOL as an outcome measure in our model. The aim was to determine the generally modifiable caregiving situational factors that influence HRQOL among caregivers of children with autism.

The present study aimed to test a few hypotheses. We hypothesized that HRQOL among caregivers of children with autism would be lower than population norms. In terms of the theoretical model, we hypothesized that primary stressors, which includes care recipient's level of functional impairment and extent of behavioral problems, would have an adverse effect on caregiver burden and HRQOL. We expected that greater functional impairment and behavioral problems in care recipients would be associated with greater burden and poorer HRQOL among caregivers. We hypothesized that social support will be associated with burden and HRQOL, with caregivers' who perceive greater social support experiencing lower burden and better HRQOL. In terms of family functioning, we expected that caregivers who perceive their family to be dysfunctional would experience greater burden and have poorer HRQOL. As per coping mechanisms, we hypothesized that greater use of maladaptive coping and lower use of adaptive 
coping would be associated with greater caregiver burden and lower HRQOL. Finally, we hypothesized that caregiver burden would be associated with caregiver HRQOL, with caregivers with higher levels of burden experiencing poorer HRQOL.

\section{Methods}

\section{Participants and procedures}

Study participants were primary caregivers of children with autism that were registered with the West Virginia Autism Training Center (WV ATC). The WV ATC at Marshall University is a statewide autism service delivery program that provides education, training, and support to family members of individuals with autism. From the list of families registered with the center, we identified those families: (1) where the child with autism was less than or equal to 18 years of age; and (2) that had no more than one child with autism. Based on the inclusion criteria, a total of 1,039 families were selected and approached for participation in the study. For study purposes, primary caregiver was defined as the individual in the family having the main responsibility for providing care to the child with autism.

Participants that met the inclusion criteria were mailed a survey packet (Appendix $\mathrm{H}$ ) which included: (1) a cover letter from the WV ATC emphasizing the protection of participant identity and voluntary participation; (2) a cover letter from the Department of Pharmaceutical Systems and Policy at West Virginia University outlining the study purpose and procedures for establishing anonymity and confidentiality; (3) a yellow-colored survey booklet with relevant study measures and an acknowledgment statement; (4) a list of psychological counseling facilities that participants could use if they experienced any emotional discomfort with the survey; and (5) a self-addressed (to the WV ATC) postage-paid reply envelope. Participants 
were requested to complete the survey along with the acknowledgement statement and return it in the pre-paid envelope. As a token of appreciation for participants' time and effort, a \$5 WalMart gift card was mailed to those who returned the completed survey with the acknowledgment statement. To maximize study response rate, a total of three mailings were undertaken. Three weeks after the first packet mailing, participants who did not respond were mailed a second survey packet. Subsequently, a third and final mailing was undertaken three weeks after the second mailing to those who did not respond to either the first or second mailing. The study was acknowledged by the Institutional Review Boards of West Virginia University and Marshall University, respectively.

A total of 304 usable survey responses were received after three mailings, yielding a usable response rate of $35 \%$. The average age of the participants was 38.9 years $(\mathrm{SD}=8.0)$, 93.1\% were female, and $95.7 \%$ were white. A majority of participants were married (74.0\%), $15.5 \%$ were divorced or separated, and the remaining were never married, widowed, or living with partner. Almost $70 \%$ had either attended or graduated from a college and $49.7 \%$ were employed (full-time or part-time). In terms of income distribution, $29.9 \%$ had annual household income less than $\$ 25,000,25.0 \%$ earned between $\$ 25,000$ and $\$ 49,999,33.9 \%$ earned between $\$ 50,000$ and $\$ 99,999$, and the remaining $10.5 \%$ made more than $\$ 100,000$. In terms of characteristics of the children with autism to whom participants provided care, a majority $(82.9 \%)$ were male. This gender distribution is consistent with higher prevalence of autism observed among males (Kogan et al., 2009). Approximately $52 \%$ of the children had a diagnosis of autistic disorder, 25.3\% were diagnosed with Asperger's syndrome, and 21.4\% had a diagnosis of PDD-NOS. Almost $7 \%$ of the children were less than 5 years of age, $44.1 \%$ were in 
the age group 5-less than 10 years, $41.4 \%$ were 10 -less than 15 years, and $6.6 \%$ were between 15-18 years.

\section{Measures}

Caregiver HRQOL. HRQOL among caregivers of children with autism was assessed using the Medical Outcomes Study Short-Form Health Survey version 2 (SF-12v2) (Ware et al., 1996). The SF-12v2 is a generic HRQOL measure developed as a shorter and efficient alternative to the SF-36. Similar to its parent instrument (SF-36), the SF-12v2 provides scores for eight health concept subscales (physical functioning, role physical, bodily pain, general health, vitality, social functioning, role emotional, and mental health), as well as summary scores for physical and mental health status. The SF-12v2 consists of 12-items, with each of the eight health subscales measured using one or two items. The Physical Component Summary (PCS) scale includes physical functioning, role physical, bodily pain, and general health subscales, whereas the Mental Component Summary (MCS) scale includes vitality, social functioning, role emotional, and mental health subscales. Using the scoring guideline provided by Ware et al. (2002), standard US norm-based scores for the eight health concept subscales and the two component scales were calculated. Higher scores indicate better health. The psychometric properties of SF12 are well established, and the instrument has been used extensively by researchers. The PCS (reliability coefficient 0.89 ) and MCS (reliability coefficient 0.86 ) scores have been shown to be reliable in the general population (Ware et al., 2002). The reliability coefficients range from 0.73 to 0.87 for the eight SF-12v2 health concept subscales (Ware et al., 2002).

Age and gender-adjusted norm-based scores for the eight health subscales and the two summary scales for the general US population have been reported (Ware et al., 2002). Norms 
for the general US population were estimated from responses to the 1998 National Survey of Functional Health Status (NSFHS), which included SF-12v2. The overall response rate for the NSFHS was $67.8 \%$. The average age of survey respondents was 50.7 years (range 18-96). Among NSFHS respondents, $59.6 \%$ were female, $84.2 \%$ were white, and $79.8 \%$ had at least 12 years of education. To adjust the sample to match the age, gender, and age by gender distribution of the US population, sampling weights based on 1998 data from the US Census Bureau were applied (Ware et al., 2002).

Caregiver burden. Caregiver burden was assessed using the Caregiver Strain Questionnaire (CGSQ) (Brannan et al., 1997). The instrument consists of 21 -items, with each item measured on a five-point Likert scale ranging from 1 (not at all a problem) to 5 (very much a problem). The instrument is reported to have three dimensions: (1) objective strain, which includes 11 items that capture the negative consequences of caring; (2) subjective internalized strain, which includes 6 items that capture feelings such as worry, guilt, and unhappiness; and (3) subjective externalized strain, which includes 4 items that capture caregiver feelings directed towards the child (Brannan et al., 1997). Subscale scores are calculated by taking the mean of items. A global burden score is calculated by summing the scores on the three subscales. The 21 -item scale has been demonstrated to have excellent internal consistency reliability (Cronbach's alpha 0.93) (Brannan et al., 1997). The internal consistency reliability of the CGSQ was 0.94 (Cronbach's alpha) in the present study.

Social support. Social support was measured using the Multidimensional Scale of Perceived Social Support (MSPSS) (Zimet et al., 1988). The MSPSS assesses an individual's perception of 
social support adequacy received from three sources: friends, family, and significant other. The instrument consists of 12-items, each of which are measured on a seven-point Likert scale format ranging from 1 (very strongly agree) to 7 (very strongly disagree). A total measure of perceived social support adequacy is determined by averaging the score on the 12-items, with higher scores indicating greater social support. The total scale has been demonstrated to have an internal consistency reliability of 0.88 (Cronbach's alpha) and test-retest reliability of 0.85 (Zimet et al., 1988). Cronbach's alpha for the MSPSS was 0.95 in this study, reflecting good internal consistency.

Family Functioning. Caregivers reported on their family functioning using the General Functioning Scale (GFS) of the McMaster Family Assessment Device (FAD) (Epstein et al., 1983). The 60-item FAD provides rating on six dimensions of family functioning: problem solving, communication, roles, affective responsiveness, affective involvement, and behavior control, with each dimension representing a subscale. A seventh subscale of the FAD is the general functioning. The 12-item GFS is a shorter version of the FAD, and provides rating of overall health of the family. Each of the 12-items in the GFS is measured on a four-point Likert scale ranging from 1 (strongly agree) to 4 (strongly disagree). A total score is calculated by summing the scores on the 12-items, with higher score reflecting unhealthy family functioning. The GFS is reported to have good internal consistency reliability (Cronbach's alpha $=0.86$ ), split-half reliability (Guttman coefficient $=0.83$ ), and construct validity (Byles et al., 1988). The internal consistency (Cronbach's alpha 0.91) of the scale was excellent in the current study. 
Coping mechanisms. The coping mechanisms used by caregivers to deal with the demands of caring were ascertained using the Brief Coping Orientation to Problem Experiences (Brief COPE) instrument (Carver, 1997). The 28-items in the self-report Brief COPE instrument can be classified into 14 scales: active coping, planning, positive reframing, acceptance, humor, religion, use of emotional support, use of instrumental support, self-distraction, denial, venting, substance use, behavioral disengagement, and self-blame. Each scale is made up of two items, with each item measured on a four-point Likert scale ranging from 1 (I haven't been doing this at all) to 4 (I've been doing this a lot). The internal consistency reliability of the 14 scales has been reported to range from 0.50 to 0.90 (Cronbach's alpha) (Carver, 1997). The 14 scales can be further reduced to two broad coping strategies: adaptive and maladaptive coping (Meyer, 2001). Adaptive coping includes 16-items that represent: active coping, planning, positive reframing, acceptance, humor, religion, use of emotional support, and use of instrumental support scale; while maladaptive coping includes 12 -items that represent self-distraction, denial, venting, substance use, behavioral disengagement, and self-blame scale (Meyer, 2001). In compliance with the Institutional Review Board recommendations, the two-items associated with substance use were not used in the present study. Item scores were summed to determine the scores for adaptive and maladaptive coping, with higher scores indicating more frequent use of the coping style.

Care recipient functional impairment. Care recipient's level of functional impairment was assessed using the Childhood Autism Rating Scale-Parent version (CARS-P) (Bebko et al., 1987). The 14-item CARS-P is an adaptation of the CARS (Schopler et al., 1980), and provides parents' perceptions of the autism severity in the child. Each of the 14-items represent a domain 
of child functioning, and includes: relationships with people, imitation, emotional response, body use, object use, adaptation to change, visual response, listening response, taste, smell, and touch response and use, anxiety, verbal communication, non-verbal communication, activity level, and level and consistency of intellectual response. The level of severity on the 14-domains is determined on a four-point Likert scale with endpoints of 1 (normal for chronological age) and 4 (severely abnormal for chronological age). An overall level of functioning score is created by summing the scores on the 14-items, with higher scores representing greater autistic behaviors and poor functioning. The instrument has been reported to have an internal consistency reliability of 0.86 (Cronbach's alpha) and split-half reliability of 0.85 (Tobing \& Glenwick, 2002).

Care recipient behavioral problems. The extent of behavioral problems in the care recipient was determined using the short form Developmental Behavioral Checklist (DBC-P24) (Taffe et al., 2007). The DBC-P24 is a shorter version of the 96-item DBC and provides a measure of total problem behavioral score. The instrument consists of 24 -items that are designed to be completed by the caregiver, and each item is scored on a three-point Likert scale ranging from 0 (no true) to 2 (very true). A total behavioral problem score is calculated by summing the scores on the 24items, with higher scores indicating higher levels of behavioral problems. The short form has been reported to achieve high sensitivity and specificity with the original DBC-P (Taffe et al., 2007).

\section{Data analysis}


Descriptive statistics for study measures were reported. Correlation (Pearson's coefficient) among theoretical variables was also reported. After adjusting for age and gender, the HRQOL scores for participants on the eight SF-12v2 health concept subscales and two summary scales were compared with published norms for the general US population (Ware et al., 2002) using a one-way t-test. The relationships proposed in the model were analyzed using both linear regression analysis and structural equation modeling (SEM). Hierarchical linear regression analysis was used to determine whether primary stressors, mediators, and secondary appraisal predicted physical and mental HRQOL of caregivers, respectively.

The relationship among the theoretical variables was also studied using SEM (SPSS AMOS version 18). This technique allows researchers to study models of linear relationship between one or more independent and dependent variables (MacCallum \& Austin, 2000). SEM also determines standardized estimates of total effects, which includes direct and indirect effects, for relationships hypothesized in the model. However, the AMOS program used to conduct SEM provides significance tests for only direct effects. Appropriateness of the hypothesized relationships was tested using maximum likelihood estimation technique. Multiple fit indices including the chi-square statistic, Goodness-of-Fit Index (GFI), Comparative Fit Index (CFI), and Root Mean Square Error of Approximation (RMSEA) were evaluated to determine model fit. Chi-square statistics with probability greater than 0.5 , GFI value close to $1.00, \mathrm{CFI}>0.95$, and RMSEA $<0.05$ indicate a good fit between the model and data (Byrne 2001). Bollen-Stine bootstrapping (500 samples) was also performed to evaluate overall model fit (Bollen \& Stine, 1992). The Bollen-Stine option is a modified bootstrap method for the chi-square goodness-offit statistic, and tests the null hypothesis that the proposed model is correct (Byrne, 2001). The stability of estimates in SEM is contingent on the sample size, and it is recommended that the 
ratio of number of cases to number of free parameters be at least 10:1 (Kline, 2005; Tabachnick \& Fidell, 2001). The statistical precision of the results for models with case to free parameter ratio of less than 5:1 is considered to be doubtful (Kline, 2005). There were 42 free parameters in the hypothesized model, and a total of 304 cases. Therefore, the ratio of number of cases to free parameters was 7:1. Given the sample size requirements for SEM, the complexity of the model tested in the present study was limited. Data cleaning and statistical analyses were conducted using SPSS version 18 (SPSS Inc., Chicago, IL).

\section{Results}

\section{Descriptive statistics and correlations}

Table 4.1 shows the descriptive statistics for study measures. The mean score for mental HRQOL was $37.48 \pm 11.78$, while that for physical HRQOL was $51.28 \pm 9.60$. When studying correlation between theoretical variables and caregiver HRQOL, certain significant relationships emerged. Table 4.2 shows the correlation observed among theoretical variables. As expected, there was a negative association between caregiver mental HRQOL and care recipient level of functional impairment $(\mathrm{r}=-0.30 ; p<0.01)$ and extent of behavioral problem $(\mathrm{r}=-0.32 ; p<$ 0.01). Caregivers who reported higher levels of functional impairment and behavioral problems in the child reported lower levels of mental HRQOL. A significant positive association was found between social support and mental HRQOL $(\mathrm{r}=0.37 ; p<0.01)$, with caregivers who perceived greater social support reporting higher score on mental HRQOL. Caregiver mental HRQOL was negatively associated with family functioning $(\mathrm{r}=-0.39 ; p<0.01)$. Caregivers who reported greater problems in family functioning reported lower levels of mental HRQOL. In terms of the relationship between caregiver coping mechanisms and mental HRQOL, greater 
use of maladaptive coping was associated with lower mental HRQOL $(\mathrm{r}=-0.48 ; p<0.01)$. Also, as expected, caregivers who reported higher levels of burden also reported lower levels of mental HRQOL $(\mathrm{r}=-0.56 ; p<0.01)$. Caregiver physical HRQOL had significant association with care recipient extent of behavioral problems $(\mathrm{r}=-0.13 ; p<0.05)$, social support $(\mathrm{r}=0.16 ; p$ $<0.01)$, and family functioning $(\mathrm{r}=-0.12 ; p<0.05)$, respectively. Specifically, an inverse relationship was found between care recipient extent of behavioral problems and caregiver physical HRQOL. Further, caregivers who perceived greater social support also reported higher levels of physical HRQOL. Finally, caregivers who perceived their family to be more dysfunctional reported lower scores on physical HRQOL.

\section{Comparison of caregiver HRQOL with US norms}

Figures $4.2 \mathrm{a}$ and $4.2 \mathrm{~b}$ depicts the HRQOL scores among caregivers of children with autism compared with US population norms (Ware et al., 2002) after adjusting for age and gender. Given the insufficient number of male caregivers and female caregivers (18-24 years, 45 years and above), comparisons with US norms were limited to females in the age group 25-34 years and 35-55 years. Female caregivers in the age group 25-34 years had significantly lower scores as compared to their age-matched US population norms in the domains of role physical (mean difference $-3.71, p<0.01$ ), bodily pain (mean difference $-3.95, p<0.01$ ), general health (mean difference $-6.58, p<0.001$ ), vitality (mean difference $-6.65, p<0.001$ ), social functioning (mean difference $-9.63, p<0.001$ ), role emotional (mean difference $-12.17, p<0.001$ ), mental health (mean difference $-9.84, p<0.001$ ), and mental component summary (mean difference $-12.53, p$ $<0.001$ ) (see Figure 4.2a). Similarly for female caregivers 35-44 years of age, differences with US norms were significant in the domains of role physical (mean difference $-5.21, p<0.001$ ), 
bodily pain (mean difference $-2.71, p<0.01$ ), general health (mean difference $-4.41, p<0.001$ ), vitality (mean difference $-4.95, p<0.001$ ), social functioning (mean difference $-6.33, p<0.001$ ), role emotional (mean difference -9.74, $p<0.001$ ), mental health (mean difference $-7.41, p<$ 0.001), and mental component summary (mean difference $-8.91, p<0.001$ ) (see Figure $4.2 b$ ). These results support the hypothesis of lower HRQOL among caregivers of children with autism as compared to US population norms.

\section{Hierarchical regression analysis of factors predicting caregiver HRQOL}

Table 4.3 shows the results of hierarchical regression analyses with caregiver HRQOL as the dependent variable. Two separate regression models were run with mental and physical HRQOL as dependent variables, respectively. In both models, care recipient level of functional impairment and extent of behavioral problems were entered as independent variables in Step I, followed by social support, adaptive coping, maladaptive coping, and family functioning in Step II, and caregiver burden in Step III. Both care recipient level of functional impairment ( $\beta=$ $0.15 ; p=0.05)$ and extent of behavioral problems $(\beta=-0.22 ; p<0.01)$ were significant predictors of caregiver mental HRQOL in Step I and explained $10.8 \%$ of the variance. With the addition of mediators in Step II, the variance explained increased significantly $\left(\mathrm{R}^{2}\right.$ change $=$ $0.23, p<0.001)$. Care recipient functional status $(\beta=-0.19 ; p<0.01)$, social support $(\beta=0.17$; $p<0.01)$, maladaptive coping $(\beta=-0.35 ; p<0.001)$, and unhealthy family functioning $(\beta=-$ $0.14 ; p<0.05$ ) emerged as significant predictors of caregiver mental HRQOL in step II. The inclusion of caregiver burden in the final step also resulted in a significant increase in the caregiver mental HRQOL variance explained $\left(\mathrm{R}^{2}\right.$ change $\left.=0.07, p<0.001\right)$. Care recipient functional status ( $\beta=-0.16 ; p<0.01$ ), social support $(\beta=0.13 ; p<0.05$ ), maladaptive coping ( $\beta$ 
$=-0.25 ; p<0.001)$, and burden $(\beta=-0.37 ; p<0.001)$ were found to be the significant predictors of caregiver mental HRQOL in the final step (Step III). Overall, the final set of variables explained $39.7 \%$ of the variance in caregiver mental HRQOL.

When examining caregiver physical HRQOL, care recipient level of functional impairment and extent of behavioral problems entered in Step I accounted for 3\% $(p<0.05)$ of the variance, with only care recipient extent of behavioral problems being a significant ( $\beta=-$ $0.24 ; p<0.01)$ predictor. The addition of social support, coping style, and family functioning to the model resulted in an insignificant change in variance explained $\left(\mathrm{R}^{2}\right.$ change $\left.=0.03, p=0.08\right)$. Care recipient behavioral problems $(\beta=-0.19 ; p<0.05)$ and social support $(\beta=0.14 ; p<0.05)$ significantly predicted caregiver physical HRQOL in Step II. Finally, the addition of caregiver burden in Step III also did not result in any significant improvement in caregiver physical HRQOL variance explained $\left(\mathrm{R}^{2}\right.$ change $\left.=0.00, p=0.86\right)$. Only care recipient extent of behavioral problems $(\beta=-0.19 ; p<0.05)$ and social support $(\beta=0.14 ; p<0.05)$ were found to be the significant predictors of caregiver physical HRQOL in the final step (III). The total variance explained for caregiver physical HRQOL was $3.3 \%$.

\section{Structural equation model of theoretical variables}

The model depicted in Figure 4.1 was also tested using SEM. The goodness-of-fit indices indicated that the proposed model did not fit well with the data (Chi-square $=232.85, p<0.05$; $\mathrm{GFI}=0.89 ; \mathrm{CFI}=0.72 ; \mathrm{RMSEA}=0.50$ ). To improve model fit, we excluded paths that were insignificant. Further, based on modification indices, the residual error covariance between care recipient level of functional impairment and extent of behavioral problems and adaptive and maladaptive coping, respectively, were specified as free parameters. The modified model is 
depicted in Figure 4.3. The paths from care recipient extent of behavioral problems to caregiver mental HRQOL and care recipient level of functional impairment to caregiver physical HRQOL were not significant in the final modified model. However, all goodness-of-fit indices indicated a good fit between the final model and data, and therefore this model was accepted. The Chisquare index (23.2) was not significant $(p=0.06)$, GFI was 0.98 , CFI was 0.99 , and RMSEA was $0.04(90 \%$ CI $0.00,0.08)$. The Bollen-Stine index was insignificant $(p$-value $=0.13)$, further indicating the appropriateness of the model fit. Table 4.4 shows the standardized estimates of total, direct, and indirect effects of relationships among theoretical variables that were significant in the final model.

The final model explained $46.9 \%, 39.9 \%$, and $4.3 \%$ of the variance in caregiver burden, mental HRQOL, and physical HRQOL, respectively. Five variables had a direct effect on caregiver burden (see Figure 4.3). As hypothesized, higher level of care recipient behavioral problems were associated with a higher level of caregiver burden (standardized direct effect regression weight $=0.41, p<0.001)$. Caregivers who perceived their family to be more dysfunctional reported greater burden (standardized direct effect regression weight $=0.18, \mathrm{p}<$ 0.001). As expected, a protective effect of social support was seen on burden, with greater social support associated with lower burden (standardized direct effect regression weight $=-0.10, p=$ 0.053). Also, as hypothesized, greater use of maladaptive coping was associated with greater burden (standardized direct effect regression weight $=0.27, p<0.001$ ). However, contrary to expectation, greater use of adaptive coping was also associated with greater burden (standardized direct effect regression weight $=0.09, p<0.05$ ). Based on the standardized estimates of total effects for relationships where a significant direct effect existed, care recipient extent of behavioral problems (standardized total effect $=0.56$ ) had the most impact on caregiver burden, 
followed by unhealthy family functioning (standardized total effect $=0.29$ ), use of maladaptive coping $($ standardized total effect $=0.27)$, social support $($ standardized total effect $=-0.10)$, and use of adaptive coping (standardized total effect $=0.07)($ see Table 4.4). The total effects represent the sum of the direct and all indirect effects of one variable on another (Kline, 2005). Indirect effect occurs when a causally prior variable has an effect on a subsequent variable through an intervening variable. For example, care recipient extent of behavioral problems had both a direct effect (standardized direct effect estimate $=0.41$ ) and indirect effect through family functioning $(0.27 * 0.18)$, maladaptive coping $(0.15 * 0.27)$, and social support $(-0.24 *-0.10)$ on caregiver burden. Therefore, the total effect of behavioral problems on caregiver burden can be calculated by summing the direct and all indirect effects $(0.41+[0.27 * 0.18]+[0.15 * 0.27]+[-$ $0.24 *-0.10]=0.56)$

Greater behavioral problems were associated with greater problems in family functioning ( standardized direct effect estimate $=0.27, p<0.001$ ). The model also highlighted the significant direct effect of family functioning on adaptive coping (standardized direct effect estimate $=-0.26, p<0.001)$, maladaptive coping (standardized direct effect estimate $=0.34, p<$ 0.001), and social support (standardized direct effect estimate $=-0.42, p<0.001$ ). Since there were no indirect effects of family functioning on these variables, the total effects were the same as direct effects. The directions of these relationships were consistent with expectation, and showed that unhealthy family functioning is associated with lower adaptive coping, greater maladaptive coping, and lower perceived social support. A direct effect of adaptive coping on social support was also seen, with greater use of adaptive coping associated with greater social support (standardized direct effect estimate $=0.20, p<0.001$ ) 
Consistent with the results from regression analysis, care recipient functional impairment, social support, maladaptive coping, and caregiver burden were seen to have direct effect on mental HRQOL. Based on the total effects of factors that had a significant direct effect on caregiver mental HRQOL, caregiver burden was found to be the most influential factor (standardized total effect $=-0.38$ ), followed by the maladaptive coping (standardized total effect $=-0.36$ ), care recipient functional impairment (standardized total effect $=-0.21$ ), and social support (standardized total effect $=0.22)($ See Table 4.4$)$. Among the theoretical variables, only care recipient extent of behavioral problems and social support had a significant direct effect on caregiver physical HRQOL (see Figure 4.3). The standardized total effect of care recipient extent of behavioral problems on caregiver physical HRQOL was -0.24 . Social support was found to mediate the effect of care recipient behavioral problems on caregiver physical HRQOL $($ standardized total effect estimate $=0.13)($ see Table 4.4).

\section{Discussion}

Using a cross-sectional survey design, the present study collected an in-depth information concerning HRQOL among caregivers of children with autism. This study is, to best of our knowledge, the first to compare the HRQOL among caregivers of children with autism to general US population norms. Furthermore, the study uses a theoretical model to identify factors that influence caregiver HRQOL. Based on the conceptual model, caregiving situational factors that have an impact on caregiver burden and HRQOL were identified.

We measured HRQOL using SF-12v2, a well-validated instrument used extensively in the literature and for which US norm-based scores are available (Ware et al., 2002). After adjusting for age, it was determined that female caregivers of children with autism had 
substantially lower HRQOL scores as compared to norm-based scores for the general female US population. The health status of female caregivers was lower in all domains measured by SF$12 \mathrm{v} 2$ except for physical functioning and PCS scale. The mean difference in SF-12v2 health concept subscale scores between female caregivers and US norms ranged from 2.71 to 12.17. The difference in mental component summary scores was as high as 12.53. A 3 point or more difference in mean summary scores is considered to be clinically significant (Ware et al., 2007). Therefore, the MCS scores for female caregivers were both statistically and clinically lower than US norms.

The impact of caring for a child with autism on the mental health of caregivers has been well documented (Abbeduto et al., 2004; Magana \& Smith, 2006; Smith et al., 2008). In their study of well-being among mothers of toddlers and adolescents with autism, Smith et al. (2008) found that more than one-third mothers had scores on a depression scale higher than the clinical cut-off. Similar results were reported by Abbeduto et al. (2004), who found a higher proportion of mothers of adolescents and young adults with autism to have depression scores in the clinical range, as compared to mothers of individuals with fragile $\mathrm{X}$ syndrome and Down syndrome. Given these results, it was not surprising to see female caregivers of children with autism in our study to have lower mental HRQOL than US norms. To put the impact of caregiving on caregiver mental HRQOL into perspective, we compared the MCS of our entire sample with US population norms for individuals with depression (Ware et al., 2002). Since US norms for depression are not stratified by age and gender, we did not adjust for these factors in our comparison. This comparison indicated that the MCS score among caregivers of children with autism is similar to US population norms for individuals with depression (37.48 versus $37.40, p$ $=0.89$ ). 
Though a number of studies in autism have focused on markers of mental health, the impact of caring for a child with autism on the physical health of caregivers has received little attention. In the current study, we did not find significant differences in PCS scores between female caregivers and US norms. However, female caregivers had significantly lower scores on role physical, bodily pain, and general health subscales, as compared to US norms. This highlights the physical health impact of caring on caregivers of children with autism. Previous studies have found the occurrence of lower physical health status among mothers of children with autism, as compared to mothers of children with typical development (Allik et al., 2006; Mugno et al., 2007). Therefore, it is essential that interventions designed to improve outcomes among caregivers of children with autism include components that focus on both the mental and physical health of caregivers. Since the number of male caregivers in our sample was low, we could not compare their mental and physical health status with US norms. Future research could focus on male primary caregivers of children with autism and compare their HRQOL to US norms.

The success of interventions aimed at improving health outcomes among caregivers of children with autism is contingent on a thorough understanding of the caregiving situational factors that influence HRQOL. In the present study, we used a theoretical model to determine factors that influence caregiver HRQOL. The relationship between these factors and HRQOL was examined using correlational, hierarchical regression, and structural equation modeling analysis. The direction of relationships between caregiver HRQOL and caregiving factors as revealed by correlational analyses were in line with general expectations. Caregiver mental HRQOL had significant negative correlation with care recipient level of functional impairment and extent of behavioral problems, unhealthy family functioning, caregiver use of maladaptive 
coping, and caregiver burden. A significant positive correlation emerged between caregiver mental HRQOL and social support. Caregiver physical HRQOL had a significant negative correlation with care recipient extent of behavioral problems and unhealthy family functioning, and a positive correlation with social support.

To study the factors impacting caregiver HRQOL, we used both hierarchical regression and SEM analysis. Regression analysis revealed predictors of HRQOL, while SEM depicted interrelationships among study variables. The final theoretical model fitted well with the data, and predicted $46.9 \%$ of the variance for caregiver burden, $39.9 \%$ for caregiver mental HRQQOL, and $4.3 \%$ for caregiver physical HRQOL. Given these results, it could be said that the model worked fairly well in terms of predicting caregiver burden and mental HRQOL, but not for physical HRQOL.

Caregiver burden was found to be directly influenced by care recipient behavioral problems, family functioning, maladaptive coping, adaptive coping, and social support in the final model. When studying burden among caregivers of newly diagnosed children with autism, Stuart and McGrew (2009) found social support to have a protective effect on burden. The authors also found an adverse effect of the use of passive avoidant coping strategy on caregiver burden. Similar to the study by Stuart and McGrew (2009), we found a protective effect of social support and the negative effect of maladaptive coping on caregiver burden. However, contrary to our expectation, adaptive coping had a small but significant direct effect on burden, indicating that an increase in the use of adaptive coping results in an increase in caregiver burden. This result is in contrast to previous studies that have shown greater use of problemfocused coping, a construct similar to adaptive coping, to be associated with better caregiver well-being (Smith et al., 2008). The adaptive coping construct used in the current study included 
the use of active coping, planning, positive reframing, acceptance, humor, religion, use of emotion support, and use of instrumental support. Of these different strategies, the use of religion as a coping tool may not always result in better outcomes. In a recent study, Shu (2009) found that mothers of children with autism who followed religion had lower quality of life (psychological and social domain) as compared to those who did not follow religion. Other studies have also reported the use of religion as a coping mechanism to be associated with greater caregiver burden (Wade et al., 2001). Since we had used two comprehensive constructs of coping, we could not tease out the individual effects of the different coping mechanisms that collectively fell under those constructs on burden and HRQOL. Rather than using broad measures like adaptive or maladaptive coping, it is recommended that future research separate out the different coping mechanisms that fall under these constructs, and use them individually.

The final model also revealed the relationships between family functioning, coping, and social support. The model highlighted the direct impact of care recipient behavioral problems on family functioning, with greater behavioral problems associated with greater problems in family functioning. Further, it was interesting to see the direct effect of family functioning on caregiver use of adaptive coping, maladaptive coping, and social support. Greater problems in family functioning were associated with lower use of adaptive coping, greater use of maladaptive coping, and lower social support. These results are similar to those reported by Altiere and von Kluge (2009) who found a greater use of positive coping mechanisms and perceived social support among parents of children with autism in enmeshed families than those in disengaged families. Family functioning plays a vital role in dealing with the burden of caring. Not only family functioning had a direct effect on coping mechanism, social support, and burden, it also had an indirect effect on caregiver HRQOL. Unhealthy family functioning was associated with 
lower caregiver physical (standardized indirect effect estimate $=-0.06$ ) and mental (standardized indirect effect estimate $=-0.28) \mathrm{HRQOL}$, respectively. Fostering relationships among family members and providing them with necessary tools that enable them to deal with the challenges presented by autism as a collective unit could have beneficial effects on caregiver outcomes.

Care recipient functional impairment, social support, maladaptive coping, and burden were seen to be significant predictors of caregiver mental HRQOL. In contrast to our study where autism severity and not behavioral problems was a significant predictor of caregiver mental HRQOL, Allik et al. (2006) found behavioral problems and not autism severity to be predictive of mental HRQOL in mothers of children with autism. In their study, Allik et al. (2006) had assessed HRQOL among parents of children with Asperger's syndrome and high functioning autism. The level of symptom severity among these children is likely to be much better than those with autistic disorder or PDD-NOS who constituted $73.4 \%$ of our sample. Social support predicted caregiver mental HRQOL, with higher social support associated with better mental HRQOL. Several studies have documented the importance of social support in improving well-being among caregivers of children with autism (Bishop et al., 2007; Bromley et al., 2004; Dunn et al., 2001; Sharpley et al., 1997). Low levels of social support have been reported to be the most powerful predictor of depression and anxiety among mothers of children with autism (Boyd, 2002). With respect to coping strategies, caregiver use of maladaptive coping had a significant adverse impact on mental HRQOL. The maladaptive coping construct in this study included the use of self-distraction, denial, venting, behavioral disengagement, and self-blame by caregivers. Similar results were reported by Smith et al. (2008), who found the use of denial, venting, and behavioral disengagement to be significant predictors of depression and anger among mothers of toddlers and adolescents with autism. Caregiver burden was found 
to be the most important predictor of mental HRQOL, with higher burden associated with lower mental HRQOL. Though the relationship between burden and HRQOL has been well studied in the caregiving literature (Hughes et al., 1999; Morimoto et al., 2003; Saunders, 2009; SerranoAguilar et al., 2006), this is the first study to document the impact of burden on caregiver mental HRQOL in autism. This is an important result, which needs to be considered by policy makers when providing support services to caregivers of children with autism. The burden measure used in the current study captures the objective, subjective internalized, and subjective externalized strain of caring. It is essential to provide multiple support services to caregivers so as to alleviate burden associated with both the tangible and intangible aspects of caring. Targeting the different facets of caregiver burden simultaneously is likely to produce better results in terms of improving caregiver outcomes than approaching it from one direction.

The caregiving model did not work well in explaining variance in caregiver physical HRQOL. Only care recipient extent of behavioral problems and social support were found to have a significant direct effect on physical HRQOL, with social support mediating the impact of behavioral problems. In this study, we had focused on the relationship between HRQOL and generally modifiable caregiving situational factors, and excluded socio-demographic variables. To see if the inclusion of these socio-demographic variables increases the caregiver physical (or mental) HRQOL variance explained, we repeated hierarchical regression analysis. In the new regression model, socio-demographics (caregiver age and gender, ethnicity, marital status, family income, care recipient age and gender, and type of diagnosis [autistic disorder, Asperger's syndrome, and PDD-NOS]) were included as independent variables in Step I, followed by care recipient functional impairment and behavioral problems in Step II, social support, adaptive coping, maladaptive coping, and family functioning in Step III, and burden in Step IV. Two 
separate regression models with caregiver physical and mental HRQOL as dependent variables, respectively, were run. With the addition of socio-demographic variables, the caregiver physical HRQOL variance explained was 5.6\% (adjusted $\mathrm{R}^{2}$ ), while for mental HRQOL the variance explained was $40 \%$. The addition of socio-demographics resulted in a significant but small increase in variance explained for physical HRQOL, but not for mental HRQOL. Therefore, even after including socio-demographic variables, the caregiver physical HRQOL variance was not explained adequately. This suggests that there are other factors affecting the physical health status of caregivers that may have not been captured in the current study. Caregiver feeling about the child, history of chronic conditions, lack of respite care, and lack of sleep are some of the factors that have been documented in the literature to affect the physical health of caregivers (Murphy et al., 2006; Myers et al., 2009; Shu, 2009). Given the sample size requirements for analyzing a complex SEM model, we included only a limited number of factors in our model. Future studies with larger sample size could expand upon the model proposed in the current study by including socio-demographic and other relevant caregiving factors.

The study had a few limitations. At 7:1, the ratio of number of cases to free parameters in our study was lower than the recommended 10:1 (Kline, 2005; Tabachnick \& Fidell, 2001). Parameter estimates derived from the study model must be interpreted in light of this limitation. Given the cross-sectional design of the study, causality among study variables could not be established. Future researchers could use longitudinal study designs and collect data on multiple occasions to determine the causal relationships among variables included in this study. Not surprisingly, most of the participants in the study turned out to be females. Because of insufficient numbers of male caregivers in our study, we were not able to compare their HRQOL score to those of the general male US population. By focusing exclusively on male primary 
caregivers, future studies could examine the impact of caring on their HRQOL. In our study, we focused on examining the relationships between caregiver HRQOL and a few modifiable caregiving situational factors. The small amount of variance explained in caregiver physical HRQOL points to the fact that there are other relevant caregiving factors that have not been captured in this study. Factors such as caregiver history of chronic conditions and sleep problems, presence of comorbid conditions in the care recipient, quality of caregiver-care recipient relationship, and availability of respite care were not included in our model. Future studies with larger samples could address this limitation by including these variables and examining their contribution in explaining caregiver HRQOL.

This is the first study to compare HRQOL among caregivers of children with autism to age and gender adjusted general US population norms. The study highlights the significant impact of caring for a child with autism on caregiver HRQOL. Female caregivers were found to have lower scores in physical and mental health domains as compared to age-adjusted US norms. Further, we used a comprehensive model to identify the factors that affect caregiver HRQOL. The model worked well in predicting caregiver burden and mental HRQOL. However, the model did not fared well in predicting caregiver physical HRQOL, suggesting that there were other factors affecting the physical health of caregivers that were not included in the model. The study highlights the role of healthy family functioning and social support in alleviating caregiver burden and improving their HRQOL. The negative impact of maladaptive coping on caregiver burden and mental HRQOL was also an important result of the study, which highlights the need for helping caregivers in developing good coping skills. The model also depicted the adverse impact of caregiver burden on mental HRQOL. The results from the model signify the importance of using a multi-pronged intervention approach that incorporates components aimed 
at improving family functioning, increasing support services, and assisting caregivers in developing healthy coping skills. 
Figure 4.1. Conceptual model of factors influencing HRQOL among caregivers of children with autism (modified version of Chappell and Reid [2002] Caregiving Model).

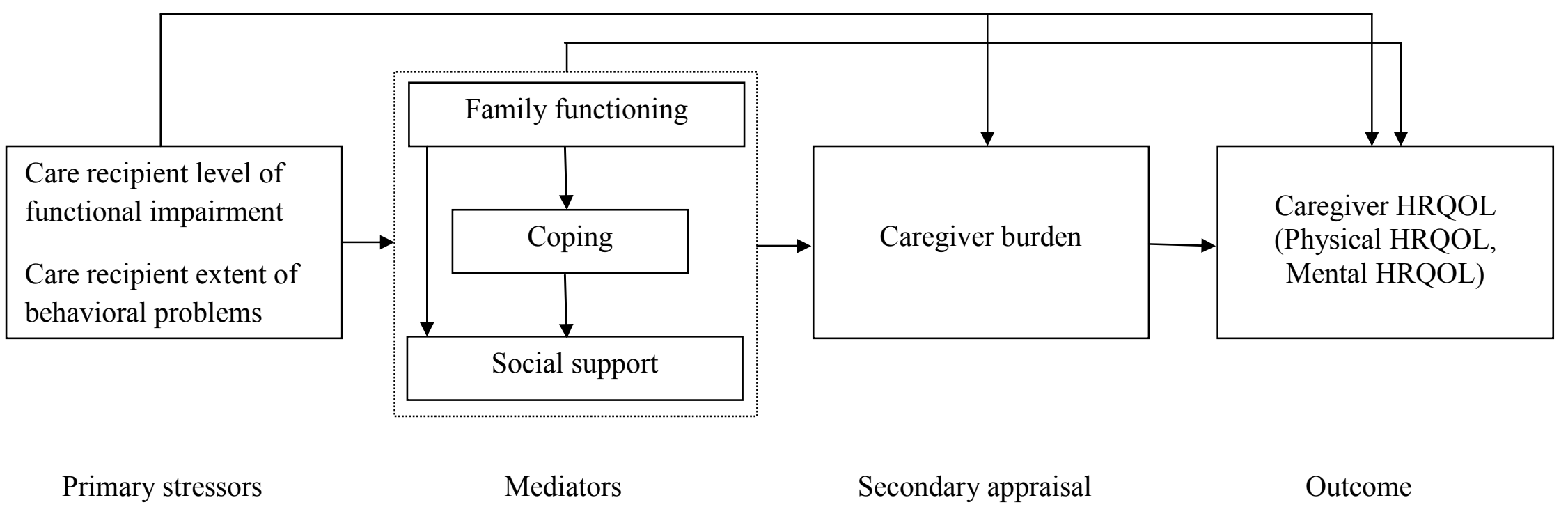


Figure 4.2a. Comparison of mean HRQOL scores among caregivers of children with autism $(n=69)$ to general US population norms $(\mathrm{n}=631-632)$, female $25-34$ years.

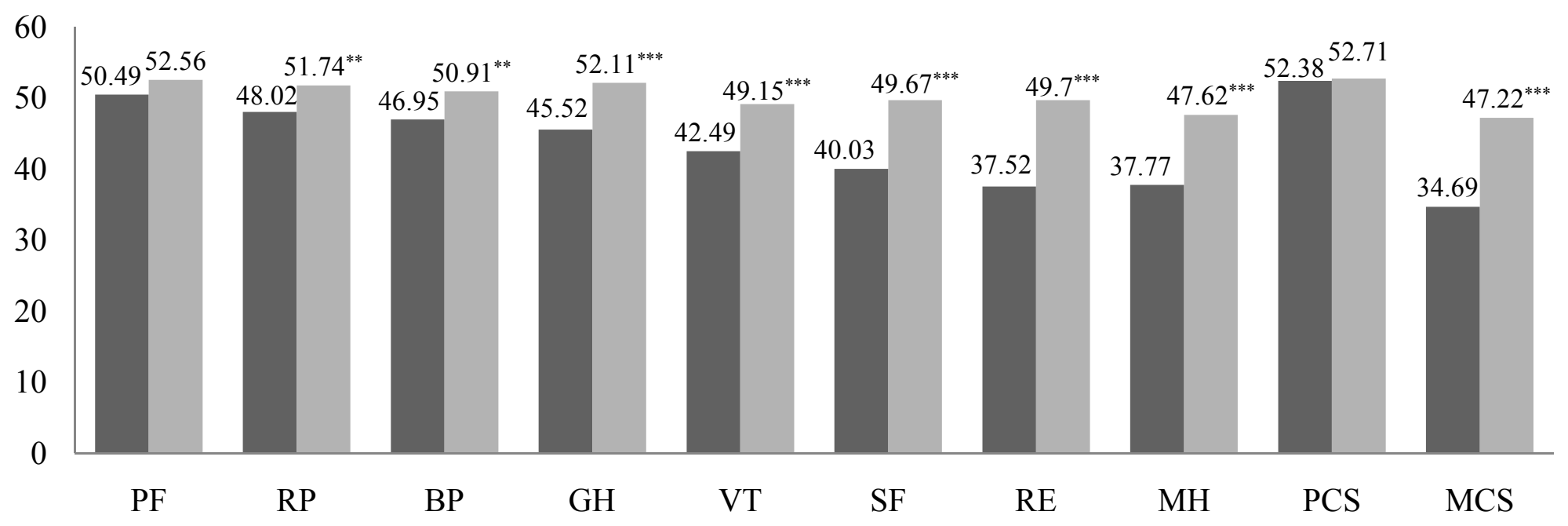


Figure 4.2b. Comparison of mean HRQOL scores among caregivers of children with autism $(\mathrm{n}=149)$ to general US population norms $(\mathrm{n}=839)$, female $35-44$ years.

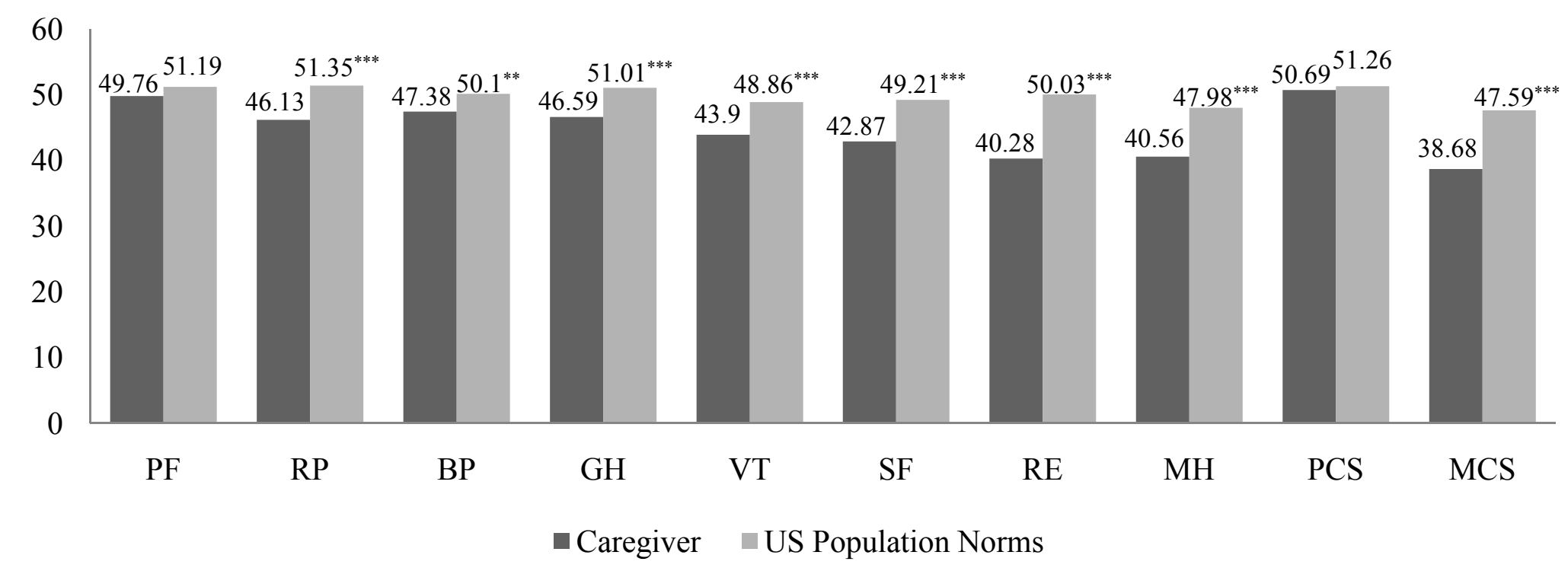

${ }^{* *} p<0.01 ; \stackrel{* * *}{p}<0.001$

$P F$ Physical functioning; $R P$ Role physical; $B P$ Bodily pain; $G H$ General health; $V T$ Vitality; SF Social functioning; $R E$ Role emotional; $M H$ Mental health; $P C S$ Physical component score; $M C S$ Mental component score

US population norms derived from Ware et al. (2002) 
Figure 4.3. Final model of factors influencing HRQOL among caregivers of children with autism.

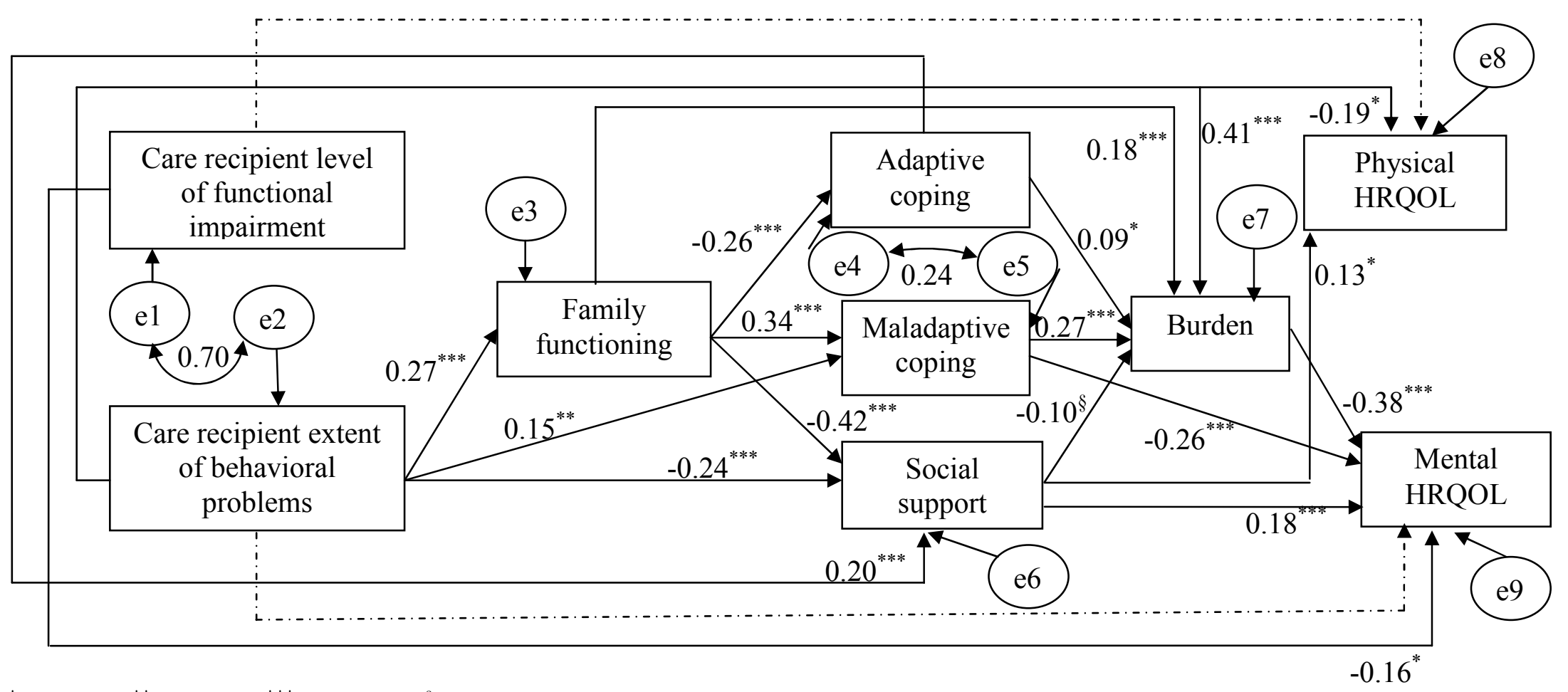

${ }^{*} p<0.05 ;{ }^{* *} p<0.01 ;{ }^{* * *} p<0.001 ;{ }^{\S} p=0.053$

Goodness-of-fit indices for the above model (Chi-square $=23.2(p=0.06)$; Chi-square $/ \mathrm{df}=1.65 ; \mathrm{GFI}=0.98 ; \mathrm{CFI}=0.99 ; \mathrm{RMSEA}=$ $0.04[90 \%$ CI $0.00,0.08])$

Dashed lines represent direct effects that were not significant in the final model. All other paths represent significant direct effects 
Table 4.1. Descriptive statistics of study measures.

\begin{tabular}{lccc}
\hline Measures & $\begin{array}{c}\text { Possible } \\
\text { score range }\end{array}$ & Mean & SD \\
\hline Primary stressors & & & \\
$\quad$ Child level of functional impairment (CARS-P) & $14-56$ & 33.20 & 9.05 \\
Child extent of behavioral problems (DBC-P24) & $0-48$ & 20.58 & 8.20 \\
Mediators & & & \\
Social support (MSPSS) & $1-7$ & 4.45 & 1.56 \\
Family functioning (GFS) & $12-48$ & 24.79 & 7.45 \\
Caregiver use of adaptive coping (Brief COPE) & $16-64$ & 42.11 & 8.08 \\
Caregiver use of maladaptive coping (Brief COPE) & $10-40$ & 18.01 & 5.22 \\
Secondary appraisal & & & \\
Caregiver burden (CGSQ) & $3-15$ & 7.94 & 2.33 \\
Outcomes & & & \\
Mental HRQOL (MCS; SF-12v2) & $0-100$ & 37.48 & 11.78 \\
Physical HRQOL (PCS; SF-12v2) & $0-100$ & 51.28 & 9.60 \\
\hline
\end{tabular}

CARS-P Childhood Autism Rating Scale-Parent version (higher score = greater functional impairment); $D B C$-P24 Short Form Developmental Behavior Checklist (higher score = greater behavioral problems); MSPSS Multidimensional Scale of Perceived Social Support (higher score = greater social support); GFS General Functioning Scale (higher score = greater problems in family functioning); Brief COPE Brief Coping Orientation to Problem Experiences (higher score = greater use of coping mechanism); CGSQ Caregiver Strain Questionnaire (higher score = greater burden); MCS Mental component summary; PCS Physical component summary; SF-12v2 Short Form-12 version 2 Health Survey (higher score = better health); ${ }^{a}$ Two items related to substance use not included in the assessment of maladaptive coping. 
Table 4.2. Correlation between theoretical variables.

\begin{tabular}{|c|c|c|c|c|c|c|c|c|}
\hline Measures & $\begin{array}{c}\text { Child } \\
\text { functional } \\
\text { impairment }\end{array}$ & $\begin{array}{c}\text { Child } \\
\text { behavioral } \\
\text { problems }\end{array}$ & $\begin{array}{c}\text { Social } \\
\text { support }\end{array}$ & $\begin{array}{c}\text { Family } \\
\text { functioning }\end{array}$ & $\begin{array}{l}\text { Adaptive } \\
\text { coping }\end{array}$ & $\begin{array}{l}\text { Maladaptive } \\
\text { coping }\end{array}$ & Burden & $\begin{array}{r}\text { Mental } \\
\text { HRQOL }\end{array}$ \\
\hline $\begin{array}{l}\text { Child behavioral } \\
\text { problems }\end{array}$ & $0.70^{* *}$ & - & - & - & - & - & - & - \\
\hline Social support & $-0.22^{* *}$ & $-0.35^{* *}$ & - & - & - & - & - & - \\
\hline Family functioning & $0.14^{*}$ & $0.27^{* *}$ & $-0.54^{* *}$ & - & - & - & - & - \\
\hline Adaptive coping & 0.04 & 0.02 & $0.31^{* *}$ & $-0.26^{* *}$ & - & - & - & - \\
\hline Maladaptive coping & $0.17^{* *}$ & $0.26^{* *}$ & $-0.25^{* *}$ & $0.38^{* *}$ & $0.12^{*}$ & - & - & - \\
\hline Burden & $0.41^{* *}$ & $0.57^{* *}$ & $-0.38^{* *}$ & $0.42^{* *}$ & 0.06 & $0.48^{* *}$ & - & - \\
\hline $\begin{array}{l}\text { Mental HRQOL } \\
(\mathrm{MCS})\end{array}$ & $-0.30^{* *}$ & $-0.32^{* *}$ & $0.37^{* *}$ & $-0.39^{* *}$ & 0.04 & $-0.48^{* *}$ & $-0.56^{* *}$ & - \\
\hline $\begin{array}{l}\text { Physical HRQOL } \\
\text { (PCS) }\end{array}$ & -0.02 & $-0.13^{*}$ & $0.16^{* *}$ & $-0.12^{*}$ & -0.01 & 0.00 & -0.08 & -0.08 \\
\hline
\end{tabular}


Table 4.3. Hierarchical regression analyses to determine predictors of caregiver HRQOL.

\begin{tabular}{|c|c|c|c|c|c|c|}
\hline \multirow[b]{2}{*}{ Constructs } & \multicolumn{3}{|c|}{ Physical HRQOL } & \multicolumn{3}{|c|}{ Mental HRQOL } \\
\hline & B & SE B & $\boldsymbol{\beta}$ & B & SE B & $\boldsymbol{\beta}$ \\
\hline \multicolumn{7}{|l|}{ Step 1} \\
\hline $\begin{array}{l}\text { Care recipient } \\
\text { functional status }\end{array}$ & 0.16 & 0.09 & 0.15 & -0.19 & 0.10 & $-0.15^{\S}$ \\
\hline $\begin{array}{l}\text { Care recipient } \\
\text { behavioral problems }\end{array}$ & -0.28 & 0.09 & $-0.24^{* *}$ & -0.31 & 0.11 & $-0.22^{* *}$ \\
\hline $\mathrm{R}^{2}$ change & $0.03^{*}$ & & & $0.11^{* * *}$ & & \\
\hline \multicolumn{7}{|l|}{ Step 2} \\
\hline $\begin{array}{l}\text { Care recipient } \\
\text { functional status }\end{array}$ & 0.15 & 0.08 & 0.14 & -0.24 & 0.09 & $-0.19^{* *}$ \\
\hline $\begin{array}{l}\text { Care recipient } \\
\text { behavioral problems }\end{array}$ & -0.22 & 0.10 & $-0.19^{*}$ & -0.01 & 0.10 & -0.01 \\
\hline Social support & 0.87 & 0.44 & $0.14^{*}$ & 1.26 & 0.45 & $0.17^{* *}$ \\
\hline Adaptive coping & -0.10 & 0.07 & -0.09 & -0.01 & 0.08 & 0.00 \\
\hline Maladaptive coping & 0.19 & 0.12 & 0.10 & -0.78 & 0.12 & $-0.35^{* * *}$ \\
\hline Family functioning & -0.09 & 0.09 & -0.07 & -0.23 & 0.09 & $-0.14^{*}$ \\
\hline $\mathrm{R}^{2}$ change & 0.03 & & & $0.23^{* * *}$ & & \\
\hline \multicolumn{7}{|l|}{ Step 3} \\
\hline $\begin{array}{l}\text { Care recipient } \\
\text { functional status }\end{array}$ & 0.15 & 0.09 & 0.14 & -0.21 & 0.08 & $-0.16^{* *}$ \\
\hline $\begin{array}{l}\text { Care recipient } \\
\text { behavioral problems }\end{array}$ & -0.23 & 0.10 & $-0.19^{*}$ & 0.19 & 0.10 & 0.13 \\
\hline Social support & 0.87 & 0.44 & $0.14^{*}$ & 0.98 & 0.43 & $0.13^{*}$ \\
\hline Adaptive coping & -0.10 & 0.08 & -0.09 & 0.05 & 0.07 & 0.03 \\
\hline Maladaptive coping & 0.18 & 0.12 & 0.10 & -0.56 & 0.12 & $-0.25^{* * *}$ \\
\hline Family functioning & -0.09 & 0.09 & -0.08 & -0.12 & 0.09 & -0.08 \\
\hline Caregiver burden & 0.06 & 0.32 & 0.01 & -1.9 & 0.31 & $-0.37^{* * *}$ \\
\hline $\mathrm{R}^{2}$ change & 0.00 & & & $0.07^{* * *}$ & & \\
\hline Overall adjusted $\mathrm{R}^{2}$ & 0.03 & & & 0.39 & & \\
\hline
\end{tabular}


Table 4.4. Standardized regression estimates of total, direct, and indirect effects for the significant relationships observed between theoretical variables in the final model.

\begin{tabular}{|c|c|c|c|}
\hline Relationship & $\begin{array}{l}\text { Total } \\
\text { effect }\end{array}$ & $\begin{array}{c}\text { Direct } \\
\text { effect }\end{array}$ & $\begin{array}{c}\text { Indirec } \\
\text { effect }\end{array}$ \\
\hline Care recipient functional impairment to caregiver mental HRQOL & -0.16 & $-0.16^{*}$ & - \\
\hline Care recipient behavioral problem to family functioning & 0.27 & $0.27^{* * *}$ & - \\
\hline Care recipient behavioral problem to maladaptive coping & 0.24 & $0.15^{* *}$ & 0.09 \\
\hline Care recipient behavioral problem to social support & -0.36 & $-0.24^{* * *}$ & -0.12 \\
\hline Care recipient behavioral problem to caregiver burden & 0.56 & $0.41^{* * *}$ & 0.15 \\
\hline Care recipient behavioral problem to caregiver physical HRQOL & -0.24 & $-0.19^{*}$ & -0.05 \\
\hline Family functioning to adaptive coping & -0.26 & $-0.26^{* * *}$ & - \\
\hline Family functioning to maladaptive coping & 0.34 & $0.34^{* * *}$ & - \\
\hline Family functioning to social support & -0.47 & $-0.42^{* * *}$ & -0.05 \\
\hline Family functioning to caregiver burden & 0.29 & $0.18^{* * *}$ & 0.11 \\
\hline Adaptive coping to social support & 0.20 & $0.20^{* * *}$ & - \\
\hline Adaptive coping to burden & 0.07 & $0.09^{*}$ & -0.02 \\
\hline Maladaptive coping to caregiver burden & 0.27 & $0.27^{* * *}$ & - \\
\hline Maladaptive coping to caregiver mental HRQOL & -0.36 & $-0.26^{* * *}$ & -0.10 \\
\hline Social support to caregiver burden & -0.10 & $-0.10^{\S}$ & - \\
\hline Social support to caregiver mental HRQOL & 0.22 & $0.18^{* * *}$ & 0.04 \\
\hline Social support to caregiver physical HRQOL & 0.13 & $0.13^{*}$ & - \\
\hline Caregiver burden to caregiver mental HRQOL & -0.38 & $-0.38^{* * *}$ & - \\
\hline
\end{tabular}
${ }^{*} p<0.05 ;{ }^{* *} p<0.01 ;{ }^{* * *} p<0.001 ;{ }^{\S} p=0.053$; Estimates are reported for only those relationships that had a significant direct path 


\section{Bibliography}

Abbeduto, L., Seltzer, M. M., Shattuck, P., Krauss, M. W., Orsmond, G., \& Murphy, M. M. (2004). Psychological well-being and coping in mothers of youths with autism, Down syndrome, or fragile X syndrome. American Journal of Mental Retardation, 109, 237-254.

Allik, H., Larsson, J. O., \& Smedje, H. (2006). Health-related quality of life in parents of schoolage children with Asperger Syndrome or High-Functioning Autism. Health and Quality of Life Outcomes, 4, 1.

Altiere, M. J., \& von Kluge, S. (2009). Family Functioning and Coping Behaviors in Parents of Children with Autism. Journal of Child and Family Studies, 18, 83-92.

American Psychiatric Association. (2000). Diagnostic and statistical manual of mental disorders fourth edition text revision. Washington, D.C.: American Psychiatric Association.

Autism and Developmental Disabilities Monitoring Network Surveillance Year 2006 Principal Investigators; Centers for Disease Control and Prevention (CDC). (2009). Prevalence of autism spectrum disorders - Autism and Developmental Disabilities Monitoring Network, United States, 2006. Morbidity and Mortality Weekly Report Surveillance Summaries, 58, $1-20$.

Bebko, J. M., Konstantareas, M. M., \& Springer, J. (1987). Parent and professional evaluations of family stress associated with characteristics of autism. Journal of Autism and Developmental Disorders, 17, 565-576.

Bishop, S. L., Richler, J., Cain, A. C., \& Lord, C. (2007). Predictors of perceived negative impact in mothers of children with autism spectrum disorder. American Journal of Mental Retardation, 112, 450-461.

Bollen, K. A., \& Stine, R. A. (1992). Bootstrapping goodness-of-fit measures in structural equation modeling. In Testing structural equation models Edited by: Bollen KA, JS Long JS. Newbury Park: Sage.

Bouma, R., \& Schweitzer, R. (1990). The impact of chronic childhood illness on family stress: a comparison between autism and cystic fibrosis. Journal of Clinical Psychology, 46, $722-$ 730.

Boyd, A. (2002). Examining the relationship between stress and lack of social support in mothers of children with autism. Focus on Autism and Other Developmental Disabilities, 17, 208 215.

Brannan, A. M., Heflinger, C. A., \& Bickman, L. (1997). The Caregiver Strain Questionnaire: Measuring the impact on the family of living with a child with serious emotional problems. Journal of Emotional and Behavioral Disorders, 5, 212-222.

Bromley, J., Hare, D. J., Davison, K., \& Emerson, E. (2004). Mothers supporting children with autistic spectrum disorders: social support, mental health status and satisfaction with services. Autism, 8, 409-423.

Buhse, M. (2008). Assessment of caregiver burden in families of persons with multiple sclerosis. Journal of Neuroscience Nursing, 40, 25-31.

Byles, J., Byrne, C., \& Boyle, M. H. (1988). Ontario Child Health Study: Reliability and validity of the General Functioning Subscale of the McMaster Family Assessment Device. Family Process, 27, 97-104.

Byrne, B. M. (2001). Structural equation modeling with Amos: Basic concepts, applications, and programming. Mahwah, NJ: Erlbaum. 
Carver, C. S. (1997). You want to measure coping but your protocol's too long: Consider the Brief COPE. International Journal of Behavioral Medicine, 4, 92-100.

Chappell, N. L., \& Reid, R. C. (2002). Burden and well-being among caregivers: examining the distinction. Gerontologist, 42, 772-780.

Davis, N. O., \& Carter, A. S. (2008). Parenting stress in mothers and fathers of toddlers with autism spectrum disorders: associations with child characteristics. Journal of Autism and Developmental Disorders, 38, 1278-1291.

Donohue, P. K. (2002). Health-related quality of life of preterm children and their caregivers. Mental Retardation and Developmental Disabilities Research Reviews, 8, 293-297.

Dunn, M. E., Burbine, T., Bowers, C. A., \& Tantleff-Dunn, S. (2001). Moderators of stress in parents of children with autism. Community Mental Health Journal, 37, 39-52.

Epstein, N. B., Baldwin, L. M., \& Bishop, D. S. (1983). The McMaster Family Assessment Device. Journal of Marital and Family Therapy, 9, 171-180.

Felce, D. \& Perry, J. (1995). Quality of life: its definition and measurement. Research in Developmental Disabilities 16, 51-74.

Felce, D. \& Perry, J. (1996). Exploring current conceptions of quality of life: a model for people with and without disabilities. In: Quality of Life in Health Promotion and Rehabilitation Conceptual Approaches, Issues and Applications (eds R. Renwick, I. Brown \& M. Nagler), pp. 51-62. Sage Publications, London.

Folkman, S., \& Lazarus, R. S. (1980). An analysis of coping in a middle-aged community sample. Journal of Health and Social Behavior. 21, 219-239.

Goldsworthy, B., \& Knowles, S. (2008). Caregiving for Parkinson's disease patients: an exploration of a stress-appraisal model for quality of life and burden. The Journals of Gerontology Series B Psychological Sciences and Social Sciences, 63, 372-376.

Hastings, R. P, Kovshoff, H., Ward, N. J.,degli Espinosa, F., Brown, T., \& Remington, B. (2005a). Systems analysis of stress and positive perceptions in mothers and fathers of preschool children with autism. Journal of Autism and Developmental Disorders, 35, 635644.

Hastings, R. P., Kovshoff, H., Brown, T., Ward, N. J., Espinosa, F. D., \& Remington, B. (2005b). Coping strategies in mothers and fathers of preschool and school-age children with autism. Autism, 9, 377-391.

Herring, S., Gray, K., Taffe, J., Tonge, B., Sweeney, D., \& Einfeld, S. (2006). Behaviour and emotional problems in toddlers with pervasive developmental disorders and developmental delay: associations with parental mental health and family functioning. Journal of Intellectual Disability Research, 50, 874-882.

Hughes, S. L., Giobbie-Hurder, A., Weaver, F. M., Kubal, J. D., \& Henderson, W. (1999). Relationship between caregiver burden and health-related quality of life. Gerontologist, 39, 534-545.

Ievers, C. E., Brown, R. T., Lambert, R. G., Hsu, L., \& Eckman, J. R. (1998). Family functioning and social support in the adaptation of caregivers of children with sickle cell syndromes. Journal of Pediatric Psychology, 23, 377-388.

Kasari, C., \& Sigman, M. (1997). Linking parental perceptions to interactions in young children with autism. Journal of Autism and Developmental Disorders, 27, 39-57.

Kavanagh, D. T. (1992). Schizophrenia: an overview and practical handbook. London: Chapman and Hall. 
Kline, R. B. (2005). Principles and practice of structural equation modeling (2nd ed.). New York: Guilford.

Kogan, M. D., Blumberg, S. J., Schieve, L. A., Boyle, C. A., Perrin, J. M., Ghandour, R. M., et al. (2009). Prevalence of parent-reported diagnosis of autism spectrum disorder among children in the US, 2007. Pediatrics, 124, 1395-1403.

Leavy, R. L. (1983). Social support and psychological disorder: a review. Journal of Community Psychology, 11, 3-21.

MacCallum, R. C., \& Austin, J. T. (2000). Applications of structural equation modeling in psychological research. Annual Review of Psychology, 51, 201-226.

Magana, S., \& Smith, M. J. (2006). Psychological distress and well-being of Latina and nonLatina White mothers of youth and adults with an autism spectrum disorder: cultural attitudes towards coresidence status. American Journal of Orthopsychiatry, 76, 346-357.

Meyer, B. (2001). Coping with severe mental illness: Relations of the Brief COPE with symptoms, functioning, and well-being. Journal of Psychopathology and Behavioral Assessment, 23, 265-277.

Montgomery, R., Gonyea, J., \& Hooyman, N. (1985). Caregiving and the experience of subjective and objective burden. Family Relations, 34, 19-26.

Morimoto, T., Schreiner, A. S., \& Asano, H. (2003). Caregiver burden and health-related quality of life among Japanese stroke caregivers. Age and Ageing, 32, 218-223.

Mugno, D., Ruta, L., D'Arrigo, V. G., \& Mazzone, L. (2007). Impairment of quality of life in parents of children and adolescents with pervasive developmental disorder. Health and Quality of Life Outcomes, 5, 22.

Murphy, N. A., Christian, B., Caplin, D. A., \& Young, P. C. (2007). The health of caregivers for children with disabilities: caregiver perspectives. Child: Care, Health and Development, 33, 180-187.

Myers, B. J., Mackintosh, V. H., \& Goin-Kochel, R. P. (2009). "My greatest joy and my greatest heart ache:" Parents' own words on how having a child in the autism spectrum has affected their lives and their families' lives. Research in Autism Spectrum Disorders, 3, 670-684.

Orsmond, G. I., Seltzer, M. M., Greenberg, J. S., \& Krauss, M. W. (2006). Mother-child relationship quality among adolescents and adults with autism. American Journal of Mental Retardation, 111, 121-137.

Rao, P. A., \& Beidel, D. C. (2009). The impact of children with high-functioning autism on parental stress, sibling adjustment, and family functioning. Behavior Modification, 33, 437-51.

Sales, E. (2003). Family burden and quality of life. Quality of Life Research, 12, 33-41.

Saunders, M. M. (2009). Indicators of health-related quality of life in heart failure family caregivers. Journal of Community Health Nursing, 26, 173-182.

Schopler, E., Reichler, R. J., De Vellis, R. F., \& Dally, K. (1980). Toward objective classifications of childhood autism: Childhood Autism Rating Scale (CARS). Journal of Autism and Developmental Disorders, 10, 91-103.

Serrano-Aguilar, P. G, Lopez-Bastida, J., \& Yanes-Lopez, V. (2006). Impact on health-related quality of life and perceived burden of informal caregivers of individuals with Alzheimer's disease. Neuroepidemiology, 27, 136-142.

Sharpley, C., Bitsika, V., \& Efremidis, B. (1997). Influence of gender, parental health, and perceived expertise of assistance upon stress, anxiety, and depression among parents of children with autism. Journal of Intellectual and Developmental Disability, 22, 19-28. 
Shu, B. C. (2009). Quality of life of family caregivers of children with autism: The mother's perspective. Autism, 13, 81-91.

Smith, L. E., Seltzer, M. M., Tager-flusberg, H., Greenberg, J. S. \& Carter, A. S. (2008). A comparative analysis of well-being and coping among mothers of toddlers and mothers of adolescents with ASD. Journal of Autism and Developmental Disorders, 38, 876-889.

Stuart, M., \& McGrew, J. H. (2009). Caregiver burden after receiving a diagnosis of an autism spectrum disorder. Research in Autism Spectrum Disorder, 3, 86-97.

Tabachnick, B. G., \& Fidell, L. S. (2001). Using Multivariate Statistics. Allyn and Bacon, Boston, London.

Wade, S. L., Borawski, E. A., Taylor, H. G., Drotar, D., Yeates, K. O., \& Stancin, T. (2001). The relationship of caregiver coping to family outcomes during the initial year following pediatric traumatic injury. Journal of Consulting and Clinical Psychology, 69, 406-415.

Ware, J. E., Kosinski, M., Bjorner, J. B., Turner-Bowker, D. M., \& Maruish, M. E. (2007). User's manual for the $S F-36^{\circledR}$ health survey (version 2), $2^{\text {nd }}$ edition. Lincoln, RI: Quality Metric Incorporated.

Ware, J. E., Kosinski, M., \& Keller, S. D. (1996). A 12 -item short-form health survey: Construction of scales and preliminary tests of reliability and validity. Medical Care, 34, 220-233.

Ware, J. E., Kosinski, M., Turner-Bowker, D. M., \& Gandek, B. (2002). User's manual for the $S F-12 v 2$ Health survey (with a supplement documenting SF-12 health survey). Lincoln, RI: Quality Metric Incorporated.

WHOQOL Group. (1995). The World Health Organization quality of life assessment (WHOQOL): position paper from the World Health Organization. Social Science and Medicine, 41, 1403-1409

Taffe, J. R., Gray, K. M., Einfeld, S. L., Dekker, M. C., Koot, H. M., Emerson, E., et al. (2007). Short form of the developmental behaviour checklist. American Journal of Mental Retardation, 112, 31-39.

Testa, M. A., \& Simonson, D. C. (1996). Assesment of quality-of-life outcomes. New England Journal of Medicine, 334, 835-840.

Tobing, L. E., \& Glenwick, D. S. (2002). Relation of the childhood autism rating scale-parent version to diagnosis, stress, and age. Research in Developmental Disabilities, 23, 211-223.

Zimet, G. D., Dahlem, N. W., Zimet, S. G., \& Farley, G. K. (1988). The Multidimensional Scale of Perceived Social Support. Journal of Personality Assessment, 52, 30-41. 
CHAPTER 5 


\section{CHAPTER 5:}

\section{SUMMARY AND CONCLUSIONS}

\section{Study Summary}

As with the prevalence of autism, the number of parents who have to assume the role of a caregiver has increased. Commonly occurring symptoms among children with autism include problems with social interaction (social isolation, limited eye contact, self-absorption), perseveration (narrow range of interests, obsessive preoccupations, repetitive or self-stimulating behavior, distress with change), somatosensory disturbance (likeness for movement, atypical feeling, limited response to verbal inputs, mouthing or smelling objects, sleep disturbance, distress with large crowds), atypical developmental pattern (delay in motor development), mood disturbance (overreactivity, irritability, tantrums, aggression, self-aggression), and problems with attention and safety (selective attention, recklessness and limited safety awareness) (Mayes \& Calboun, 1999). Given these symptoms, it is fair to say that caring for a child with autism is a uniquely challenging experience for the parent. Over the years, several studies have documented the adverse impact of caring for a child with autism on different facets of caregivers' lives, whether it be their physical, mental, financial, or social health (Allik et al., 2006; Davis \& Carter 2008; Magana \& Smith, 2006; Montes \& Halterman, 2008; Mugno et al., 2007; Phelps et al., 2009; Shu, 2009; Smith et al., 2008; Stuart \& McGrew, 2009).

Using both qualitative and quantitative research tools, this study captures the caregiving experiences of primary caregivers of children with autism. The purpose of this study was to fill critical gaps in the autism caregiving literature. First, this study gathers qualitative data concerning the impact of caring on primary caregivers of children with autism. Most of the 
caregiving-related studies in autism have used quantitative methodology for data collection. A major limitation of studies using quantitative research techniques is that they do not capture the true feelings, experiences, and opinions of caregivers. Considering these limitations, researchers have highlighted the need for more qualitative work in autism caregiving (Phelps et al., 2009). Therefore, focus groups of primary caregivers of children with autism were conducted to determine their self-perspective on the impact of caring on their physical and mental health. Data related to caregivers' needs and concerns were also captured in the first study.

The second study tests the psychometric properties of a burden instrument for use in caregivers of children with autism. To date, there is no instrument developed specifically to ascertain burden experienced by caregivers of children with autism. The challenges faced by different population of caregivers vary, which necessitates the use of population-specific burden instrument. In the second study, validity and reliability of a burden instrument, originally developed for caregivers of children with serious emotional and behavioral disorders, is tested in caregivers of children with autism.

The third study in this project was conducted with the purpose of determining the HRQOL of caregivers of children with autism. Caregivers of children with autism have been reported to have high levels of anxiety and depression (Abbeduto et al., 2004; Smith et al. 2008). However, there is limited literature concerning the impact of caring on HRQOL of caregivers (Allik et al., 2006). In the third study, HRQOL scores of caregivers of children with autism are compared to age and gender adjusted norm-based scores for general US adult population. Further, the third study uses a theoretical model to identify caregiving situational factors that are related to HRQOL of primary caregivers of children with autism. Together, the three studies provide an in-depth view of the experiences and challenges faced by caregivers and contribute 
uniquely to the autism caregiving literature. The results from each of the three studies have been discussed in detail in the previous chapters. Key results from each of the three studies and their implications in autism caregiving have been discussed below.

In the first study, qualitative data was collected using focus groups of 19 primary caregivers of children with autism. Based on content analysis, data collected from the focus group discussions were classified into six themes: 1) impact on caregiver health;2) impact on relationships; 3) objective burden; 4) needs of caregiver; 5) caregiver coping mechanisms; and 6) caregiver concerns. Some of the results of this study have been well described in the literature, while others have received little attention. Caregivers reported significant negative mental and physical health impact of caring. The mental health consequences of caring for a child with autism have been extensively studied; however, the impact of caring on the physical health of carers has received little attention from researchers. Caregivers shared that the stress of caring has affected their physical health. Positive emotional consequences of caring were also reported, with caregivers reporting feelings of joy, pride, and enrichment over small behavioral or functional improvements in the child. Though the prevalence of autism has increased dramatically over the years, there is still wide spread ignorance about this disorder. Caregivers reported facing lack of understanding on the part of their extended family members and the general public. With diminished social opportunities, it was not surprising to hear from caregivers that they felt isolated from the rest of the world. Caregivers reported that every aspect of their life is affected by autism, including their financial health, career, personal hygiene, and immediate environment. Lack of insurance coverage for autism treatment places significant financial burden on caregivers. The impact of autism on the different facets of caregivers' lives is further compounded by a lack of adequate respite care and support from services providers. 
With all their daily challenges, caregivers reported developing coping mechanisms such as work, faith in God, and exercise that enables them to maintain normality, and helps them deal with autism-related issues. With all the research that has been done in the field of autism, a number of questions still remain unanswered. One such question is regarding the future of children with autism. Lack of safe group homes leaves little option for caregivers but to care for these children as they grow old. The first study highlights the critical need for a collaborative effort on the part of policy makers, health care professionals, schools, and society in order to support caregivers of children with autism.

The second study assesses the psychometric soundness of a burden instrument in caregivers of children with autism. It is now well known that there is a substantial burden associated with caring for a child with autism. However, for interventions aimed at helping caregivers of children with autism to be successful, it is necessary that they be preceded by a reliable and valid assessment of the true extent of burden experienced by this population. To date, there is not burden instrument designed specifically for caregivers of children with autism. As a result, to assess burden among caregivers in autism (Orsmond et al., 2006; Stuart \& McGrew, 2009), researchers tend to use instruments that were originally designed for a different caregiver population. For different caregiver groups, caregiving holds different meaning, and it is essential that researchers account for these differences in their assessment (John et al., 2001). The burden experienced by caregivers of children with mental, emotional, or behavioral problems is likely to be different than for caregivers of adults (Brannan et al., 1997). It is therefore essential that researchers use instruments assess the unique experiences of caregivers of children with autism. The factorial validity, convergent validity, discriminant validity, internal consistency reliability, and floor and ceiling effects of CGSQ in caregivers of children with 
autism were tested in the second study. The CGSQ was constructed for caregivers of children with serious behavioral and emotional disorders (Brannan et al., 1997). The study revealed CGSQ to have adequate factorial, convergent, and discriminant validity in autism. Consistent with the original report (Brannan et al., 1997), factor analysis revealed three dimensions of the CGSQ in autism: objective strain, subjective internalized strain, and subjective externalized strain. The three domains correlated well with other similar caregiving constructs including caregiver mental HRQOL, social support, family functioning, and coping. Low correlation of the three domains with caregiver physical HRQOL indicated that the CGSQ has adequate discriminant validity. The internal consistency of the overall instrument and the three dimensions was also good. The results of this study suggest that the CGSQ is an appropriate instrument to determine burden experienced by caregivers of children with autism.

The third study compares the HRQOL of caregivers of children with autism with US population norms and identifies the factors that impact HRQOL using a theoretical model. Using the SF-12v2, which is a well-validated measure for which US norms are available, the HRQOL of caregivers was assessed. After adjusting for age and gender, the HRQOL scores of caregivers were determined to be lower than norm-based scores for US population in both the physical and mental health domains. The impact of caring for a child with autism could be gauged from the fact that the mental HRQOL score of caregivers was similar to US norm for individuals with depression. Previous studies have documented the occurrence of depression among mothers of children with autism (Abbeduto et al., 2004; Smith et al., 2008). This study adds to the literature by documenting the impact of caregiving on the physical health status of caregivers. A majority of caregiving literature in autism has focused on studying the mental health effects on caregivers, with limited research done on the physical health effects of caring. 
Allik et al. (2006) found the physical HRQOL of mothers of children with autism to be lower than mothers of children with typical development. The third manuscript highlights the significant impact caring has not only on the mental health but also on the physical health of caregivers.

Further, the study revealed the factors that impact caregiver HRQOL. Relationship between care recipient level of functional impairment and extent of behavioral problems, family functioning, coping mechanisms, social support, caregiver burden, and HRQOL were studied using a theoretical model. The model worked well in explaining variance in caregiver mental HRQOL (39\%), but not so for physical HRQOL (3\%). Mental HRQOL was found to be directly related with care recipient level of functional impairment, social support, maladaptive coping, and caregiver burden. The direction of these relationships were consistent with study hypothesis, with lower functional impairment, greater social support, lower use of maladaptive coping, and lower burden associated with higher levels of mental HRQOL. However, care recipient behavioral problems and social support were the only significant predictors of caregiver physical HRQOL, with lower behavioral problems and greater social support associated with higher levels of physical HRQOL. The protective effect of social support and the damaging effect of unhealthy family functioning necessitates that components addressing these factors be included in interventions aimed at helping caregivers. Previous studied have documented social support to be an important factor affecting caregiving outcomes in autism (Boyd, 2002). In our study, social support was shown to mediate the effect of primary stressors on caregiver burden and HRQOL. As a construct, family functioning had an effect not only on caregiver burden and HRQOL, but also on caregiver coping mechanisms and social support. When caring for a family member with a chronic disorder like autism, it is important for the family system to work 
cohesively and efficiently. As found in the first study, caregivers perceive a lack of understanding among the extended family members and the general public. This makes it all the more important for members in the immediate family to work together and assist the primary caregiver in dealing with the issues presented by autism. Lack of assistance from family could drive caregivers to use poor coping strategies that further compound the burden they experience resulting in poor outcomes. The way caregivers deal with the demands placed on them plays an important role in determining the caregiving outcomes. The use of negative coping strategies such as self-blame, denial, and venting, has negative consequences for caregiver's health. Given its chronic nature, there is no escape from autism for caregivers. Therefore, it is essential that caregivers build positive coping skills so as to be able to deal with their daily demands in an effective way.

To summarize, this project provides an in-depth view of the profound impact autism has on different aspects of a caregiver's life. The qualitative data collected from focus group of caregivers revealed the positive and negative emotional consequences of caring, and the impact of caring on their physical health. Caregivers reported an urgent need for respite services and assistance from service providers. They felt concerned for the future of their child. Similar to results from the focus groups, quantitative data collected using survey also highlighted the negative mental and physical health impact of caring on caregivers. The HRQOL of caregivers of children with autism was found to be lower than that of the general US population. Caregivng situational factors including care recipient level of functioning and extent of behavioral problems, family functioning, coping strategies, social support, and caregiver perceived level of burden were found to be related to caregiver HRQOL. 


\section{Significance of the Study}

Significance of study I: A qualitative study of the experiences of primary caregivers of children with autism spectrum disorders

Understanding the impact of autism on primary caregivers from their own perspective is essential in the management of issues being faced by families of children with autism. For intervention strategies aimed at assisting caregivers to be successful, it is critical that they attend to the needs and concerns of this population. The study highlights caregivers need for respite care, assistance from service providers, support groups, and insurance reform. With this knowledge, policy makers could work towards putting mechanisms in place that attend to caregiver needs. Issues concerning health insurance reform are being widely debated these days. This study reveals the urgent need for insurance coverage of autism-related services. Caregivers concern for their child's future highlights the importance of establishing safe group homes for adults with autism.

Significance of study II: Psychometric properties of the Caregiver Strain Questionnaire (CGSQ) among caregivers of children with autism

Autism places considerable emotional, financial, and social burden on caregivers. In order to assist caregivers, it is first necessary that there be a reliable and valid assessment of the burden that they experience. The caregiving experiences differ among different groups of caregivers, which make it necessary to use instruments that capture the unique experiences of the population under investigation. To date, there is no burden instrument developed specifically for caregivers of children with autism. This study provides information concerning the psychometric properties of a burden instrument (CGSQ) in this population. This would be helpful in making a reliable 
and valid measurement of caregiver burden in autism. Interventions could gauge their success based on improvements in caregiver burden score.

Significance of study III: Assessment of health-related quality of life among primary caregivers of children with autism spectrum disorders

An assessment of HRQOL provides a clear picture of the true health impact of caring on caregivers. By comparing the HRQOL scores of caregivers to the general US population norms; this study highlights the significant health effect of autism on caregivers. Caregiving situational factors that impact caregiver burden and HRQOL are also identified. Based on the level of contribution of each variable on caregiver burden and HRQOL, interventions could be developed and tailored to reduce the influence of those variables. The result suggests an important effect of family functioning on caregiver burden and HRQOL, which necessitate the implementation of family focused interventions, so as to improve dynamics in families of children with autism. The results also suggest the importance of support groups, which could enable caregivers to share their feelings with other families facing similar issues. It is also important to know that the use of poor coping strategies negatively affects burden and well-being among caregivers. Therefore, it is important to target interventions towards instilling good coping strategies in caregivers. The results of study III are also significant from a policy perspective. With limited availability of healthcare dollars, it is important these days to make rational resource allocation decisions. Having realized the importance of family functioning, social support, and coping strategies in predicting caregiver burden and HRQOL, it is necessary that resources be invested on services that incorporate these constructs. 


\section{Study Limitations}

For each of the three studies, their limitations have been discussed in detail previously. However, a general summary of the overall limitations of the study has been provided in this section. Participation in this study (focus groups and survey-based) was restricted to families of children with autism that were less than or equal to 18 years of age. The experiences of caregivers of adults with autism were not captured in this study. Also, we restricted our sample to those families who had no more than one child with autism. The impact of caring for multiple children with autism is likely to be different than caring for one child with the disorder.

Participants in the study were families registered with the WV ATC. We sought participation in the study from primary caregivers. Not surprisingly, most of the participants in the study turned out to be females. Thus, the study does not provide insight into caregiving experiences for male caregivers. Results from study one were based on focus groups of 19 primary caregivers of children with autism. For the survey-phase, the response rate was $35 \%$. Given all these factors, the results of the study are likely to have limited generalizability.

Though well-validated measures were used to capture the relevant study constructs in the survey-phase, social desirability and recall bias could have affected the study results. HRQOL, which was a key construct in study three, can be influenced by life situations that are not related to caring. It was not possible to tease out the unique effect of caring for a child with autism on caregiver HRQOL. Given the cross-sectional design of study three, causality among variables in study three cannot be established.

\section{Directions for Future Research}


Little attention has been paid to caregiving experiences among caregivers of adults with autism. Similar to this study, future studies could use both qualitative and quantitative tools to capture the impact of caring on caregivers of adults with autism.

Given the genetic predisposition of autism, several families have more than one child with autism. Determining the experiences, needs, and concerns of caregivers who provide care to more than one child with autism could be useful from a public policy perspective.

Study two tests the psychometric properties of the CGSQ. However, given the crosssectional design of the study, it was not possible to determine its test-retest reliability and predictive validity. Future studies could see whether the scores on CGSQ are stable over a period of time, and also if CGSQ is able to predict "at-risk" caregivers who suffer from poor outcomes.

For the most part, females play the role of a primary caregiver in families of children with autism. However, there are likely to be several single parent households where males serve the role of primary caregiver of a child with autism. It is important to know whether the HRQOL of male primary caregivers is lower than their counterparts in the general population. Also, the factors that affect HRQOL of male primary caregivers are likely to be different than those that affect HRQOL of female caregivers. Thus, future researchers could validate HRQOL model separately in both male and female caregivers.

Investigators could test the relationships between primary stressors (care recipient level of functional impairment and extent of behavioral problems), mediators (family functioning, social support, and coping mechanisms), secondary appraisal (burden), and outcome (HRQOL) in a longitudinal setting. This would help establish causality between these caregiving situational factors and caregiver HRQOL. 


\section{Bibliography}

Abbeduto, L., Seltzer, M. M., Shattuck, P., Krauss, M. W., Orsmond, G., \& Murphy, M. M. (2004). Psychological well-being and coping in mothers of youths with autism, Down syndrome, or fragile X syndrome. American Journal of Mental Retardation, 109, 237-254.

Allik, H., Larsson, J. O., \& Smedje, H. (2006). Health-related quality of life in parents of schoolage children with Asperger Syndrome or High-Functioning Autism. Health and Quality of Life Outcomes, 4, 1.

Boyd, A. (2002). Examining the relationship between stress and lack of social support in mothers of children with autism. Focus on Autism and Other Developmental Disabilities, 17, 208215.

Brannan, A. M., Heflinger, C. A. \& Bickman, L. (1997). The Caregiver Strain Questionnaire: Measuring the impact on the family of living with a child with serious emotional problems', Journal of Emotional and Behavioral Disorders, 5, 212-222.

Davis, N. O., \& Carter, A. S. (2008). Parenting stress in mothers and fathers of toddlers with autism spectrum disorders: associations with child characteristics. Journal of Autism and Developmental Disorders, 38, 1278-1291.

John, R., Hennessy, C.H., Dyeson, T.B. \& Garrett, M.D. (2001). Toward the conceptualization and measurement of caregiver burden among Pueblo Indian family caregivers. Gerontologist, 41, 210-219.

Magana, S., \& Smith, M. J. (2006). Psychological distress and well-being of Latina and nonLatina White mothers of youth and adults with an autism spectrum disorder: cultural attitudes towards coresidence status. American Journal of Orthopsychiatry, 76, 346-357.

Mayes, S. D., \& Calhoun, S. L. (1999). Symptoms of autism in young children and correspondence with the DSM. Infants and Young Children, 12, 90-97.

Montes, G., \& Halterman, J. S. (2008). Association of childhood autism spectrum disorders and loss of family income. Pediatrics, 121, e821-826.

Mugno, D., Ruta, L., D'Arrigo, V. G., \& Mazzone, L. (2007). Impairment of quality of life in parents of children and adolescents with pervasive developmental disorder. Health and Quality of Life Outcomes, 5, 22.

Orsmond, G. I., Seltzer, M. M., Greenberg, J. S., \& Krauss, M. W. (2006). Mother-child relationship quality among adolescents and adults with autism. American Journal of Mental Retardation, 111, 121-137.

Phelps, K. W., Hodgson, J. L., McCammon, S. L., \& Lamson, A. L. (2009). Caring for an individual with autism disorder: a qualitative analysis. Journal of Intellectual and Developmental Disability, 34, 27-35.

Shu, B. C. (2009). Quality of life of family caregivers of children with autism: The mother's perspective. Autism, 13, 81-91.

Smith, L. E., Seltzer, M. M., Tager-flusberg, H., Greenberg, J. S. \& Carter, A. S. (2008). A comparative analysis of well-being and coping among mothers of toddlers and mothers of adolescents with ASD. Journal of Autism and Developmental Disorders, 38, 876-889.

Stuart, M. \& McGrew, J. H. (2009). Caregiver burden after receiving a diagnosis of an autism spectrum disorder. Research in Autism Spectrum Disorder, 3, 86-97. 


\section{APPENDIX}

(IRB approval for all documents on file) 


\section{Appendix A: Script for Telephonic Invitation to Focus Groups}

[Read] Hello, my name is and I am calling from the West Virginia Autism Training Center. Could I please speak with the primary caregiver i.e., the individual in your family who has the primary responsibility of providing daily care to the child with autism? We would like to see if the primary caregiver would be willing to participate in a focus group discussion meeting.

[To be read to the primary caregiver]

Researchers from the West Virginia University School of Pharmacy are conducting a research study in collaboration with the West Virginia Autism Training Center to determine the experiences of primary caregivers of children with autism, and the impact of caregiving. This research study is part of a doctoral (Ph.D.) research project, and has been acknowledged by the Institutional Review Boards of West Virginia University and Marshall University.

The focus group is a discussion meeting that will involve about 15 caregivers and will last about 2 hours. Participants will be asked about their experiences of caring for a child with autism, in addition to the impact of caregiving on their physical and emotional well-being.

Participation in this study is completely voluntary, and refusal to participate will not affect in any way your family's relationship with the West Virginia Autism Training Center. All information collected from the focus group discussions will be kept confidential, and you do not have to answer any question during the discussion which you do not wish to answer. The information discussed during this focus group will be analyzed as a whole, and no names will be used in the analysis of the discussion content. If you agree to participate, you will receive a study and contact information from the investigators prior to the focus group meeting.

Focus groups will be conducted in the $-2^{\text {nd }}$ week of September [2009] at the West Virginia Autism Training Center main office at Fairmont (to be mentioned to those residing around Fairmont $) / 3^{\text {rd }}$ week of September [2009] at the West Virginia Autism Training Center main office at Marshall University, Huntington Campus (to be mentioned to those residing around Huntington). Upon completion of the focus group discussion, we will present you with a $\$ 25$ Wal-Mart gift card as a token of our appreciation for your time and participation. Would you be interested in participating in our focus group study?

YES | NO

If NO, ....That's all right! We appreciate your taking the time to talk to us. In case you change your mind, please let us know at (304) 696-2332 at your earliest convenience so we can schedule you [END CALL].

If YES, .... 


\section{FOR PARTICIPANTS AROUND FAIRMONT}

Which of the following dates and times are you (primary caregiver) available during the week of September $7^{\text {th }}$ to participate in our focus group?

\section{(CHECK MARK AVAILABLE DATES AND TIMES BASED ON OPTIONS BELOW)}

\begin{tabular}{|l|l|l|l|l|l|l|l|}
\hline & $\begin{array}{l}\text { Monday } \\
\text { (Sep. } \\
07)\end{array}$ & $\begin{array}{l}\text { Tuesday } \\
\text { (Sep. } \\
\text { 08) }\end{array}$ & $\begin{array}{l}\text { Wednesda } \\
\text { (Sep. 09) }\end{array}$ & $\begin{array}{l}\text { Thursday } \\
\text { (Sep. 10) }\end{array}$ & $\begin{array}{l}\text { Friday } \\
\text { (Sep. } \\
\text { (S) }\end{array}$ & $\begin{array}{l}\text { Saturday } \\
\text { (Sep. } \\
12)\end{array}$ & $\begin{array}{l}\text { Sunday } \\
\text { (Sep. } \\
13)\end{array}$ \\
\hline $\begin{array}{l}10: 00 \mathrm{am} \\
-12: 30\end{array}$ & & & & & & & \\
$\mathrm{pm}$ & & & & & & \\
\hline $\begin{array}{l}12: 30 \mathrm{pm} \\
-3: 00 \mathrm{pm}\end{array}$ & & & & & & & \\
\hline $\begin{array}{l}3: 00 \mathrm{pm}- \\
5: 30 \mathrm{pm}\end{array}$ & & & & & & & \\
\hline $5: 30 \mathrm{pm}-$ & & & & & & & \\
$8: 00 \mathrm{pm}$ & & & & & & & \\
\hline
\end{tabular}

\section{FOR PARTICIPANTS AROUND HUNTINGTON}

Which of the following dates and times are you (primary caregiver) available during the week of September $14^{\text {th }}$ to participate in our focus group?

(CHECK MARK AVAILABLE DATES AND TIMES BASED ON OPTIONS BELOW)

\begin{tabular}{|l|l|l|l|l|l|l|l|}
\hline & $\begin{array}{l}\text { Monday } \\
\text { (Sep. } \\
14)\end{array}$ & $\begin{array}{l}\text { Tuesday } \\
\text { (Sep. } \\
\text { 15) }\end{array}$ & $\begin{array}{l}\text { Wednesda } \\
\text { (Sep. 16) }\end{array}$ & $\begin{array}{l}\text { Thursday } \\
\text { (Sep. 17) }\end{array}$ & $\begin{array}{l}\text { Friday } \\
\text { (Sep. } \\
\text { 18) }\end{array}$ & $\begin{array}{l}\text { Saturday } \\
\text { (Sep. } \\
19)\end{array}$ & $\begin{array}{l}\text { Sunday } \\
\text { (Sep. } \\
\text { 20) }\end{array}$ \\
\hline $\begin{array}{l}10: 00 \mathrm{am} \\
-12: 30 \\
\mathrm{pm}\end{array}$ & & & & & & & \\
\hline $\begin{array}{l}12: 30 \mathrm{pm} \\
-3: 00 \mathrm{pm}\end{array}$ & & & & & & & \\
\hline $\begin{array}{l}3: 00 \mathrm{pm}- \\
5: 30 \mathrm{pm}\end{array}$ & & & & & & & \\
\hline $5: 30 \mathrm{pm}-$ & & & & & & & \\
$8: 00 \mathrm{pm}$ & & & & & & & \\
\hline
\end{tabular}

Thank you for your interest in participating. We will contact you when a date and time has been identified that is convenient to most of the careregivers that we are inviting. It is possible that the date and time we select may not be convenient to you. We apologize if that happens and you cannot participate.

I would like to confirm your contact information (CONFIRM NAME AND ADDRESS).

Thank you and we will be contacting you with a scheduled focus group date and time in the next few weeks. 
[Investigator contact information to be given out only on the request of the participants and will not be verbally communicated otherwise]

Investigators Contact Information:

Barbara Becker-Cottrill, Ed.D. (Co-investigator)

Executive Director

West Virginia Autism Training Center

Marshall University

One John Marshall Drive

Huntington, West Virginia 25755

Phone: (304) 696-2332

Rahul Khanna, MBA, MS (Co-Investigator)

West Virginia University, School of Pharmacy

Department of Pharmaceutical Systems and Policy

P.O. Box 9510

Morgantown WV 26506-9510

Phone: (304) 293-7674

S. Suresh Madhavan, Ph.D., MBA (Principal Investigator)

West Virginia University, School of Pharmacy

Department of Pharmaceutical Systems and Policy

P.O. Box 9510

Morgantown WV 26506-9510

Phone: (304) 293-1652 


\section{Appendix B: Follow-up Cover Letter for Focus Groups}

Dear

Taking care of a child with an autism spectrum disorder is a life altering experience for caregivers. Researchers at West Virginia University School of Pharmacy have collaborated with the West Virginia Autism Training Center to conduct a research study to determine the impact of caring for a child with autism on primary caregivers. This research study is part of a doctoral (Ph.D.) research project. The study has been acknowledged by the Institutional Review Boards of West Virginia University and Marshall University.

Based on your willingness to participate in our focus group discussion meeting, we have scheduled you for XXX (day and date) from XXX (time) to XXX (time) to be held at (for participants around Huntington) the West Virginia Autism Training Center, Marshall University, One John Marshall Drive, Huntington, West Virginia 25755/ (for participants around Fairmont) Autism Training Center - North, Rt. 250 Fairmont, WV 26554. You will meet a designated person at the entrance of the Autism Training Center and he/she will guide you to the room.

In case you need to cancel your appointment - please let us know at (304) 696-2332 at your earliest convenience.

Participation in this study is completely voluntary, and refusal to participate will not affect in any way your family's relationship and/or any service that you receive from the West Virginia Autism Training Center. All information collected from the focus group discussions will be kept confidential, and you do not have to answer any question which you do not wish to answer. The information discussed during this focus group will be analyzed as a whole, and no names will be used in the analysis of the discussion content. We will not ask any information that will reveal your identity as a participant. However, it is possible that focus group participants may talk to each other or others about what will be discussed during the focus group. We cannot bear any responsibility for that if it happens. You will receive a study and contact information from the investigators prior to the focus group meeting.

The focus group discussion will take about 2 hours. Upon completion of the session, we will present you with a \$25 Wal-Mart gift card as a token of our appreciation for your time and participation.

If you have any questions or need more information, please do not hesitate to contact, Dr. Barbara Becker-Cottrill at (304) 696-2332, Rahul Khanna at (304) 293-7674, or Dr. Suresh Madhavan at (304) 293-1652.

Sincerely,

Barbara Becker-Cottrill, Ed.D. Rahul Khanna, MS Executive Director, WV ATC Ph.D. Candidate
S. Suresh Madhavan, MBA, Ph.D. Professor 


\section{Appendix C: Information Sheet for Focus Groups}

Dear Participant,

This letter is a request for you to participate in a focus group discussion as part of a research study to determine the impact of caring for a child with autism on primary caregivers. This study is being conducted by researchers from the West Virginia University School of Pharmacy in association with the West Virginia Autism Training Center. This research study is a part of a doctoral (Ph.D.) research project. Your participation in this project is greatly appreciated and it will take about 2-hours to complete the focus group discussion. The study has been acknowledged by the Institutional Review Boards of West Virginia University and Marshall University.

Participation in this study is completely voluntary, and refusal to participate will not affect in any way your family's relationship and/or any service that you receive from the West Virginia Autism Training Center. Your involvement in this project will kept as confidential as legally possible. The focus group discussion will be audio-recorded so that the data can be transcribed; however, responses will be kept confidential and individual names will not be associated with any reported data. We will not ask any information that will reveal your identity as a participant. It is possible that focus group participants may talk to each other or others about what will be discussed at this meeting. We cannot bear any responsibility for that if it happens. Audio tapes will be kept in a locked file cabinet in a secured office location for up to five years following study completion. All data on tapes will be deleted and tapes will be destroyed and disposed of in locked secured containers once the study is completed. Before the focus group discussion, you will be requested to complete a questionnaire with some basic information. You must be 18 years or older to participate. You may refuse to answer any question, or skip any question that you do not wish to answer. You may discontinue participation at any time.

We hope that you will participate in this research project, as it will enhance our understanding of needs associated with this growing population of caregivers of children with autism. Thank you very much for your time. Should you have any questions about this letter or the research project, please feel free to contact Dr. Barbara Becker-Cottrill at (304) 696-2332, Rahul Khanna at (304) 293-7674, or Dr. Suresh Madhavan at (304) 293-1652.

Thank you for your time and help with this project.

Sincerely,

Barbara Becker-Cottrill, Ed.D. Rahul Khanna, MS Executive Director, WV ATC
Ph.D. Candidate
S. Suresh Madhavan, MBA, Ph.D. Professor 


\section{Appendix D: Socio-demographic Questionnaire for Focus Groups}

Participation in this study is completely voluntary, and refusal to participate will not affect in any way your family's relationship and/or any service that you receive from the West Virginia Autism Training Center. You may refuse to answer any question, or skip any question that you do not wish to answer. You may discontinue participation at any time. The information provided by you will be kept as confidential as legally possible.

INSTRUCTIONS: This questionnaire gathers basic information about you and the child with autism to whom you provide care. Please check-mark $(\sqrt{ })$ your response.

1. Are you $\square$ Male $\square$ Female 2. Your Age?

3. Your ethnicity? $\square$ White $\square$ Black $\square$ Hispanic $\square$ Other (please specify)

4. What is your current marital status?

$\square \begin{aligned} & \text { Never Married } \square \text { Married } \square \text { Divorced/Separated } \square \text { Widowed } \\ & \text { Not married, living with partner }\end{aligned}$

5. What is the highest level of education that you have completed?

$\square$ Less than high school $\square$ Graduated high school

$\square$ Attended college/technical school $\square$ College graduate

6. Which of the following describes your main occupation?

$\square$ Employed/Self-employed full-time $\square$ Employed part-time $\square$ Seeking work $\square$ Student $\square$ Retired $\square$ Homemaker $\square$ Other (please specify)

7. What is your annual household income from all sources?
$\square<\$ 25,000$
$\$ 25,000-\$ 49,999$
$\square 50,000-\$ 99,999$
$\square \geq \$ 100,000$

8. What is your relationship to the child with autism to whom you provide care?

$\square$ Mother $\square$ Father $\square$ Other (please specify)

9. What is the gender of the child with autism to whom you provide care? $\square$ Male $\square$ Female

10. Please indicate the age group of the child with autism to whom you provide care?

$\square$ Less than 5 years $\square 5$ years-Less than 10 years $\square 10$ years-Less than 15 years
$\square 15$ years -18 years

11. What is the primary diagnosis of the child with autism to whom you provide care?

$\square$ Classic autism/autistic disorder $\square$ Asperger's syndrome

$\square$ Pervasive developmental disorder not otherwise specified (PDD-NOS) 
12. Does the child with autism to whom you provide care have any kind of health care coverage, including health insurance, prepaid plans such as HMOs, or government plans such as Medicaid?

$\square$ Yes

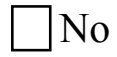

If YES, then what type of health care coverage does the child with autism have:

13. Do you have any out-of-pocket costs for the use of autism-related services for the child with autism?

$\square$ Yes $\quad \square$ No

If YES, then how often are these costs reasonable?

Never
Always Sometimes $\square$ Usually




\section{Appendix E: Addresses of Counseling Facilities if Emotional Distress Experienced from Focus Group Discussion}

Contact information for facilities in the event you experience any emotional discomfort with the focus group discussion meeting:

Morgantown Pastoral

Counseling

1062 Maple Dr \#1

Morgantown, WV 26505

Phone - (304)599-5751

Valley Healthcare System 301 Scott Ave

Morgantown, WV 26508

Phone - (304)296-1731
Fremouw Psychological Associates 1224 Pineview Dr \# B Morgantown, WV 26505

Phone - (304)598-2300
Chestnut Ridge Counseling Services

Suite 116, 100 New Salem

Road

Uniontown, PA 15401

Phone - (724)437-0729

Chestnut Ridge Hospital of

Morgantown WV

930 Chestnut Ridge Rd

Morgantown, WV 26505

Phone - (304)598-6400 


\section{Appendix F: Discussion Guide for Focus Groups}

Total focus group time required (approximate): 2 hours

Moderator (script):

Dear Participants: First, I wish to thank you all for taking the time off from your busy schedules to come here and participate in this research discussion. For that we are very grateful to you. Participation in this study is completely voluntary, and refusal to participate will not affect in any way your family's relationship and/or any service that you receive from the West Virginia Autism Training Center. The study has been acknowledged by the Institutional Review Boards of West Virginia University and Marshall University.

Your involvement in this project will kept as confidential as legally possible. The focus group discussion will be audio-recorded so that the data can be transcribed; however, responses will be kept confidential and individual names will not be associated with any reported data. We will not ask any information that will reveal your identity as a participant. It is possible that focus group participants may talk to each other or others about what will be discussed at this meeting. We cannot bear any responsibility for that if it happens. You may refuse to answer any question, or skip any question that you do not wish to answer. You may discontinue participation at any time.

This research is being conducted to assess the impact of caring for children with autism on the different aspects of a caregiver's life. The results of this study will improve our understanding of the health-related needs of caregivers of children with autism.

This [the moderator will at this time provide participants a handout of list of referral services] is the contact information for facilities in the event you experience any emotional discomfort with this focus group discussion meeting.

The discussion is informal, so there is no need for you to wait for us to call on you to respond. Before I begin with the discussion, I will like you to complete a questionnaire. This should take you less than 5 minutes.

(After participants hand in the questionnaire, the moderator will initiate the discussion using the questions outlined below.)

1. What are all your responsibilities in your family?

2. What are your caregiving responsibilities towards the child with autism in your family?

3. How do you feel about your caregiving responsibilities towards the child with autism?

4. How would you describe your current physical health?

5. How does being a caregiver for a child with autism affect your physical health?

6. How would you describe your current emotional health?

7. How does being a caregiver for a child with autism affect your emotional health?

8. Have you heard of the term 'burden'? What does 'burden' mean to you?

9. Do you experience caregiver 'burden'? How often?

10. What do you do to take care of yourself during periods of high demands and high stress? 
11. How has caregiving affected your family functioning? (e.g., your relationship with your spouse/significant other, your relationship with your other children)

12. Do you feel you have adequate support/help from your spouse/other family/extended family/friends/neighbors in your caregiving responsibilities?

13. What types of assistance (from any source) would be most helpful to you in your caregiving role?

14. As a primary caregiver, what major concerns do you have about caring for a child with autism?

Other questions may be asked as a follow-up to responses received from participants or if a new line of inquiry is necessary. 


\section{Appendix G: Acknowledgment Statement for Focus Groups}

\section{ACKNOWLEDGMENT STATEMENT}

Dear Principal Investigator,

I acknowledge the receipt of a gift card in the amount of $\$ 25$ for my participation in the focus group discussion meeting for the study titled "Burden of Care and Health-Related Quality of Life Among Caregivers of Children with Autism Spectrum Disorder." I also understand that it is my responsibility to verify if any action regarding the taxation of said gift card is needed.

Thank you.

Name

Signature

Date

Wal-Mart gift card number: 
Appendix H: Questionnaire Packet for Survey 


\section{Appendix H1: Survey Cover Letter from the West Virginia Autism Training Center}

Dear Madam/Sir,

The West Virginia Autism Training Center (WV ATC) is collaborating with researchers from the West Virginia University School of Pharmacy (WVU SOP) to conduct a research study to determine the burden and health-related quality of life among caregivers of children with autism. This research study is part of a doctoral (Ph.D.) research project, and has been reviewed by the Institutional Review Boards of West Virginia University and Marshall University to protect the interests of human subjects.

We at the WV ATC have not shared your name, contact, or other information with the WVU SOP. Participation in this study is completely voluntary, and refusal to participate will not affect in any way your family's relationship and/or any service that you receive from the West Virginia Autism Training Center.

Included in this packet is a letter from the WVU SOP that further describes the study purpose and other relevant information concerning study participation, a yellow-colored survey, a acknowledgement statement, and a business reply envelope. The acknowledgement statement has an identification number for mailing purposes and gift card distribution only. This number does not connect your name to your survey answers. Once your completed survey and acknowledgment statement are received, the acknowledgment statement will be used to send you a \$5 Wal-Mart gift card as a token of our appreciation for completing the survey. The deidentified survey will be sent to the WVU SOP for research purposes.

We hope you will participate in this important research project. If you have any questions, please do not hesitate to contact me at (304) 696-2332.

Sincerely,

Barbara Becker-Cottrill, Ed.D.

Executive Director

West Virginia Autism Training Center

Marshall University

One John Marshall Drive

Huntington, West Virginia 25755 


\section{Appendix H2: Survey Cover Letter for First Mailing}

\section{Dear Madam/Sir,}

Taking care of a child with an autism spectrum disorder is a life altering experience for caregivers. Researchers at the West Virginia University School of Pharmacy have collaborated with the West Virginia Autism Training Center (WV ATC) to conduct a research study to determine the impact of caring for a child with autism on primary caregivers. Enclosed with this letter is a yellow-colored survey. The survey will collect information about the primary caregiver's experiences while taking care of a child with autism. This research study is part of a doctoral (Ph.D.) research project. The study has been acknowledged by the Institutional Review Boards of West Virginia University and Marshall University.

Your family has been selected for this study based on your current or past association with the WV ATC. We would appreciate it very much if the primary caregiver, i.e., the individual in the family who has the primary responsibility of providing daily care to the child with autism, would take a few minutes to complete the enclosed survey. Please return the completed survey with the acknowledgement statement in the postage-paid business reply envelope included in this packet. It will take approximately 20-25 minutes for the primary caregiver to answer all the questions. Within two weeks of receipt of your completed survey and acknowledgment statement, a \$5 Wal-Mart gift card will be mailed to you by the WV ATC as a token of our appreciation for your participation.

Participation in this study is completely voluntary, and refusal to participate will not affect in any way your family's relationship and/or any service that you receive from the WVATC. The primary caregiver does not have to answer questions with which he/she is not comfortable.

The information provided by you will be kept as confidential as legally possible. The acknowledgement statement has an identification number for mailing purposes and gift card distribution only. The WV ATC will separate the acknowledgement statement from the completed survey and use it to send you the $\$ 5$ Wal-Mart gift card. The de-identified survey will then be sent to us for the purpose of study analyses. A summary of results of the study after completion will be posted on the website of the WV ATC in about six months from the present.

Attached you will find a list of resources/services to contact if you experience any emotional discomfort with this questionnaire.

We THANK YOU in advance for your time and contribution in providing us with this valuable information. If you have any questions or need more information, please do not hesitate to contact, Dr. Barbara Becker-Cottrill at (304) 696-2332, Rahul Khanna at (304) 293-7674, or Dr. Suresh Madhavan at (304) 293-1652.

Sincerely,

Barbara Becker-Cottrill, Ed.D. $\quad$ Rahul Khanna, MS S. Suresh Madhavan, MBA, Ph.D. Executive Director, WV ATC Ph.D. Candidate Professor 


\section{Appendix H3: Survey Cover Letter for Second Mailing}

Dear Madam/Sir,

About two weeks ago, you may remember receiving a yellow-colored survey asking you about your caregiving experiences while taking care of a child with autism. If you have already completed and returned the survey, please accept our sincere thanks. In case you missed that mailing or have misplaced the survey, another survey is enclosed with this letter. This research study is being undertaken by the West Virginia University School of Pharmacy in collaboration with the West Virginia Autism Training Center (WV ATC) to help us better understand the impact of caregiving of children with autism on primary caregivers. The study has been acknowledged by the Institutional Review Boards of West Virginia University and Marshall University.

Your family has been selected for this study based on your current or past association with the WV ATC. We would appreciate it very much if the primary caregiver, i.e., the individual in the family who has the primary responsibility of providing daily care to the child with autism, would take a few minutes to complete the enclosed survey. Please return the completed survey with the acknowledgement statement in the postage-paid business reply envelope included in this packet. It will take approximately 20-25 minutes for the primary caregiver to answer all the questions. Within two weeks of receipt of your completed survey and acknowledgment statement, a \$5 Wal-Mart gift card will be mailed to you by the WV ATC as a token of our appreciation for your participation.

Participation in this study is completely voluntary, and refusal to participate will not affect in any way your family's relationship and/or any service that you receive from the WVATC. The primary caregiver does not have to answer questions with which he/she is not comfortable.

The information provided by you will be kept as confidential as legally possible. The acknowledgement statement has an identification number for mailing purposes and gift card distribution only. The WV ATC will separate the acknowledgement statement from the completed survey and use it to send you the \$5 Wal-Mart gift card. The de-identified survey will then be sent to us for the purpose of study analyses. A summary of results of the study after completion will be posted on the website of the WV ATC in about six months from the present.

Attached you will find a list of resources/services to contact if you experience any emotional discomfort with this questionnaire.

We THANK YOU in advance for your time and contribution in providing us with this valuable information. If you have any questions or need more information, please do not hesitate to contact, Dr. Barbara Becker-Cottrill at (304) 696-2332, Rahul Khanna at (304) 293-7674, or Dr. Suresh Madhavan at (304) 293-1652.

Sincerely,

Barbara Becker-Cottrill, Ed.D. $\quad$ Rahul Khanna, MS S. Suresh Madhavan, MBA, Ph.D. Executive Director, WV ATC Ph.D. Candidate Professor 


\section{Appendix H4: Survey Cover Letter for Third Mailing}

Dear Madam/Sir,

About four weeks ago, you may remember receiving a yellow-colored survey asking you about your caregiving experiences while taking care of a child with autism. If you have already completed and returned the survey, please accept our sincere thanks. In case you missed that mailing or have misplaced the survey, another survey is enclosed with this letter. This research study is being undertaken by the West Virginia University School of Pharmacy in collaboration with the West Virginia Autism Training Center (WV ATC) to help us better understand the impact of caregiving of children with autism on primary caregivers. The study has been acknowledged by the Institutional Review Boards of West Virginia University and Marshall University.

Your family has been selected for this study based on your current or past association with the WV ATC. We would appreciate it very much if the primary caregiver, i.e., the individual in the family who has the primary responsibility of providing daily care to the child with autism, would take a few minutes to complete the enclosed survey. Please return the completed survey with the acknowledgement statement in the postage-paid business reply envelope included in this packet. It will take approximately 20-25 minutes for the primary caregiver to answer all the questions. Within two weeks of receipt of your completed survey and acknowledgment statement, a \$5 Wal-Mart gift card will be mailed to you by the WV ATC as a token of our appreciation for your participation.

Participation in this study is completely voluntary, and refusal to participate will not affect in any way your family's relationship and/or any service that you receive from the WVATC. The primary caregiver does not have to answer questions with which he/she is not comfortable.

The information provided by you will be kept as confidential as legally possible. The acknowledgement statement has an identification number for mailing purposes and gift card distribution only. The WV ATC will separate the acknowledgement statement from the completed survey and use it to send you the \$5 Wal-Mart gift card. The de-identified survey will then be sent to us for the purpose of study analyses. A summary of results of the study after completion will be posted on the website of the WV ATC in about six months from the present.

Attached you will find a list of resources/services to contact if you experience any emotional discomfort with this questionnaire.

We THANK YOU in advance for your time and contribution in providing us with this valuable information. If you have any questions or need more information, please do not hesitate to contact, Dr. Barbara Becker-Cottrill at (304) 696-2332, Rahul Khanna at (304) 293-7674, or Dr. Suresh Madhavan at (304) 293-1652.

Sincerely,

Barbara Becker-Cottrill, Ed.D. $\quad$ Rahul Khanna, MS S. Suresh Madhavan, MBA, Ph.D. Executive Director, WV ATC Ph.D. Candidate Professor 


\section{Appendix H5: Addresses of Counseling Facilities if Emotional Distress Experienced from Survey}

\section{Important Resources}

Contact information for facilities in the event you experience any emotional discomfort with the survey:

Morgantown Pastoral

Counseling

1062 Maple Dr \#1

Morgantown, WV 26505

Phone - (304)599-5751

Valley Healthcare System

301 Scott Ave

Morgantown, WV 26508

Phone - (304)296-1731
Fremouw Psychological Associates 1224 Pineview Dr \# B

Morgantown, WV 26505

Phone - (304)598-2300
Chestnut Ridge Counseling Services

Suite 116, 100 New Salem

Road

Uniontown, PA 15401

Phone - (724)437-0729

Chestnut Ridge Hospital of

Morgantown WV

930 Chestnut Ridge Rd

Morgantown, WV 26505

Phone - (304)598-6400 
Appendix H6: Survey Questionnaire 


\section{CAREGIVER SURVEY}

NOTE: The survey should be completed by the primary caregiver, i.e., the individual in the family who has the primary responsibility of providing daily care to the child with autism. There is no right or wrong answers.

The survey has three sections:

\section{SECTION I:}

Part A - Your Health and Well-Being

Part B - Your Caregiving Experience

Part C - Your Social Support

Part D - Your Coping Strategies

Part E - Your Family Functioning

\section{SECTION II:}

Part A - Level of Functioning of the Child with Autism to Whom You Provide Care

Part B - General Behavior of the Child with Autism to Whom You Provide Care

\section{SECTION III:}

Part A - Autism-Related Services Use

Part B - About You and the Child with Autism to Whom You Provide Care

Part C - Your Opinions

Please return the completed survey and the acknowledgement statement in the enclosed self-addressed, business reply envelope.

NO POSTAGE IS REQUIRED! 


\section{SECTION I: PART A - Your Health and Well-Being}

\section{INSTRUCTIONS:}

This survey asks for your views about your health. This information will help keep track of how you feel and how well you are able to do your usual activities. Thank you for completing this survey!

For each of the following questions, please mark an $\bigotimes$ in the one box that best describes your answer.

1. In general, would you say your health is:

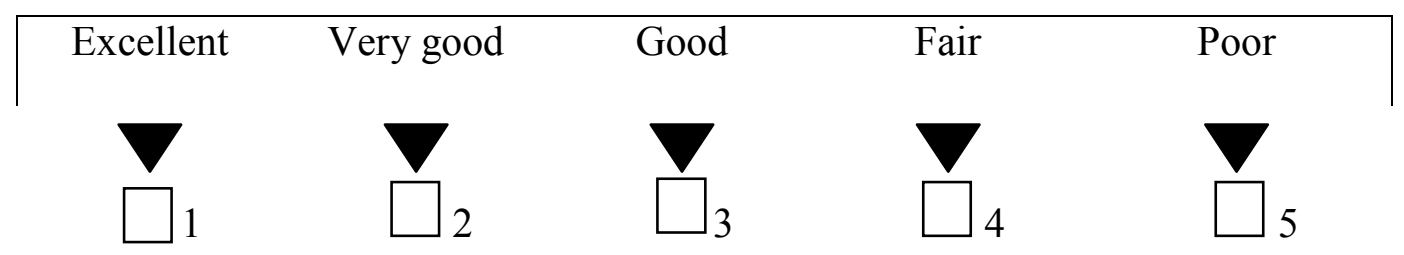

2. The following questions are about activities you might do during a typical day. Does your health now limit you in these activities? If so, how much?

$\begin{array}{ccc}\text { Yes, } & \text { Yes, } & \text { No, not } \\ \text { limited } & \text { limited } & \text { limited } \\ \text { a lot } & \text { a little } & \text { at all }\end{array}$

a Moderate activities, such as moving a table, pushing a vacuum cleaner, bowling, or playing golf.

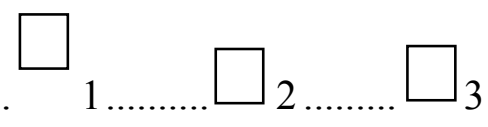

b Climbing several flights of stairs ............................ $\square_{1} \ldots \ldots \ldots \square_{2} \ldots \ldots \ldots . \square_{3}$ 
3. During the past 4 weeks, how much of the time have you had any of the following problems with your work or other regular daily activities as a result of your physical health?

All of Most of Some A little None of
the time the time of the of the the time
time time

a Accomplished less than you would

like

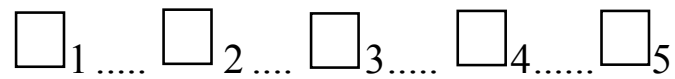

b Were limited in the kind of work or

other activities

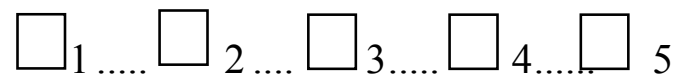

4. During the past 4 weeks, how much of the time have you had any of the following problems with your work or other regular daily activities as a result of any emotional problems (such as feeling depressed or anxious)?

All of Most
Some A little
the of the of the of the the time
time time time time

a Accomplished less than you would

like
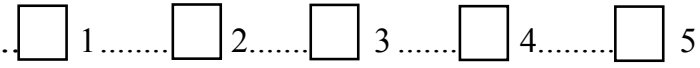

b Did work or other activities less

carefully than usual
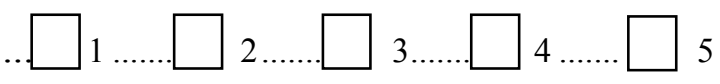
5. During the past 4 weeks, how much did pain interfere with your normal work (including both work outside the home and housework)?

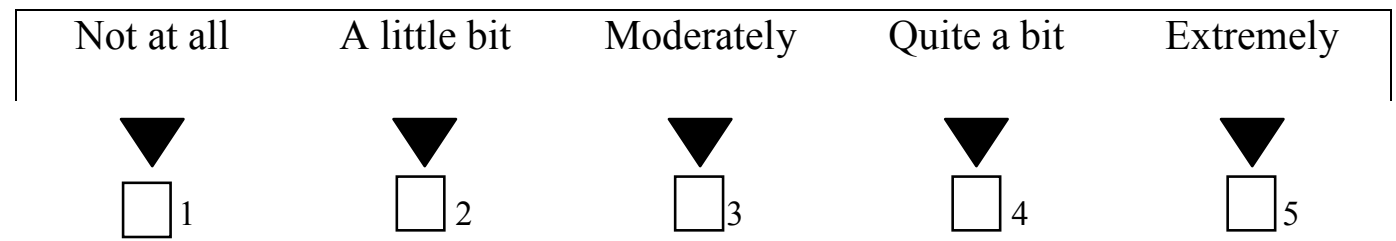

6. These questions are about how you feel and how things have been with you during the past 4 weeks. For each question, please give the one answer that comes closest to the way you have been feeling. How much of the time during the past 4 weeks...

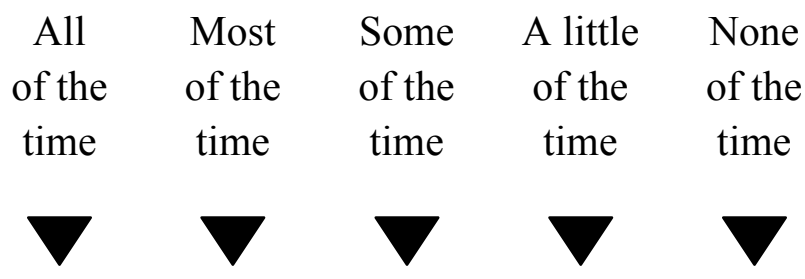

a Have you felt calm and peaceful? .......... $\square 1$......... $\square_{2} \ldots \ldots . . \square 3 \ldots \ldots . \square 4 \ldots \ldots \ldots . \square 5$

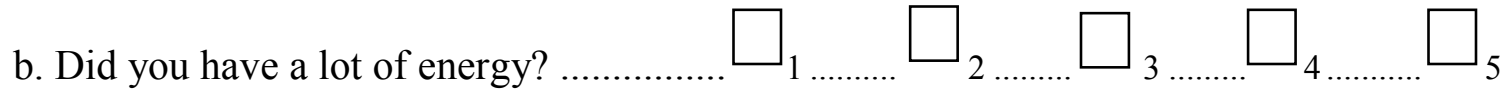

c Have you felt downhearted and

depressed?
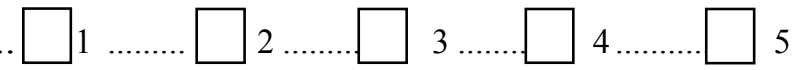

7. During the past 4 weeks, how much of the time has your physical health or emotional problems interfered with your social activities (like visiting friends, relatives, etc.)?

\begin{tabular}{ccccc|}
$\begin{array}{c}\text { All of the } \\
\text { time }\end{array}$ & $\begin{array}{c}\text { Most of the } \\
\text { time }\end{array}$ & $\begin{array}{c}\text { Some of the } \\
\text { time }\end{array}$ & $\begin{array}{c}\text { A little of the } \\
\text { time }\end{array}$ & $\begin{array}{c}\text { None of the } \\
\text { time }\end{array}$ \\
\hline 1 & &
\end{tabular}




\section{SECTION I: PART B - Your Caregiving Experience}

\section{INSTRUCTIONS:}

Please think back over the past 6 months and try to remember how things have been for your family. We are trying to get a picture of how life has been in your household over that time. For each question, please tell us which response (which number) fits best.

In the past 6 months, how much of a problem was the following:

1. Interruption of personal time resulting from your child's emotional or behavioral problem?

2. You missing work or neglecting other duties because of your child's emotional or behavioral problem?

3. Disruption of family routines due to your child's emotional or behavioral problem?

4. Any family member having to do without things because of your child's emotional or behavioral problem?

5. Any family member suffering negative mental or physical health effects as a result of your child's emotional or behavioral problem?

6. Your child getting into trouble with the neighbors, the school, the community, or law enforcement?

7. Financial strain for your family as a result of your child's emotional or behavioral problem?

8. Less attention paid to other family members because of your child's emotional or behavioral problem?

9. Disruption or upset of relationships within the family due to your child's emotional or behavioral problem?

10. Disruption of your family's social activities resulting from your child's emotional or behavioral problem?

$\begin{array}{ccccc}\begin{array}{c}\text { Not at } \\ \text { all }\end{array} & \begin{array}{c}\text { A } \\ \text { little }\end{array} & \begin{array}{c}\text { Some } \\ \text { what }\end{array} & \begin{array}{c}\text { Quite } \\ \text { a bit }\end{array} & \begin{array}{c}\text { Very } \\ \text { much }\end{array} \\ 1 & 2 & 3 & 4 & 5\end{array}$

$\begin{array}{lllll}1 & 2 & 3 & 4 & 5\end{array}$

$\begin{array}{lllll}1 & 2 & 3 & 4 & 5\end{array}$

$\begin{array}{lllll}1 & 2 & 3 & 4 & 5\end{array}$

$\begin{array}{lllll}1 & 2 & 3 & 4 & 5\end{array}$

$\begin{array}{lllll}1 & 2 & 3 & 4 & 5\end{array}$

$\begin{array}{lllll}1 & 2 & 3 & 4 & 5 \\ 1 & 2 & 3 & 4 & 5\end{array}$

$\begin{array}{lllll}1 & 2 & 3 & 4 & 5\end{array}$

$\begin{array}{lllll}1 & 2 & 3 & 4 & 5\end{array}$




\section{INSTRUCTIONS:}

In this section, please continue to look back and try to remember how you have felt during the past 6 months. For each question, please tell us which response (which number) fits best.

In the past 6 months, how much of a problem was the following:

$\begin{array}{ccccc}\text { Not at } & \text { A } & \text { Some } & \text { Quite } & \text { Very } \\ \text { all } & \text { little } & \text { what } & \text { a bit } & \text { much }\end{array}$

11. How isolated did you feel as a result of your child's emotional or behavioral problem?

12. How sad or unhappy did you feel as a result of your child's emotional or behavioral problem?

13. How embarrassed did you feel about your child's emotional or behavioral problem?

14. How well did you relate to your child?

15. How angry did you feel toward your child?

16. How worried did you feel about your child's future?

17. How worried did you feel about your family's future?

$\begin{array}{lllll}1 & 2 & 3 & 4 & 5 \\ 1 & 2 & 3 & 4 & 5\end{array}$

5

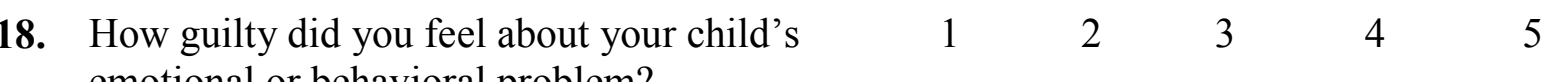
emotional or behavioral problem?

19. How resentful did you feel toward your child?

20. How tired or strained did you feel as a result
of your child's emotional or behavioral problem?

21. In general, how much of a toll has your child's emotional or behavioral problem taken on your family? 


\section{SECTION I: PART C - Your Social Support}

\section{INSTRUCTIONS:}

We are interested in how you feel about the following statements. Read each statement carefully. Indicate how you feel about each statement.

\section{Circle the "1" if you Very Strongly Disagree \\ Circle the " 2 " if you Strongly Disagree \\ Circle the " 3 " if you Mildly Disagree \\ Circle the " 4 " if you are Neutral \\ Circle the " 5 " if you Mildly Agree \\ Circle the "6" if you Strongly Agree \\ Circle the "7" if you Very Strongly Agree}

1. There is a special person who is around when I am in need.

2. There is a special person with whom I can $\quad \begin{array}{lllllllll}1 & 2 & 3 & 4 & 5 & 6 & 7\end{array}$ share my joys and sorrows.

3. My family really tries to help me.

4. I get the emotional help and support I nee from my family.

5. I have a special person who is a real source $\quad \begin{array}{lllllllll}1 & 2 & 3 & 4 & 5 & 6 & 7\end{array}$ of comfort to me.

6. My friends really try to help me.

$\begin{array}{lllllll}1 & 2 & 3 & 4 & 5 & 6 & 7\end{array}$

7. I can count on my friends when things go

$\begin{array}{lllllll}1 & 2 & 3 & 4 & 5 & 6 & 7\end{array}$
wrong.

8. I can talk about my problems with my

$\begin{array}{lllllll}1 & 2 & 3 & 4 & 5 & 6 & 7\end{array}$
family.

9. I have friends with whom I can share my joys and sorrows.

10. There is a special person in my life who cares about my feelings.

11. My family is willing to help me make decisions.

12. I can talk about my problems with my friends. 


\section{SECTION I: PART D - Your Coping Strategies}

\section{INSTRUCTIONS:}

These items deal with ways you've been coping with the stress in your life since the child you care for was diagnosed with autism. Different people deal with things in different ways, but we are interested in how you've tried to deal with it. Each item says something about a particular way of coping. We want to know to what extent you've been doing what the item says. Don't answer on the basis of whether it seems to be working or not - just whether or not you're doing it.

Using the response choices below, please circle your response for each question.

$$
\begin{aligned}
& 1=\text { I haven't been doing this at all } \\
& 2=\text { I've been doing this a little bit } \\
& 3=\text { I've been doing this a medium amount } \\
& 4=\text { I've been doing this a lot }
\end{aligned}
$$

1. I've been turning to work or other activities to take my $\quad \begin{array}{lllll}1 & 2 & 3 & 4\end{array}$ mind off things.

2. I've been concentrating my efforts on doing something $\quad \begin{array}{llll}1 & 2 & 3 & 4\end{array}$ about the situation I'm in.

3. I've been saying to myself "this isn't real".

4. I've been getting emotional support from others.

5. I've been giving up trying to deal with it.

6. I've been taking action to try to make the situation better. $\quad \begin{array}{lllll}1 & 2 & 3 & 4\end{array}$

7. I've been refusing to believe that it has happened. $\quad \begin{array}{llllll}1 & 2 & 3 & 4\end{array}$

8. I've been saying things to let my unpleasant feelings $\quad \begin{array}{lllll}1 & 2 & 3 & 4\end{array}$ escape.

9. I've been getting help and advice from other people. $\quad \begin{array}{lllll}1 & 2 & 3 & 4\end{array}$

10. I've been trying to see it in a different light, to make it $\quad \begin{array}{lllll}1 & 2 & 3 & 4\end{array}$ seem more positive.

11. I've been criticizing myself. $\quad \begin{array}{lllll}1 & 2 & 3 & 4\end{array}$

12 I've been trying to come up with a strategy about what to $\quad \begin{array}{lllll}1 & 2 & 3 & 4\end{array}$ do. 
Using the response choices below, please circle your response for each question.

$$
\begin{aligned}
& 1=\text { I haven't been doing this at all } \\
& 2=\text { I've been doing this a little bit } \\
& 3=\text { I've been doing this a medium amount } \\
& 4=\text { I've been doing this a lot }
\end{aligned}
$$

13. I've been getting comfort and understanding from someone. $\begin{array}{lllll}1 & 2 & 3 & 4\end{array}$

14. I've been giving up the attempt to cope. $\quad \begin{array}{lllll} & 2 & 3 & 4\end{array}$

15. I've been looking for something good in what is happening. $\begin{array}{lllll}1 & 2 & 3 & 4\end{array}$

16. I've been making jokes about it. $\quad \begin{array}{llll}1 & 2 & 3 & 4\end{array}$

17. I've been doing something to think about it less, such as $\quad \begin{array}{lllll}1 & 2 & 3 & 4\end{array}$ going to movies, watching TV, reading, daydreaming, sleeping, or shopping.

18. I've been accepting the reality of the fact that it has $\quad \begin{array}{llll}1 & 2 & 3 & 4\end{array}$ happened.

19. I've been expressing my negative feelings. $\quad 1 \quad \begin{array}{llll}2 & 3 & 4\end{array}$

20. I've been trying to find comfort in my religion or spiritual $\quad \begin{array}{lllll}1 & 2 & 3 & 4\end{array}$ beliefs.

21. I've been trying to get advice or help from other people $\quad \begin{array}{lllll}1 & 2 & 3 & 4\end{array}$ about what to do.

22. I've been learning to live with it. $\quad \begin{array}{llll}1 & 2 & 3 & 4\end{array}$

23. I've been thinking hard about what steps to take. $\quad \begin{array}{lllll} & 1 & 2 & 3 & 4\end{array}$

24. I've been blaming myself for things that happened. $\quad \begin{array}{llll}1 & 2 & 3 & 4\end{array}$

25. I've been praying or meditating. $\quad \begin{array}{lllll}1 & 2 & 3 & 4\end{array}$

26. I've been making fun of the situation. $\quad \begin{array}{llll} & 1 & 2 & 3\end{array}$ 


\section{SECTION I: PART E - Your Family Functioning}

\section{INSTRUCTIONS:}

We are interested in your personal view of your family. Please read each statement below carefully, and decide how well it describes your own family. You should answer according to how you see your family. For each statement below, there are four (4) possible responses:

Strongly Agree (SA). Check SA if you feel that the statement describes your family very accurately.

Agree (A). Check A if you feel that the statement describes your family for the most part.

Disagree (D). Check D if you feel that the statement does not describe your family for the most part.

Strongly Disagree (SD). Check SD if you feel that the statement does not describe your family at all.

Please mark $(\sqrt{ })$ all your answers in the space provided below each statement.

1. Planning family activities is difficult because we misunderstand each other.

SA

A

$\mathrm{D}$

SD

2. In times of crisis we can turn to each other for support.

SA A

D SD

3. We cannot talk to each other about the sadness we feel.

SA A

D SD

4. Individuals are accepted for what they are.

$\mathrm{SA}$ A

D

SD

5. We avoid discussing our fears and concerns.

SA

A

D

SD

6. We can express feelings to each other.

SA

A

D

SD

7. There are lots of bad feelings in the family.

SA

A

$\mathrm{D}$

SD

8. We feel accepted for what we are.

SA

A

D

SD

9. Making decisions is a problem for our family.

SA

A

D

SD

10. We are able to make decisions about how to solve problems.

SA

A

$\mathrm{D}$

$\mathrm{SD}$

11. We don't get along well together.

SA

A

$\mathrm{D}$

SD

12. We confide in each other.

SA

A

D

SD 


\section{INSTRUCTIONS:}

For each of the symptoms described below, please use the symptom rating, from 1 (normal for chronological age) to 4 (severely abnormal), to indicate the level of functioning in the child with autism to whom you provide care.

\section{$\underline{\text { SYMPTOMS }}$}

1. Ability to relate to people (i.e. does not return interest others show in him/her)

2. Imitation (extent to which child imitates, verbal or motor )

3. Appropriateness of emotions; (e.g. giggling, crying, etc.)

4. Unusual body movements and /or repetitive motions or routines

5. Unusual ways of relating to objects (e.g. spinning of cups)

6. Difficulty with change in the environment (e.g. new living room furniture)

7. Interest in visual information (e.g. staring at lights, avoiding eye contact)

8. Response to sounds (i.e. overreacts or underreacts)

9. Use of other senses (e.g. mouthing, licking, smelling, rubbing)

10. Anxiety reaction (e.g. separation from parents, unusual fears)

11. Verbal communication (e.g. mute, echoes, pronoun reversal, repetitive language

12. Nonverbal communication (e.g. use of or response to gestures)

13. Extremes of activity level (i.e. high or low activity level)

14. Intellectual abilities (e.g. rating 2 means even impairment in all intellectual areas; rating 4 means some areas very impaired other areas normal)

\section{SYMPTOM RATING}

$1=$ Normal for chronological age

$2=$ Mildly abnormal

$3=$ Moderately abnormal

$4=$ Severely abnormal 


\section{SECTION II: PART B - General Behavior of the Child with Autism to Whom You Provide Care}

INSTRUCTIONS: Some of the following behaviors may not apply to the child or teenager in your care. For each item that does describe the person in your care, now or within the past six months, please circle the $\mathbf{2}$ if the item is very true or often true. Circle $\mathbf{1}$ if the item is somewhat or sometimes true of your child. If the item is not true of your child circle the 0 . $0=$ not true as far as you know $1=$ somewhat or sometimes true $\quad 2=$ very true or often true

If your child is unable to behave in the way referred to in an item, circle the $\mathbf{0}$. For example, if your child has no speech, then for the item "Repeats the same word over and over" circle the $\mathbf{0}$.

\section{Please circle}

\begin{tabular}{|c|c|c|c|c|}
\hline 1. & 0 & 1 & 2 & Becomes over-excited. \\
\hline 2. & 0 & 1 & 2 & Chews or mouths objects or body parts \\
\hline 3. & 0 & 1 & 2 & Confuses the use of pronouns e.g., uses "you" instead of "I". \\
\hline 4. & 0 & 1 & 2 & Doesn't show affection. \\
\hline 5. & 0 & 1 & 2 & Grinds teeth. \\
\hline 6. & 0 & 1 & 2 & Has nightmares, night terrors, or walks in sleep. \\
\hline 7. & 0 & 1 & 2 & Impatient. \\
\hline 8. & 0 & 1 & 2 & Inappropriate sexual activity with another \\
\hline 9. & 0 & 1 & 2 & Jealous. \\
\hline 10. & 0 & 1 & 2 & Kicks, hits others. \\
\hline 11. & 0 & 1 & 2 & Laughs or giggles for no obvious reason. \\
\hline 12. & 0 & 1 & 2 & Preoccupied with only one or two particular interests. \\
\hline 13. & 0 & 1 & 2 & Refuses to go to school, activity center, or workplace. \\
\hline 14. & 0 & 1 & 2 & Repeats the same word or phrase over and over. \\
\hline 15. & 0 & 1 & 2 & Smells, tastes, or licks objects. \\
\hline 16. & 0 & 1 & 2 & $\begin{array}{l}\text { Switches lights on and off, pours water over and over; or } \\
\text { similar repetitive behavior. }\end{array}$ \\
\hline 17. & 0 & 1 & 2 & Stubborn, disobedient or uncooperative. \\
\hline 18. & 0 & 1 & 2 & Says he/she can do things that he/she is not capable of. \\
\hline 19. & 0 & 1 & 2 & Sees, hears, something which isn't there. Hallucinations. \\
\hline 20. & 0 & 1 & 2 & Tells lies. \\
\hline 21. & 0 & 1 & 2 & Tense, anxious, worried. \\
\hline 22. & 0 & 1 & 2 & Underreacts to pain. \\
\hline 23. & 0 & 1 & 2 & $\begin{array}{l}\text { Upset or distressed over small changes in routine or } \\
\text { environment. }\end{array}$ \\
\hline 24. & 0 & 1 & 2 & Wanders aimlessly. \\
\hline
\end{tabular}




\section{SECTION III: PART A - Autism-Related Services Use}

\section{INSTRUCTIONS:}

Please answer the following questions to help us understand your use of autism-related services for the child with autism to whom you provide care. Please check-mark $(\sqrt{ })$ your response.

1. Have you ever participated in the Family Focus Positive Behavior Support (FFPBS) Program conducted by the West Virginia Autism Training Center?

$\square$ Yes $\square$ No If YES, then in which year did you participate in the FFPBS?

2. Does the child with autism to whom you provide care attend school? $\square$ Yes $\square$ No

3. Indicate if your SCHOOL DISTRICT provides the following autism-related services to the child with autism to whom you provide care? If YES, please also indicate the extent to which you are satisfied or dissatisfied with those services.

a) Speech/language therapy

b) Occupational therapy

c) Social skills training

d) Physical therapy

e) Behavioral intervention (e.g., ABA)

f) Assistance in improving study skills

g) Parent/caregiver counseling or training $\square$ Yes

h) Other services (please specify):
EXTREMELY DISSATISFIED

EXTREMELY SATISFIED

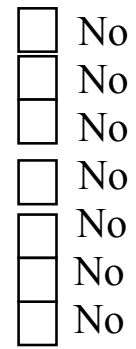

$\begin{array}{ll}1 & 2 \\ 1 & 2 \\ 1 & 2 \\ 1 & 2 \\ 1 & 2 \\ 1 & 2 \\ 1 & 2\end{array}$

45

45

$4 \quad 5$

$\begin{array}{lll}3 & 4 & 5\end{array}$

$\begin{array}{lll}3 & 4 & 5\end{array}$

345

$\begin{array}{lll}3 & 4 & 5 \\ & 4 & 5\end{array}$

4. Indicate if you have used the following autism-related services SEPARATE from the above school-provided services for the child with autism to whom you provide care? If YES, please also indicate the extent of availability of those services in your community?

\section{EASILY}

AVAILABLE

a) Speech/language therapy

b) Occupational therapy

c) Social skills training

d) Physical therapy

e) Behavioral intervention (e.g., ABA)

f) Respite care for parent/caregiver

g) Parent/caregiver support services

h) Nutritional services

(e.g., casein or gluten free diet, vitamin therapy)

$\square$ No
$\square$ No
$\square$ No
No
$\square$ No
$\square$ No
$\square$ No
No

NOT EASILY AVAILABLE

\begin{tabular}{l}
$\square$ Yes \\
\hline$\square$ Yes \\
\hline$\square$ Yes \\
\hline$\square$ Yes \\
\hline$\square$ Yes \\
$\square$ Yes \\
$\square$ Yes \\
$\square$ Yes
\end{tabular}

i) Other services you utilize for the child with autism (please specify): 


\section{SECTION III: PART B - About You and the Child with Autism to Whom You Provide Care}

\section{INSTRUCTIONS:}

Please answer the following questions to help us better understand your responses. Please check-mark $(\sqrt{ })$ your response.

1. Are you $\square$ Male $\square$ Female $\quad$ Your Age:

2. What is your ethnicity? (Please check one box)

$\square$ White $\square$ Black/African-American $\square$ Hispanic/Latino $\square$ American Indian/Alaskan $\square$ Asian $\square$ Native Hawaiian/Pacific Islander $\square$ Other (please specify)

3. What is your current marital status? (Please check one box)

$\square$ Never Married $\square$ Married $\square$ Divorced/Separated $\square$ Widowed
$\square$ Not married, living with partner

4. What is the highest level of education that you have completed? (Please check one box)

$\square$ Less than high school $\square$ Graduated high school $\square$ Attended college/technical school College graduate

5. Which of the following describes your main occupation? (Please check one box)

$\square$ Employed/Self-employed full-time $\square$ Employed part-time $\square$ Retired $\square$ Home-maker $\square$ Student $\square$ Seeking work $\square$ Other (please specify)

6. What is your annual household income from all sources? (Please check one box) $\square$ Less than $\$ 25,000 \square \$ 25,000-\$ 49,999 \square \$ 50,000-\$ 99,999 \square$ \$100,000or more

7. What is your relationship to the child with autism to whom you provide care? (Please check one box)

$\square$ Mother $\square$ Father $\square$ Other (please specify)

8. What is the gender of the child with autism to whom you provide care? $\square$ Male $\square$ Female

9. Please indicate the age group of the child with autism to whom you provide care? (Please check one box)

$\square$ Less than 5 years $\square 5$ years-Less than 10 years $\square 10$ years-Less than 15 years

15 years- 18 years

10. What is the primary diagnosis of the child with autism to whom you provide care? (Please check one box)

$\square$ Classic autism/autistic disorder $\square$ Asperger's syndrome

$\square$ Pervasive developmental disorder not otherwise specified (PDD-NOS) 
11. Does the child with autism to whom you provide care have any kind of health care coverage, including health insurance, prepaid plans such as HMOs, or government plans such as Medicaid?

$\square$ Yes $\quad \square$ No

If YES, then what type of health care coverage does the child with autism have:

12. Do you have any out-of-pocket costs for the use of autism-related services for the child with autism?

$\square$ Yes $\quad \square$ No

If YES, then how often are these costs reasonable? (Please check one box)

$\square$ Never $\square$ Sometimes $\square$ Usually $\square$ Always 


\section{SECTION III: PART C - Your Opinions}

\section{INSTRUCTIONS:}

Please answer the following two questions below.

1. As a primary caregiver, what major concerns do you have about caring for a child with autism?

2. What types of assistance (from any source) would be most helpful to you in your care giving role?

Please return the completed survey and the acknowledgement statement in the enclosed self-addressed, business reply envelope.

NO POSTAGE IS REQUIRED!

THANK YOU IN ADVANCE FOR YOUR TIME AND EFFORT! 


\section{Appendix H7: Survey Acknowledgment Statement}

(For appropriate financial accounting, we request that you kindly complete this acknowledgement statement and return it in the enclosed business-reply envelope along with your completed survey)

Dear Principal Investigator:

I acknowledge the receipt of a gift card in the amount of $\$ 5$ for my participation in the survey titled "Caregiver Survey". I also understand that it is my responsibility to verify if any action regarding the taxation of said gift card is needed.

Thank you.

Name (Please print)

Signature (Sign)

Date

Upon receipt of this statement and your completed survey, you will be mailed the Wal-Mart Gift Card (\$5). Thank you for your participation.

\section{For office use only.}

Wal-Mart Gift Card No:

Mailed on: 


\section{CURRICULUM VITAE}

\section{RAHUL KHANNA}

112 Ellen Lane, Apt 5

Morgantown, WV 26505

Email: rkhanna@hsc.wvu.edu

\section{ACADEMIC CREDENTIALS}

August 2004 - March 2010

Ph.D., Department of Pharmaceutical Systems and Policy, School of Pharmacy, West Virginia University

Dissertation Title: Burden of Care and Health-Related Quality of Life Among Caregivers of Children with Autism Spectrum Disorder

August 2004 - April 2007

Master of Science (M.S.), Department of Pharmaceutical Systems and Policy, School of Pharmacy, West Virginia University

Thesis Title: Predicting Physicians' Intention to Measure Body Mass Index and Assessing Their Identification and Evaluation Practices in Overweight Children and Adolescents

July 2002 - April 2004

Master of Business Administration in International Business (MBA [IB]), Indian Institute of Foreign Trade, New Delhi, India

September 1997 - May 2001

Bachelor of Pharmacy (B. Pharm.), Delhi University, New Delhi, India

\section{WORK EXPERIENCE}

June 2006 - Current

Research assistant on a grant "Building the West Virginia Collaborative Health Outcomes Research of Therapies and Services (CoHORTS) Center" funded by the Agency for Healthcare Research and Quality (Grant No. P20 HS15930)

- Responsibilities include storage, management, and analysis of limited and public-use data sets

May 2007 - July 2007

Summer Intern, Xcenda, Florida

Impact of Carvedilol dose titration on re-hospitalization rates in older patients

- Conducted retrospective claims data analysis to determine the effect of Carvedilol dose titration on cardiovascular events in a hypertensive population using survival analysis

Cost-effectiveness of Xyzal in the treatment of chronic idiopathic urticaria

- Conducted meta-analysis using the Comprehensive Meta-Analysis (CMA) software to calculate a pooled effect size estimate 


\section{RESEARCH EXPERIENCE}

April 2008 - March 2009

Screening, Prevalence, and Healthcare Utilization and Costs of Breast Cancer in the West Virginia Medicaid Population: Baseline Estimates for Bonnie's Bus

Co-investigator on a grant funded by the Susan G. Komen for the Cure Foundation to determine trends in breast cancer screening, prevalence, and economic burden in a state Medicaid population

April 2008 - March 2009

Using Health Claims Data for Surveillance of Cervical Cancer and Precancerous Cervical Intraepithelial Lesions

Research assistant on a study funded by the Agency for Healthcare Research and Quality to determine patterns of cervical cancer screening and management of precancerous lesions among women in West Virginia

August 2006 - August 2007

Utilization and Costs of Drugs and Office Services Among Recipients of Medicaid with Rheumatoid Arthritis With Versus Without Co-morbid Depression

Principal investigator on a study funded by the Association of Rheumatology Health

Professionals student award to determine the impact of co-morbid depression on rheumatoid arthritis-related healthcare utilization and costs

\section{TEACHING EXPERIENCE}

August 2008 - May 2009

Graduate Instructor, School of Pharmacy, West Virginia University

- Pharmacy Management: Responsibilities included developing course content, lecturing, facilitating student projects, and conducting laboratory sessions

- Pharmacy Systems: Responsibilities included lecturing, creating and managing course materials, grading, and facilitating student projects

August 2004 - May 2006

Graduate Teaching Assistant, School of Pharmacy, West Virginia University

- Patient Health Education: Responsibilities included conducting communication skill exercises, evaluating student verbal and non-verbal patient counseling skills, and grading

- Health Promotion and Disease Management and Pharmacy Management:

Responsibilities included grading student exercises, facilitating student projects, and management of course materials

\section{GRANT WRITING EXPERIENCE}

Contributed to the development of a three-year non-competitive renewal grant application "West Virginia Collaborative Health Outcomes Research of Therapies and Services (WV CoHORTS)" - awarded funding by the Agency for Healthcare Research and Quality (Principal Investigator: S. Suresh Madhavan) 
Co-investigator on grant titled - "Screening, Prevalence, and Healthcare Utilization and Costs of Breast Cancer in the West Virginia Medicaid Population: Baseline Estimates for Bonnie's Bus" - awarded funding by the Susan G. Komen for the Cure Foundation (Principal Investigator: S. Suresh Madhavan). Amount: $\$ 33,000$

\section{PUBLICATIONS}

Khanna R, Madhavan SS, Bhanegaonkar A. Healthcare Utilization and Cost of Breast Cancer: A Case-Control Study of a State Medicaid Program. In preparation for the Journal of Health Care for the Poor and Underserved

Khanna R, Bhanegaonkar A, Colsher P, Madhavan SS, Halverson J. Breast Cancer Screening, Incidence, and Mortality in West Virginia. West Virginia Medical Journal 2009; 105 Spec No:2432

Khanna R, Kavookjian J, Scott VG, Kamal KM, Neal WA, Miller LA. Using the Theory of Reasoned Action to Determine Physicians' Intention to Measure Body Mass Index In Children and Adolescents. Research in Social and Administrative Pharmacy 2009;5(2):170-181

Khanna R, Smith MJ. Utilization and Costs of Medical Services and Prescription Medications for Rheumatoid Arthritis Among Recipients Covered by a State Medicaid Program: A Retrospective, Cross-Sectional, Descriptive, Database Analysis. Clinical Therapeutics 2007;29(11):2456-2467

\section{PRESENTATIONS}

Khanna R, Madhavan SS, Smith MJ, Bhanegaonkar AJ. Pap Smear Testing in a Fee-ForService State Medicaid Program. Poster presentation at the American Public Health Association (APHA) $137^{\text {th }}$ Annual Meeting and Exposition, November 7-11, 2009, Philadelphia, PA

Khanna R, Winans SA, Madhavan SS. Perceptions of and Attitudes toward Research and Graduate Education Among Pharmacy Students: A 17-year Follow-up. Poster presentation at the Annual Association of Colleges of Pharmacy Annual Meeting and Seminars, July 17-22, 2009, Boston, MA

Khanna R, Madhavan SS. Autism-Related Hospitalizations: Estimates from 2006 Health Care Costs and Utilization Project KIDS' Inpatient Database. Poster presentation at the International Society for Pharmacoeconomics and Outcomes Research (ISPOR) $14^{\text {th }}$ Annual International Meeting, May 16-20, 2009, Orlando, FL

Khanna R, Madhavan SS, Bhanegaonkar A. Breast Cancer Prevalence and Health Care Utilization and Cost Trends Among Fee-For-Service Female Recipients in a State Medicaid Program. Poster presentation at the International Society for Pharmacoeconomics and Outcomes Research (ISPOR) $14^{\text {th }}$ Annual International Meeting, May 16-20, 2009, Orlando, FL 
Bhanegaonkar A, Khanna R, Madhavan SS. Screening Mammography Trends Among Women in a Fee-For-Service Medicaid Population. Poster presentation at the International Society for Pharmacoeconomics and Outcomes Research (ISPOR) $14^{\text {th }}$ Annual International Meeting, May 16-20, 2009, Orlando, FL

Khanna R, Madhavan SS, Colsher P, Bhanegaonkar A. Early Detection and Costs of Breast Cancer in West Virginia Women. Podium presentation at the West Virginia University E.J.Van Liere Memorial Research Convocation and Research Day, April 28-29, 2009, Morgantown, WV

Khanna R, Madhavan SS, Colsher P, Bhanegaonkar A. Early Detection and Costs of Breast Cancer in West Virginia Women. Poster presentation at the West Virginia University E.J.Van Liere Memorial Research Convocation and Research Day, April 28-29, 2009, Morgantown, WV

(Received First Place Poster Presentation Award)

Bhanegaonkar A, Khanna R, Madhavan SS, Colsher P. Patterns of Mammography Screening Among Women in a Fee-For-Service State Medicaid Program. Poster presentation at the E.J.Van Liere Memorial Research Convocation, April 28-29, 2009, Morgantown, WV

Khanna R, Madhavan SS. Trends in the Prevalence of Autism Spectrum Disorders and Related Healthcare Utilization and Costs in a State Medicaid Program. Poster presentation at the International Society for Pharmacoeconomics and Outcomes Research (ISPOR) $13^{\text {th }}$ Annual International Meeting, May 3-7, 2008, Toronto, Canada

Khanna R, Smith MJ, Kamal KM. Utilization and Costs of Drugs and Office Services Among Recipients of Medicaid with Rheumatoid Arthritis With Versus Without Comorbid Depression. Poster presentation at the International Society for Pharmacoeconomics and Outcomes Research (ISPOR) $13^{\text {th }}$ Annual International Meeting, May 3-7, 2008, Toronto, Canada

Khanna R, Scott VG, Kavookjian J, Kamal KM, Miller LA, Neal WA. Physicians' Intention to Measure Body Mass Index in Children and Adolescents: A Theory of Reasoned Action Model. Poster presentation at the International Society for Pharmacoeconomics and Outcomes Research (ISPOR) $13^{\text {th }}$ Annual International Meeting, May 3-7, 2008, Toronto, Canada

Khanna R, Smith MJ, Kamal KM. Utilization of Chronic Arthritis-Related Healthcare Services by Children and Adolescents in a Medicaid Population. Poster presentation at the International Society for Pharmacoeconomics and Outcomes Research (ISPOR) $12^{\text {th }}$ Annual International Meeting, May 19-23, 2007, Arlington, VA

Khanna R, Smith MJ. Utilization Patterns of Drugs and Medical Services Among Recipients With Rheumatoid Arthritis in a Medicaid Population. Poster presentation at the American Public Health Association (APHA) $134^{\text {th }}$ Annual Meeting and Exposition, November 4-8, 2006, Boston, MA

Khanna R, Smith MJ. Patterns of Medical Services and Prescription Medication Use Among Recipients With Rheumatoid Arthritis Covered by a State Medicaid Program. Poster 
presentation at the Drug Information Association (DIA) 42 ${ }^{\text {nd }}$ Annual Meeting, June 18-22, 2006, Philadelphia, PA

Khanna R, Kavookjian J. A Systematic Review of Physician Knowledge and Practice Patterns Related to Colorectal Cancer Screening. Poster presentation at the International Society for Pharmacoeconomics and Outcomes Research (ISPOR) $10^{\text {th }}$ Annual International Meeting, May 15-18, 2005, Washington, DC

\section{AWARDS}

West Virginia University School of Pharmacy 2009 Outstanding Achievement Award West Virginia University School of Pharmacy 2008 Graduate Student Research Award Association of Rheumatology Health Professionals 2006 Graduate Student Recognition Award

\section{CERTIFICATION}

Certificate in Health Care Administration, Department of Public Administration, West Virginia University Faculty Development Teaching Scholars Summer Institute 2008 Certificate, West Virginia University

\section{RELEVANT COURSEWORK}

Multivariate Analysis, Secondary Data Analysis, Pharmacoeconomics, Decision Analysis in Healthcare, Social and Behavioral Theory, Survey Research Methods, Research Design and Data Analysis, Statistical Analysis System, Applied Biostatistics, Pharmacoepidemiology, Advanced Epidemiology, Health Systems, Healthcare Finance, Health Care Organization and Operation

\section{MANUSCRIPT REVIEWER}

Journal of the American Pharmacists Association (JAPhA)

Preventing Chronic Disease (PCD)

\section{COMPUTER SKILLS}

Statistical Software (SAS, SPSS), Database Development System (Microsoft Visual FoxPro), Decision Analysis Software (DATA TreeAge), Comprehensive Meta-Analysis, Microsoft Office

\section{PROFESSIONAL AFFILIATIONS}

2009-Current Member - West Virginia Autism Spectrum Disorders Registry (WVASDR) Advisory Council

2006-Current Member - Rho Chi Pharmaceutical Honor Society

2004-Current Member - International Society for Pharmacoeconomics and Outcomes Research (ISPOR)

2006-2007 President - WVU ISPOR Student Chapter 